\title{
Drugs on the internet: Mapping the terrain of engagement with darknet drug cryptomarkets in New Zealand
}

\author{
By \\ Lucy Alexandra Moss-Mason
}

A thesis submitted to the Victoria University of Wellington in fulfilment of the requirements for the degree of Master of Arts in Criminology

Social and Cultural Studies

Victoria University of Wellington

2019 


\section{Table of Contents}

ACKNOWLEDGEMENTS

ABSTRACT

CHAPTER 1: INTRODUCTION

Context

CHAPTER 2: LITERATURE REVIEW

The History of the Darknet

Cryptomarkets and Tor

Bitcoin and Other Cryptocurrencies

Drug Cybercrime and Online Pharmacies

The History and Organisation of Cryptomarkets

The Challenges of Cryptomarkets to Authorities

Drug Cryptomarkets and the Media

Contextualising Drugs on the Darknet

Vendor Practices on Cryptomarkets

Consumer Practices on Cryptomarkets

Harm Reduction on Cryptomarkets

International Cryptomarket Practices

CHAPTER 3: METHODOLOGY AND METHODS

Methodological Framework

Philosophical and Epistemological Underpinnings

Methodological Approach

Research Methods

Research design.

Participants, data collection, and analysis.

Participant demographics.

Data analysis.

Advertising and personal challenges. 
$\begin{array}{lr}\text { Perceptions of Risk and Apprehension } & 60\end{array}$

$\begin{array}{ll}\text { Reducing the risk of detection and apprehension. } & 60\end{array}$

Lived experiences of detection and apprehension. $\quad 67$

Supply: Social, Commercial, and 'something in between' $\quad 70$

$\begin{array}{lr}\text { Gentrification Hypothesis } & 77\end{array}$

$\begin{array}{lr}\text { Summary } & 78\end{array}$

CHAPTER 5: COMPARING THE NEW ZEALAND DOMESTIC CONVENTIONAL ILLICIT DRUG MARKET WITH ILLICIT DRUG CRYPTOMARKETS - PUSH AND PULL FACTORS

Push Factors: Constraints of the Conventional Illicit Drug Market in New Zealand 8 $\begin{array}{lr}\text { Effective border security. } & 81\end{array}$ $\begin{array}{lr}\text { Poor availability and quality. } & 84\end{array}$ $\begin{array}{lr}\text { Poor authenticity and purity. } & 87\end{array}$

Pull Factors: Positive Aspects of Illicit Drug Cryptomarkets for New Zealanders $\quad 92$ $\begin{array}{lr}\text { Low price. } & 92\end{array}$ $\begin{array}{lr}\text { Trustworthy rating and review systems. } & 94\end{array}$ $\begin{array}{lr}\text { High quality. } & 95 \\ \text { Wide range, convenience, and low chance of violence. } & 95\end{array}$

$\begin{array}{lr}\text { Wide range, convenience, and low chance of violence. } & 99\end{array}$

$\begin{array}{lr}\text { Summary } & 101\end{array}$

CHAPTER 6: OUT OF THE FIRE AND INTO THE FRYING PAN - NEGATIVE ASPECTS OF CRYPTOMARKETS

$\begin{array}{ll}\text { Paper Trail } & 103\end{array}$

$\begin{array}{ll}\text { Time } & 105\end{array}$

$\begin{array}{ll}\text { Perspectives on the Law and Criminal Charges } & 108\end{array}$

$\begin{array}{ll}\text { Summary } & 113\end{array}$

CHAPTER 7: CONCLUSION 115

$\begin{array}{ll}\text { APPENDICES } & 118\end{array}$

$\begin{array}{lr}\text { Appendix A: Recruitment Poster } & 118\end{array}$

Appendix B: Information Sheet $r 19$

$\begin{array}{lr}\text { Appendix C: Consent Form } & 121\end{array}$

$\begin{array}{lr}\text { Appendix D: Interview Guide } & 123\end{array}$

$\begin{array}{lr}\text { Appendix E: Interview Coding Example } & 126\end{array}$ 
REFERENCES

127 


\section{Acknowledgements}

This thesis would not have been possible without the guidance and support of many people around me.

First, I would like to acknowledge the 12 men and women who participated in this research. Thank you for allowing me a glimpse into your worlds, and for your openness in sharing your insights and experiences with me. Your trust in me is a gift that I cannot repay.

I wish to thank my supervisor, Fiona Hutton, for her guidance and encouragement throughout this work. I was at the end of my undergraduate degree in 2015 when I first took one of Fiona's classes, and I am grateful to have had her as a mentor throughout my postgraduate study. Fiona, thank you for tirelessly supporting me, reading and rereading drafts, answering emails, and always being around for advice and a laugh.

I would also like to acknowledge the other lecturers in the Institute of Criminology, and the administrative staff of the School of Social and Cultural Studies - thank you for the work that you do.

To my friends, colleagues, and office mates, thank you for being familiar faces and supporters over the past year. There are too many of you to name individually, but I would also like to thank those who have proofread work for me and given advice.

To my family. When I finished my undergraduate degree, I was the first in my immediate family to graduate from university. Without you, this work would not have been possible. I hope that I have done you proud.

To my partner, Charlie. Thank you for your pep talks, for making me salads for lunch, and for being my biggest cheerleader. You and Billie are the best. 


\begin{abstract}
This thesis explores the experiences of New Zealanders who order illicit drugs from cryptomarkets, with particular attention to their perspectives on New Zealand's conventional illicit drug market, the negatives and positives of drug cryptomarkets, and their notable insights and features. Internationally, research on engagement with drug cryptomarkets is emergent. However, peer-reviewed research on New Zealand drug cryptomarket users remains absent. This thesis attempts to begin to fill this gap, exploring the experiences and viewpoints of New Zealand drug cryptomarket users within the context of existing international literature. The study utilised qualitative, semi-structured interviews with 12 New Zealanders who have accessed drug cryptomarkets. The data from the interviews were interpreted through thematic analysis using constructivist grounded theory.

The research found that the constraints of New Zealand's conventional drug market push some drug consumers to use cryptomarkets to access illicit drugs. Although drug cryptomarkets have various pull factors that attract participants to them, they also have negative aspects which influence participants' choices and behaviours when accessing cryptomarkets. The findings that are presented give voice to the lived experiences of New Zealanders who access drug cryptomarkets, extend scholarly knowledge of cryptomarket users, and highlight further avenues for research.
\end{abstract}




\section{Chapter 1: Introduction}

\section{Context}

Cryptomarket drug trading is an innovation which has arisen against a long-standing backdrop of punitive international drug prohibition. Cryptomarkets are located on the darknet, a region of the internet that cannot be accessed without specialised technologies (Maddox, Barratt, Allen \& Lenton, 2016). The darknet is accessed via anonymising software such as Tor ('The Onion Router'), a virtual private network (VPN) that routes users' IP addresses (unique codes assigned to each device that connects to the internet) through numerous other locations so that their identities cannot be traced (Maddox et al., 2016). The relative anonymity afforded by the darknet has led to it being utilised by individuals who wish to discuss, and engage in, illegal and stigmatised activities. The darknet is home to a community of established cryptomarkets which facilitate the trade of goods and services, including illicit drugs. Cryptomarkets rely on minimally-traceable and decentralised cryptocurrencies such as Bitcoin (Maddox et al., 2016). Accessing illicit drugs through the darknet is an alternative to in-person illicit drug supply arrangements in conventional markets. Cryptomarket drug purchasing is particularly significant in situations where individuals are reluctant or unable to purchase illicit drugs through conventional markets, either because of their social positioning or geographical location. The emergence of drug cryptomarkets provides researchers with a unique opportunity to investigate drug market relations. Further, drug cryptomarkets serve as a stark example of the steps that some individuals take to access illicit drugs in the context of global drug prohibition.

To understand drug cryptomarkets, it is necessary to contextualise the wider historical backdrop of drug prohibition that has led to their emergence. Drug prohibition has widereaching effects, both internationally and within New Zealand. Its effects are felt along social and cultural lines that are both racialised and gendered, with disproportionate effects on vulnerable individuals. Drug prohibition legislation that emerged in the United States in the late $19^{\text {th }}$ and early $20^{\text {th }}$ centuries was grounded in conceptions of racial and ethnic otherness. The first prohibitionist laws in San Francisco in the 1870s prohibited white people from frequenting opium dens in Chinatown, in part due to the fear that white women would be seduced by Chinese men who were associated with the 'Yellow Peril' (Cohen, 2006). The popular soft drink Coca-Cola contained coca leaf, the raw plant material used to manufacture cocaine, until the early 1900s when a moral panic over African Americans' cocaine use emerged, where African American men were characterised as menacing 'Negro cocaine fiends' 
(Cohen, 2006; Williams, 1914). Further xenophobia was evident in the development of cannabis laws in the United States, as cannabis was prohibited in the 1930s to target and criminalise Mexican migrant farm workers (Cohen, 2006; Gieringer, 1999). These examples demonstrate the historical roots of drug prohibition, which continues to have harmful effects.

Contemporary drug prohibition is informed by three United Nations international drug conventions, the Single Convention on Narcotic Drugs 1961, the Convention on Psychotropic Substances 1971, and the Convention against Illicit Traffic in Narcotic Drugs and Psychotropic Substances 1988 (UNODC, 2013). The conventions have been heavily criticised by critical drug researchers for preventing the development of pragmatic illicit drug policies, instead favouring a hard-line 'drug-free world' rhetoric (Bewley-Taylor, 2003, 2005; Csete et al., 2016; Taylor, 2007). International drug control conventions have had deleterious and farreaching effects, exacerbated by their failure to distinguish between illicit drug use and drug misuse, and inability to provide appropriate responses to the different needs of problematic and non-problematic drug users. The health impacts of international drug prohibition have been felt widely. Prohibitionist policing has been linked to the transmission of blood-borne viruses such as HIV and hepatitis C among populations of people who inject drugs (PWID) (Drucker, 1999). As well as this, harsh policing is a barrier to highly effective harm reduction initiatives such as needle and syringe programmes (NSPs), naloxone (a medication to block the effects of opioids and reverse overdoses), and opioid substitution therapy (OST) for those who are most in need of them (Csete et al., 2016). Drug prohibition also contributes to overdose, as it is not possible for authorities to control the purity and contents of black market substances (Csete et al., 2016).

Globally, criminal justice responses to illicit drug possession and use have led to a large proportion of the international incarcerated population serving sentences for minor, non-violent drug offences (Penal Reform International, 2018). Moreover, application of drug laws is often discriminatory. In the United States in 2014, African American men were five times more likely than white individuals to be incarcerated for drug offences in their lifetime, despite there being no significant disparity in rates of illicit drug use between ethnic groups (Csete et al., 2016). Similar ethnic inequities are present within New Zealand, where most drug convictions are for low-level offences (New Zealand Drug Foundation, n.d.). In 2016, 5,011 individuals were convicted of illicit drug offences, and Māori received $42 \%$ of all illicit drug convictions despite comprising only $15 \%$ of the general population. ${ }^{1}$ Additionally, young people are

\footnotetext{
${ }^{1}$ Māori are the indigenous ethnic group in New Zealand.
} 
disproportionate recipients of drug convictions, with those under thirty receiving $47 \%$ of possession, use, and utensil convictions in 2016 (New Zealand Drug Foundation, n.d.).

The wider effects of international drug control conventions and the drug war include ecological, social, and political harms. United States-led international drug prohibition regimes have targeted drug-related crops (e.g., coca leaf, opium poppy, and cannabis), including aerial spraying of crops and forced displacement of poor rural communities, mostly in developing countries such as Colombia and Peru (Csete et al., 2016; Felbab-Brown, 2005; Rincón-Ruiz \& Kallis, 2013). More recently, the life expectancy of Mexican men has reduced as a direct result of the drug war, as the Mexican homicide rate increased from 9.5 per 100,000 people in 2005 to more than 22.0 per 100,000 people in 2010 , coinciding with military operations to disrupt drug cartels (Aburo, Beltrán-Sánchez, García-Guerrero \& Canudas-Romo, 2016). ${ }^{2}$

The undeniable harms of drug prohibition notwithstanding, prohibitionist policies are largely ineffective. Cannabis cultivation, use, and normalisation have increased since the second half of the $20^{\text {th }}$ century (Levine, 2003). In New Zealand, the lifetime prevalence of cannabis use is $42 \%$, with $11 \%$ of adults over the age of 15 reporting cannabis use within the past year (Degenhardt et al., 2008; Ministry of Health, 2015). Drug prohibition incurs a significant financial cost and has a negligible impact on illicit drug consumption. Prohibition has not resulted in any meaningful reductions in illicit drug supply or demand as it fails to make illicit drugs more expensive or less attractive to consumers (Miron, 2004; Reuter, 2001; Werb et al., 2011). The risk of detection by authorities is not a deterrent to illicit drug use (Miron, 2004; Werb et al., 2011). In fact, drug prohibition raises the crime rate, not only through drug-defined crimes but also through violent crime associated with the black market (Goldstein, 1985; Miron, 2004; Werb et al., 2011).

It has been suggested that drug cryptomarkets may transform or reduce some drug-related and prohibition-related harms (Aldridge \& Décary-Hétu, 2016a; Bancroft, 2017; Bancroft \& Scott Reid, 2016; Barratt, Lenton, Maddox \& Allen, 2016; Caudevilla, 2016; Cox, 2014; Ormsby, 2016). There has been emergent academic discussion about cryptomarkets such as Silk Road (Aldridge \& Décary-Hétu, 2014; Barratt, 2012a; Maddox et al., 2016; Phelps \& Watt, 2014) and consumer experiences of trading on the darknet (Barratt, Lenton, Maddox \& Allen, 2016;

\footnotetext{
${ }^{2}$ There have been movements away from drug prohibition in some countries in recent years, including the 2001 decriminalisation of drugs for personal use in Portugal, and cannabis law reform throughout Canada and various jurisdictions in the United States over the past decade (Cox, 2018; Greenwald, 2009; Hall \& Kozlowski, 2018). However, the general trend of punitive prohibitionist policies remains, and governments are hamstrung by the constraints of the UN conventions.
} 
van Hout \& Bingham, 2013a, 2013b, 2014). However, at present, no New Zealand-specific peer-reviewed research has been published.

This thesis presents qualitative interview-based research which focuses on the experiences of New Zealand consumers and dealers who have purchased illicit drugs through the darknet. New Zealand occupies a noteworthy position in the cryptomarket ecosystem, as its conventional illicit drug market is constrained by its small population and geographical isolation. This acts as a 'push' factor, increasing the appeal of cryptomarket illicit drug purchases for some New Zealanders. Participants referred to the geographical isolation of New Zealand and the constraints of its conventional drug market as influential in their engagement with cryptomarkets. Other constraints of the domestic conventional drug market include poor availability and quality of drugs, poor authenticity and purity, high price, and risk of violence. Entangled with these push factors, there are several 'pulls' for New Zealanders who are drawn to drug cryptomarkets. Drug cryptomarkets offer comparatively low prices, trustworthy rating and review systems, high quality, a wide range of substances, convenience and low chance of violence. They are not without their downsides, however, which include paper trails, time investment, and the severity of criminal charges under New Zealand's principal drug legislation, the Misuse of Drugs Act (1975).

The cryptomarket landscape is complex terrain, and further research on the role of cryptomarkets in the illicit drug trade is warranted. Such research may have implications for policy, research, and harm reduction initiatives. It is vital to understand developments in the mechanisms through which individuals access illicit drugs, and it is anticipated that this research will assist in furthering academic understanding of the illicit drug landscape in New Zealand.

To guide the research for this thesis, four overarching aims were developed:

1. Gaining insight into the experiences of New Zealand consumers and dealers who have interacted with cryptomarkets through drug purchases and/or sales.

2. Exploring how and why New Zealand consumers choose to purchase illicit drugs through cryptomarkets instead of alternatives.

3. Comparing cryptomarket illicit drug trading and purchase with conventional illicit drug trading in New Zealand.

4. Contrasting the experiences of New Zealanders accessing illicit drugs through cryptomarkets with overseas consumers and dealers in the extant literature. 
The research has implications for New Zealand harm reduction initiatives, by providing insight that could inform harm reduction policy. The research prioritises the lived experiences of New Zealanders who access drug cryptomarkets, including their insights about detection and apprehension by authorities and the various forms of drug trading that they engage in. The insights gathered may support drug law reform in New Zealand, particularly underscoring the importance of reconsidering the treatment of cryptomarket-related offences under the Misuse of Drugs Act (1975). 


\section{Chapter 2: Literature Review}

\section{The History of the Darknet}

Since its inception, the internet has facilitated illicit drug trading. ARPANET, an early precursor to the internet, was used for the first online cannabis deal between students at Stanford and MIT in 1971 (Martin, 2017b). There is an apparent 'symbiotic relationship' between illicit drugs and the internet (Walsh, 2011, p. 55). Walsh (2011) asserts that the 'leaderlessness' of the internet is heavily influenced by the hippie counterculture of the era in which it developed, a time when psychedelics such as LSD and psilocybin (magic mushrooms) were widespread. Influential computer programmers who worked in California in the 1960s were known to take LSD, and Steve Jobs stated that psychedelics such as LSD aided this thought process in developing the some of the more challenging aspects of modern computing (Markoff, 2005).

Alongside the shared history of illicit drugs and the internet, there are observable similarities between them. Both can be understood as forms of technology that can be purposefully applied to achieve practical outcomes, whether an expansion of knowledge or an altered state. Both transform culture and society, providing a portal to a dream-like altered reality with the potential to diffuse and distort time and space. The internet can also foster a sense of community around subcultures that are difficult to locate offline, particularly niche psychedelic subcultures and 'cyber psychonauts' who form identities centred on exploring human consciousness and existence through the altered states provided by psychoactive substances (O’Brien, Chatwin, Jenkins \& Measham, 2015; "Psychonautics", n.d.; van Hout \& Bingham, 2013b; Walsh, 2011). The internet can provide an arena for illicit drug education and harm reduction in the form of drug information and trip reports on sites such as Bluelight and Erowid (“Trip Reports", n.d.; "Erowid Experience Vaults", n.d.). More widespread are internet drug markets of varying legality in the form of online pharmacies, retailers of new psychoactive substances (NPS), and darknet cryptomarkets (Castronova, 2006; Lavorgna, 2014; Walsh, 2011). ${ }^{3}$ These markets utilise the relative anonymity of the internet to circumvent legal and advertising restrictions on illicit drug sales (Walsh, 2011). The online illicit drug landscape also highlights the irony of the draconian zeal with which states pursue drug prohibition against a backdrop of fervent consumer capitalism. Reith (2004) argues that the combination of

\footnotetext{
${ }^{3}$ EMCDDA (2011) defines 'new psychoactive substance' as a "new narcotic or psychotropic drug, in pure form or in preparation, that is not controlled by the 1961 United Nations Single Convention on Narcotic Drugs or the 1971 United Nations Convention on Psychotropic Substances, but which may pose a public health threat comparable to that posed by substances listed in these conventions" (p. 1).
} 
'addictive consumption' and prohibition is becoming increasingly unsustainable with the proliferation of internet culture in late modernity, as "conspicuous consumption and selffulfillment increasingly become elevated to the status of individual "rights"' (p. 286). The paradox of material consumption and hard-line drug prohibition is clear in the internet sphere, and the online illicit drug landscape allows researchers to witness the striking lengths to which some individuals go to access illicit drugs under prohibition.

To understand the various forms of online illicit drug trading, it is necessary to distinguish between different sections of the internet. Internet content can be divided into two broad categories - the clearnet (sometimes referred to as the 'surface net') and the deep web (Barratt \& Aldridge, 2016; Ciancaglini, Balduzzi, McArdle \& Rösler, 2015). The clearnet denotes areas of the internet that can be indexed through conventional search engines without specialised software or settings (Barratt \& Aldridge, 2016; Ciancaglini et al., 2015). The deep web refers to webpages that cannot be indexed by conventional search engines for a variety of reasons, such as being locked behind a paywall or requiring login credentials (Barratt \& Aldridge, 2016; Ciancaglini et al., 2015). The darknet (sometimes referred to as the 'hidden web') forms a portion of the deep web which can only be located through specialised tools or access arrangements (Ciancaglini et al., 2015). ${ }^{4}$ Software that can be used to access the darknet includes the Tor browser, which is the most popular option, the Invisible Internet Project (I2P), and Freenet (Ciancaglini et al., 2015). The deep web, inclusive of the darknet, is very large, 500 times that of the clearnet, comprising about $96 \%$ of the total internet (Epstein, 2014). Given the monumental size of the darknet, academic enquiry into its nature is warranted.

\section{Cryptomarkets and Tor}

Cryptomarkets, located on the darknet, are a direct descendant of the early interplay between illicit drugs and the internet, and more recent online illicit drug trading that emerged in the 1990s and 2000s. Martin (2014) defines a cryptomarket as "an online forum where goods and services are exchanged between parties who use digital encryption to conceal their identities" (p. 356). Cryptomarkets are associated with the trade of illicit drugs and other illegal goods and services such as weapons and fraudulent identities, but it is necessary to note that not all goods and services that are available on cryptomarkets are illegal (Martin, 2014).

\footnotetext{
${ }^{4}$ Some publications and researchers refer to the 'deep web' and the 'darknet' interchangeably. For clarity, the terms used herewith will be in accordance with those provided above by Barratt and Aldridge (2016) and Ciancaglini et al. (2015).
} 
Similar to Martin (2014), Barratt and Aldridge (2016) define a cryptomarket as "a marketplace that hosts multiple sellers or 'vendors', provides participants with anonymity via its location on the hidden web and use of cryptocurrencies for payment, and aggregates and displays customer feedback ratings and comments" (p. 1). ${ }^{5}$ To access cryptomarkets, users are required to download and install anonymising software such as Tor and then navigate to cryptomarket web addresses. Physical goods that are purchased through cryptomarkets are sent to the consumer via conventional postal services (Martin, 2014). The most popular illicit drugs sold on cryptomarkets appear to be relatively consistent between markets, regions, and time periods. Barratt and Aldridge (2016) state that the most popular cryptomarket illicit drugs are cannabis, MDMA, LSD, and pharmaceuticals, with 'harder' illicit drugs being less popular. This tentatively suggests that drug cryptomarket consumers are a subset of recreational illicit drug users, with 'problematic' users of 'hard' illicit drugs such as heroin and methamphetamine less likely to source their illicit drugs through cryptomarkets. However, it is possible that individuals in regions with constrained domestic markets access a wider range of substances through cryptomarkets than those who live in areas with more bountiful domestic markets.

Typical characteristics of cryptomarkets include reliance on the Tor network; utilisation of cryptonyms to conceal user identity; utilisation of traditional postal systems to deliver goods; third-party hosting and administration of websites; decentralised exchange networks; and the use of cryptocurrency such as Bitcoin (Martin, 2014). When Tor is employed correctly, it is extremely difficult for users to be linked to their online activity (Buxton \& Bingham, 2015). Tor has a 'hidden services' feature which allows individuals to anonymously host and browse content with end-to-end encryption (Lewman, 2016). To access a hidden service on Tor, users must know the hidden service's onion address (equivalent to a web address on the clearnet) (Lewman, 2016). In 2015, it was estimated by the Tor Project, the organisation responsible for the development of Tor, which originated from a United States Naval Research Laboratory project, that there were approximately 30,000 Tor hidden services that were active daily, indicating that activity on hidden services is significant and widespread (Lewman, 2016).

Anonymising technology, such as Tor, poses a major challenge to authorities' efforts to disrupt the illicit drug trade, and the cross-border nature of cryptomarket illicit drug trading flouts multiple United Nations drug control conventions (UNODC, 2013). However, cryptomarkets present a user-friendly and secure means of trading illicit drugs while lessening some of the

\footnotetext{
${ }^{5}$ The requirement of 'multiple vendors' in this definition excludes cryptomarkets that are hosted by individual vendors although vendor-hosted sites are less popular than those administered by a third party.
} 
negative aspects of conventional illicit drug trading, such as the possibility of coercion, violence, and apprehension (Buxton \& Bingham, 2015). Additionally, fora that are often attached to darknet cryptomarkets can facilitate discussion about illicit drugs and distribute harm reduction information (Buxton \& Bingham, 2015). Presently, cryptomarkets comprise a very small portion of the international illicit drug trade, and their growth is inhibited by reliance on postal networks. However, they represent a striking transformation in international illicit drug markets, as they allow vendors to sell to customers who are unknown to them, effectively 'reopening' closed markets in a manner which may eventually provide a direct link between illicit drug manufacturers and consumers without the need for a go-between (Aldridge, 2012; Aldridge \& Décary-Hétu, 2016a; Bakken, Moeller \& Sandberg, 2017; May \& Hough, 2004).

\section{Bitcoin and Other Cryptocurrencies}

Aside from anonymising networks such as Tor, the major technological innovation that has given rise to cryptomarkets is cryptocurrency. Chohan (2017a) defines cryptocurrency as "a digital asset that is constructed to function as a medium of exchange, premised on the technology of cryptography, to secure the transactional flow, as well as to control the creation of additional units of currency" (p. 1). Additionally, the United States Department of the Treasury Financial Crimes Enforcement Network (2013) refers to 'virtual currency' as "a medium of exchange that operates like a currency in some environments but does not have all the attributes of real currency," including that it is not recognised as legal tender in any jurisdiction (p. 1).

The most popular cryptocurrency is Bitcoin. Use of Bitcoin requires a Bitcoin wallet, and many individuals purchase Bitcoin in a manner that links their wallet to their legal identity (e.g., by using transfers from their personal bank account). Concerns have been raised that authorities may be able to link Bitcoin transactions in cryptomarkets to specific individuals by tracing transactions in the public Bitcoin ledger and linking them to individuals' Bitcoin wallets in a process called 'blockchain analysis' (Cox, 2016c; Narayanan, Bonneau, Felten, Miller \& Goldfeder, 2016). For this reason, Narayanan et al. (2016) suggest that it is more accurate to describe Bitcoin as pseudonymous than anonymous. Obviously, anonymity is a necessary prerequisite for purchasing illegal goods and services from cryptomarkets, so some cryptomarket consumers opt to further conceal their identities through obfuscation systems such as Bitcoin tumblers which 'mix' Bitcoin transactions in a manner like traditional money laundering, thus making them more difficult to link to an individual's identity (Cox, 2016c). Aside from Bitcoin, there are several smaller altcoins (alternative coins) which are based on 
the Bitcoin protocol but include in-built anonymity features that Bitcoin lacks, thus increasing the privacy and security of users (Cox, 2016c). When combined with anonymising software such as Tor, cryptocurrencies create a platform for cryptomarkets to thrive, as individuals can purchase illicit drugs and other goods and services in a pseudonymous manner, with an apparently reduced chance of detection.

\section{Drug Cybercrime and Online Pharmacies}

The internet has transformative potential for all stages of the illicit drug market, from drug production to transit and distribution. Online illicit drug trading is arguably less risky than the conventional illicit drug trade due to increased anonymity, minimal physical interaction, and lower likelihood of being detected by authorities (Lavorgna, 2016). Due to the benefits of online platforms, illicit drug trading occurs on both the clearnet and the deep web. In particular, the clearnet has experienced an increase in sales of NPS, as they occupy a legal 'grey area' in many jurisdictions, as well as a proliferation of online pharmacies of varying legitimacy and legal status (Castronova, 2006; Lavorgna, 2016; Mounteney, Oteo \& Griffiths, 2016).

Alongside the increasing volume of vendors and illicit drug listings, there is statistical evidence that supports the growing popularity of cryptomarkets as a means for consumers to access illicit drugs. In the Global Drug Survey (GDS) (2015), 10\% of respondents indicated that they had purchased illicit drugs online (both on the clearnet and the deep web) within the past year (cited in Mounteney et al., 2016). Further, the findings of the GDS (2018) revealed that $2.8 \%$ of New Zealand respondents had made cryptomarket illicit drug purchases in the past year. Though this is a very small proportion when compared to the $17.2 \%$ of Australian respondents who reported past-year cryptomarket illicit drug purchases, the number of respondents accessing the darknet for illicit drug purchases has steadily increased since the GDS began asking about darknet purchases in 2014 (GDS, 2018). ${ }^{6}$ The ad hoc nature of the wider internet illicit drug trade (both clearnet and darknet) and its growing popularity challenges the dominant narrative of highly structured criminal organisations controlling the international illicit drug trade.

\footnotetext{
${ }^{6}$ Although the GDS utilises a purposive sample, its findings provide important context on cryptomarket drug use that would not otherwise be available to researchers. The percentage of Australian GDS respondents who reported darknet drug purchases over the past year may be increasing at a greater rate than New Zealand respondents. 8.2\% of Australian respondents reported a cryptomarket drug purchase in the GDS (2017), but 17.2\% reported the same in the GDS (2018). In 2017, 1.9\% of New Zealand respondents reported a cryptomarket drug purchase, compared with $2.8 \%$ in the GDS (2018).
} 


\section{The History and Organisation of Cryptomarkets}

The negotiation of cannabis sales between Stanford and MIT students in the 1970s is the first known example of online illicit drug trading (Martin, 2017b). However, modern cryptomarkets emerged in the 2000s, with early cybercrime and credit card fraud fora, such as ShadowCrew which also had a limited illicit drug trade (Hoffman, 2015). Another early cryptomarket, The Farmer's Market (formerly Adamflowers), launched in 2006 and migrated to Tor in 2010 (Zetter, 2012). Though it was seized by the United States Drug Enforcement Agency in 2012, The Farmer's Market was a proto-cryptomarket, an early predecessor to modern cryptomarkets. Unlike modern cryptomarkets, it did not use cryptocurrency, instead requiring customers to pay for goods and services with unencrypted payment services like PayPal and Western Union (Zetter, 2012). Other proto-cryptomarkets on Tor in the late 2000s and early 2010s included The Drugstore and the Open Vendor Database (Buxton \& Bingham, 2015).

In February 2011, the first modern cryptomarket, Silk Road, was launched by Ross Ulbricht under the alias 'Dread Pirate Roberts' (Phelps \& Watt, 2014). Unlike previous markets, Silk Road utilised both Bitcoin and Tor Mail, an encrypted Tor email service, to facilitate communication between vendors and consumers (Buxton \& Bingham, 2011). In its first year, Silk Road accrued approximately 39,000 accounts, facilitating illicit drug trading activity on a far larger scale than its predecessors (Buxton \& Bingham, 2011). The sudden popularity of Silk Road was possibly related to a blog article that was written by Adrian Chen and published on Gawker in 2011, only a few months after the launch of Silk Road (Chen, 2011). As Silk Road gathered public attention, it predictably accumulated negative assessments from drug prohibitionists. For example, New York Democratic Senator Chuck Schumer described Silk Road as "a certifiable one stop shop for illegal drugs that represents the most brazen attempt to peddle drugs online that we have ever seen" (Ball, 2013, cited in Buxton \& Bingham, 2015, p. 10). Calculating the revenue of Silk Road is difficult, but Aldridge and Décary-Hétu (2016a) estimate that it generated US\$89.7 million in 2013. On 3 October 2013, Silk Road was seized by the FBI after they found weaknesses in its operational security (van Buskirk, Roxburgh, Farrell \& Burns, 2014). In 2015, Silk Road's founder, Ross Ulbricht, was sentenced to life imprisonment with no possibility of parole after he was found guilty of seven charges relating to illicit drugs and money laundering (Thielman, 2015).

The closure of Silk Road led to a flourishing of alternative cryptomarkets in its wake, including Black Market Reloaded (BMR), Sheep Marketplace, and Silk Road 2.0 (van Buskirk et al., 2014). van Buskirk et al. (2014) traced the number of active vendors on cryptomarkets over 
the six-week period following the closure of Silk Road. They found that the number of registered BMR vendors more than doubled, and Sheep Marketplace experienced a $461 \%$ increase in vendors. Further, Buxton and Bingham (2015) suggest that the closure of Silk Road had the unintended consequence of increasing cryptomarket users' awareness of security and privacy practices. Therefore, they conclude that the closure of Silk Road had "no long term or catastrophic impact on the Silk Road project or hidden markets more broadly," but it stimulated the development of new cryptomarkets and evinced the adaptability of cryptomarkets to the demands and desires of consumers (Buxton \& Bingham, 2015, p. 14). Their assertions are mirrored by findings from research on conventional illicit drug markets which suggests that illicit drug dealers are swiftly replaced by other actors following police intervention (McKeganey \& McGallagly, 2013). According to journalist Mike Power, the closure of Silk Road "[h]as inadvertently been the most brilliant advertising for hidden web drug markets. The FBI have acted as the most creative marketing and advertising agency that the hidden web drugs sector could have possibly hoped for." (Buxton \& Bingham, 2015, p. 14-15). The unintended effects of the closure of Silk Road remain, and the transformative nature of these effects continues to influence cryptomarkets.

Throughout 2014, several cryptomarkets vied for a market share of vendors and consumers, including Agora, Hydra, Evolution, and Silk Road 2.0 (Aldridge \& Décary-Hétu, 2016a). In November 2014, Operation Onymous, a collaborative effort between various international authorities, led to the closure of numerous cryptomarkets, several arrests, and the seizure of US\$1 million in Bitcoin, illicit drugs, weapons, and other goods (Afilipoaie \& Shortis, 2015). It remains unclear how authorities were able to infiltrate and seize the cryptomarkets or identify some of the individuals who were linked to them. Several explanations for the infiltration and seizure have been suggested, including substandard operational security practices by the cryptomarket administrators, blockchain analysis leading to Bitcoin deanonymisation, and attacks on the Tor network (Afilipoaie \& Shortis, 2015). Although representatives of the Tor Project publicly stated they did not believe that the Tor network had been compromised, Operation Onymous led to significant community concern about the security and integrity of Tor-hosted cryptomarkets (Décary-Hétu \& Giommoni, 2016; Lee, 2014).

Despite the effects of Operation Onymous, cryptomarkets continue to expand, though their lifespan is reduced by enforcement operations (Aldridge \& Décary-Hétu, 2016a). Cryptomarkets that were unscathed by Operation Onymous, particularly Evolution and Agora, experienced large growth in its aftermath (Afilipoaie \& Shortis, 2015). Remaining 
cryptomarkets quickly adapted to authorities' efforts, thus limiting the repercussions of Operation Onymous (Décary-Hétu \& Giommoni, 2016; van Buskirk, Bruno, Dobbins, Breen, Burns, Naicker \& Roxburgh, 2017). Adaptations included the implementation of more secure authentication techniques and communication methods between vendors and consumers (Décary-Hétu \& Giommoni, 2016). Both Décary-Hétu and Giommoni (2016) and van Buskirk et al. (2017) found significant reductions in the number of vendors on remaining cryptomarkets in the wake of Operation Onymous, though these reductions were short-lived, as two months after Operation Onymous, the volume of sales across the remaining cryptomarkets appeared to be twice that of pre-Operation levels. van Buskirk et al. (2017) conclude that enforcement activities appear to be fruitless as cryptomarkets are highly resilient to disruption. As with the closure of Silk Road, Buxton and Bingham (2015) and van Buskirk et al. (2014) suggest that police operations may promote cryptomarket growth as they increase public awareness of cryptomarkets. Following Operation Onymous, there were several cryptomarket scams and enforcement operations between 2015 and 2017. There have also been several smaller operations involving the New Zealand Police in recent years, including Operation Hyperion in 2016 which targeted individual users, and Operation Garden in late 2018 which focused on education and harm reduction instead of prosecution (New Zealand Police, 2016, 2018).

Along with the actions of international authorities, cryptomarkets have been subject to scams and fraud from within the community. Moeller, Munksgaard and Demant (2017) note that while cryptomarkets may experience less systemic violence than that which is associated with conventional illicit drug markets (Aldridge \& Décary-Hétu, 2014, 2016a; Aldridge, Stevens \& Barratt, 2018; Bakken et al., 2017; Goldstein, 1985; Martin, 2017a), their technological foundations give rise to opportunities for stealing and fraud, as "malicious peers exploit vulnerabilities in the technological infrastructure of the Tor network, the irreversibility of Bitcoin transactions, the use of feedback, whitewashing, and the inherent uncertainty associated with sending illicit drugs in the mail" (Moeller et al., 2017, p. 1443). Such activity can include distributed denial of service (DDoS) attacks which seek to make cryptomarkets unavailable by overwhelming them with online traffic, and exit scams where individuals take advantage of the irreversibility of Bitcoin transactions to steal substantial amounts of money (“What is a DDoS Attack?", n.d.; Moeller et al., 2017). Escrow services can be exploited by vendors to scam consumers by asking them to 'finalise early' (confirm that they have received the goods so that the payment is released from escrow prior to shipping) without sending the 
purchased goods (Tzanetakis, Kamphausen, Werse \& von Laufenberg, 2016). ${ }^{7}$ Cases of fraud are complicated by the fact that there is no legal recourse available to victims, as they are engaging in illegal activity (Moeller et al., 2017). Nevertheless, the cryptomarket ecosystem continues to evolve, with Wall Street Market, Dream Market, and Point Marketplace currently among the most popular cryptomarkets (“Top Markets", n.d.).

\section{The Challenges of Cryptomarkets to Authorities}

Kruithof et al. (2016) suggest four modes of detection and intervention that may be applied in enforcement activities targeted at cryptomarkets and the apprehension of administrators, vendors, and consumers. These include conventional investigation techniques (e.g., surveillance and undercover operations), postal detection and interception, online detection and data analysis (e.g., blockchain analysis and other big data techniques), and online disruption (seizing and closing cryptomarkets). Despite these methods of disruption, Martin (2014) notes that cryptomarkets present several challenges to authorities. These include online encryption through Tor and cryptocurrencies, as well as difficulties linking seized post items to the individuals who have ordered them.

Cryptomarkets rely on conventional postal services for the delivery of goods, and this is where detection is most likely to occur (Aldridge \& Askew, 2017). International shipping is particularly risky, as drug parcels may be detected during checks at the border (Décary-Hétu, Paquet-Clouston \& Aldridge, 2016). Nevertheless, significant issues arise with the monitoring of postal services, as the rise of online shopping has resulted in a pronounced increase in the volume of international post over recent years (Martin, 2014). Most international post items are from legitimate sources, making it exceedingly difficult for authorities to detect illegal items which can be 'needles in a haystack' (Martin, 2014). Compounding this, cryptomarket vendors and consumers are acutely aware of the monitoring of postal items (Aldridge \& Askew, 2017). Cryptomarkets have guides on techniques to avoid the detection of postal services, including vacuum sealing, inconspicuous outer packaging, framing delivery-related activities around a non-criminal persona, and refraining from making purchases from countries that are considered particularly 'high-risk' (Aldridge \& Askew, 2017; Martin, 2014). Additionally, consumer feedback on vendor profiles often mentions the 'stealth' of orders, and consumers

\footnotetext{
${ }^{7}$ Escrow refers to a process whereby a third party (usually the marketplace administrators) hold the buyer's payment until the buyer confirms that the goods have been received in the expected condition. Once the buyer confirms this, the third party releases the payment to the vendor. Escrow systems can be used to prevent scams (Gilbert \& Dasgupta, 2017; Mounteney et al., 2016).
} 
report that reviews of stealth are a contributing factor in selecting which vendors to purchase from (Martin, 2014).

Décary-Hétu et al. (2016) used data from Silk Road to propose four categories of risk associated with illicit drug dealing. These include the risk of arrest, the risk of violence, the risk to profits, and the risk to reputation. They report that risk-taking in the form of vendor willingness to ship illicit drugs internationally is dependent on the weight of illicit drugs being shipped, the vendor's reputation, the perceived effectiveness of authorities, and the vendor's opportunity to profit (Décary-Hétu et al., 2016). Décary-Hétu et al. (2016) identified a positive relationship between both small parcel weights and international shipping, and between the vendor's number of listings and international shipping. As well as this, they found a significant negative correlation between international shipping and illicit drug expenditure in the vendor's country of residence. They suggest that this is due to high domestic illicit drug expenditure resulting in vendors not needing to take the risk of offering international shipping in order to reap significant profits. The risks associated with illicit drug dealing emerge differently in conventional and cryptomarket environs, partially due to the spatial diffusion of illicit drug trading that is associated with cryptomarkets (Aldridge \& Décary-Hétu, 2016a). Aldridge and Askew (2017) characterise cryptomarkets as 'stretched' across time, and virtual and physical space. Cryptomarkets also expand the availability of information about illicit drug markets so that vendors and consumers can make informed decisions about mitigating risk, but this information is also available to authorities and may necessitate innovation on both sides of the law.

The cryptomarket ecosystem is resilient and resistant to the effects of intervention, and interruption of the technologies that sustain cryptomarkets leads to further innovation in encryption (EMCDDA, 2017). Even when items are intercepted by authorities, there are barriers to linking the parcel to an individual's legal identity and achieving a successful prosecution. Vendors often recommend that consumers request that their orders be addressed to a pseudonym and posted to an address that they do not reside at, thus making it more difficult for authorities to identify the intended recipient of intercepted parcels (Martin, 2014). The organisational structure of cryptomarkets also poses challenges to authorities, who have traditionally focused primarily on retail-level drug sales, because cryptomarkets decrease the number of illicit drug supply chain actors, allowing distribution networks to connect directly with consumers. Aside from resulting in practical complications in detecting and apprehending those who purchase illicit drugs, Martin (2014) asserts that there are unintended symbolic 
consequences for the drug war. He argues that prohibitionist rhetoric that links illicit drug use with violence and organised crime is threatened by cryptomarkets through the loss of the symbolic devices that are associated with the war on drugs, as cryptomarkets largely function "[w]ithout large individual shipments of narcotics, and in the absence of guns, gangsters and turf wars" (Martin, 2014, p. 363).

Buxton and Bingham (2015) have also questioned the logic of enforcement operations targeted at cryptomarket technologies. Even if it were possible to completely suppress cryptomarkets, illicit drug trading would return to conventional street-based markets, which they deem to be more harmful than cryptomarkets. They assert that enforcement activities should be targeted towards more harmful darknet criminal offences such as child exploitation material, cyber terrorism, and weapons trafficking, suggesting that authorities could collaborate with 'ethical' drug cryptomarkets to help users understand the issues related to high-level darknet criminal activity (Buxton \& Bingham, 2015). Such diversification of cryptomarkets could assist users in making ethical purchasing decisions (e.g., not purchasing drugs from markets that also list weapons for sale) (Buxton \& Bingham, 2015). They suggest other evidence-based approaches to cryptomarkets which centre on funding and conducting comprehensive ethical research, avoiding interventions that target 'soft' illicit drugs which cause little harm, and avoiding alarmist, panic-based responses to cryptomarkets (Buxton \& Bingham, 2015). Other possible interventions include using big data techniques, international information-sharing, early warning systems, and multi-agency approaches to take down illicit drug cryptomarkets and apprehend individuals who use them (EMCDDA, 2017; Lewman, 2016; Pompidou Group, 2013; van Slobbe, 2016). Regardless of individual perspectives on illicit drug prohibition and the various intervention techniques suggested, there is little evidence to support the efficacy of supply-side drug enforcement. Pollack and Reuter (2014) reviewed empirical research on supply enforcement and found little evidence that increasing the risk of arrest, incarceration, or seizure at different points in the supply chain increased illicit drug retail prices. Similar cryptomarket-specific findings have also been reported by Décary-Hétu and Giommoni (2017). Despite their dubious supply control efficacy, law enforcement efforts to disrupt cryptomarkets have had unintended effects, including expanding public awareness of cryptomarkets.

\section{Drug Cryptomarkets and the Media}

Chen's (2011) Gawker article was the first mainstream media coverage of Silk Road, the first major drug cryptomarket, a few months after Silk Road commenced trading. Since then, there have been several online articles from alternative news sites such as Vice and DeepDotWeb, 
which is available both on the clearnet and the darknet, and frequently reports on academic research findings (Cox, 2014; Sameeh, 2017a; Sameeh, 2017b; Spotz, 2014; "While markets get seized", 2014). Major news outlets such as The Guardian have also reported on interactions between the criminal justice system and drug cryptomarkets, and seizures of prominent cryptomarkets (Greenberg, 2014; Halliday, 2018).

New Zealand media reports demonstrate that New Zealand authorities are aware of cryptomarkets, with prominent news outlets reporting on court proceedings in darknet cases (e.g., Day, 2012; Ellingham; 2013; Galuszka, 2015). There have also been numerous press releases relating to darknet activity from New Zealand Customs Service (Customs) and New Zealand Police in recent years, making it clear that cryptomarkets are a point of interest for both New Zealand media and authorities (New Zealand Customs Service, 2017b; New Zealand Police, 2016, 2017). However, critical analysis of individuals' motivations for engaging with drug cryptomarkets is largely absent from mainstream media accounts, which favour fact-based court reporting and sensational accounts of illicit drug 'kingpins' profiting from large-scale cryptomarket drug supply ventures or deaths attributed to cryptomarket drug purchases (e.g., Falvey, 2018; Fox-Brewster, 2017; Fricker, 2016; O’Neill, 2017).

Academic interest in cryptomarkets followed from initial media coverage. Barratt and Aldridge (2016) contend that cryptomarkets are significant for drug researchers because they provide an opportunity to view the illicit drug supply chain in its totality, examine links between cryptomarkets and other forms of illicit drug supply, and monitor emergent trends. Cryptomarkets also demonstrate the extent of innovative efforts to access illicit drugs under regimes of prohibition and provide wide-ranging harm reduction advice and information to people who use illicit drugs (PWUD) in a manner that is regulated by community norms rather than the legal system (Barratt \& Aldridge, 2016). Despite issues of accuracy and sensationalism, the prominence of the media means that it undoubtedly contributes, at least somewhat, to the perspectives and interests of the public and academics.

\section{Contextualising Drugs on the Darknet}

Individuals' interactions with the darknet are complicated by numerous access limitations, not least of which is technical prowess (Aldridge \& Décary-Hétu, 2016a). Successful cryptomarket drug purchasing and selling require practical knowledge and proficiency in encryption technologies, namely cryptocurrencies and anonymising protocol. The decision to purchase illicit drugs cannot be made on a whim, as consumers must plan cryptocurrency transactions 
and require knowledge of how to protect their privacy and security online. This information is often not readily available or commonly known, so individuals must develop an interest in cryptomarkets and actively seek out practical information on how to make successful transactions prior to commencing orders.

Access limitations inevitably impact the demographic makeup of individuals who interact with and purchase illicit drugs from cryptomarkets. According to Barratt and Aldridge (2016), current research indicates that people who purchase illicit drugs from cryptomarkets are at least $80 \%$ male and aged in their early to mid-twenties, perhaps reflecting individuals who are most likely to have the technical competence and desire to access cryptomarkets. However, Barratt and Aldridge (2016) also note that cryptomarkets have the potential to expand the overall number of PWUD, as those who may not have access to conventional illicit drug markets are able to purchase drugs without relying on their social networks.

Barratt, Ferris and Winstock (2016) analysed data from the GDS 2014 to examine the types of drugs that are purchased from cryptomarkets. In the sample, the drugs most commonly obtained from cryptomarkets were MDMA, cannabis, and LSD, with 'harder' illicit drugs being less popular. As well as examining the types of illicit drugs used, Barratt, Lenton, Maddox and Allen's (2016) digital ethnography research investigated Silk Road users' patterns of illicit drug use and drug use trajectories. They assert that cryptomarkets appear to facilitate introspective, solitary drug use. Echoing the suggestions of Barratt and Aldridge (2016), for some participants, Silk Road stimulated the onset of illicit drug use, or a recommencement of illicit drug use after a period of abstinence. Many participants reported overindulgence or excessive illicit drug use in the first few months of accessing Silk Road. Contrarily, others felt that the extensive availability of illicit drugs on Silk Road reduced their desire to stockpile and assisted them in moderating and feeling more in control of their drug use (Barratt, Lenton, Maddox \& Allen, 2016). Cryptomarket-related drug consumption is evidently complex and nuanced, and evidence suggests that the drug use practices of cryptomarket users may be distinctive from those associated with conventional illicit drug markets.

Cryptomarkets also alter international illicit drug markets through the spatial diffusion of drugs and the opening of closed markets. Aldridge and Décary-Hétu (2016a) indicate that the market share of cryptomarkets is expanding as they grow in popularity. As a result, the accessibility, quality, and range of illicit drugs increases. Expansion of cryptomarkets also shifts individual perception, as vendors observe that they are less likely to be individually apprehended, and can 
attract a larger pool of potential customers in a market which can transcend space to trade internationally (Aldridge \& Décary-Hétu, 2016a). This spatial diffusion is particularly apparent when cryptomarkets are compared to conventional illicit drug markets, as conventional dealers sell to a relatively small customer base, in some cases only to those with whom they have established trusted relationships (Aldridge \& Décary-Hétu, 2016a).

The role of technology in facilitating the transformation of illicit drug markets is further evidenced in the opening and closing of markets. Aldridge (2012) contends that over time, there has been a gradual movement of some illicit drug markets from open to closed (cf. May \& Hough, 2004). The shift toward closed markets can be partially attributed to technical advances such as mobile phones, but more recent innovations may have reopened some closed markets, as dealers are able to sell drugs online to customers with whom they do not have a personal relationship. These recent shifts have been facilitated by cryptomarkets, but also by other internet fora, social networks, and geo-social networking applications such as Grindr (Aldridge, 2012). ${ }^{8}$ Similarly, Bakken et al. (2017) stress that cryptomarkets blur the distinction between open and closed drug markets. In theory, cryptomarkets are open markets in the sense that they are accessible to all. However, in practice, there are technical hurdles to cryptomarket access, so they are only open to those who possess the necessary knowledge and skill. Further complicating the classification of cryptomarkets as either open or closed, marketplaces and third-party administrators act as go-betweens for vendors and consumers, meaning that parties can assess each other before transactions are made. Cryptomarkets' unique blend of openness and secrecy appeals to vendors and consumers alike, as secrecy provides low risk, while openness facilitates a high volume of traffic and transactions.

Cryptomarkets are associated with high-quality drugs, and this perception has contributed to their appeal (Bancroft \& Scott Reid, 2016). However, forensic analysis of cryptomarket drugs has yielded mixed findings. van der Gouwe, Brunt, Laar and Pol (2017) undertook an analysis of 32,663 illicit drug samples in the Netherlands between 2013 and 2016, 928 of which were purchased online. They found that there were no large differences in illicit drug purity between online and offline samples. It is important not to overstate the significance of these findings, as the samples were sourced from a single European country, and the online samples were purchased from a variety of online markets, not solely from cryptomarkets (van der Gouwe et al., 2017). In another study, Caudevilla et al. (2016) analysed 219 drug samples obtained from

\footnotetext{
${ }^{8}$ Grindr is a popular online dating and hook-up application, mainly used by men seeking men. Location data from mobile phones is used to display nearby users, with options to chat and send photos (Aldridge, 2012).
} 
international cryptomarkets. In 200 of the samples, the main compound detected was consistent with the advertised substance. Purity levels differed between drugs, but most samples had high purity (Caudevilla et al., 2016). Additionally, a Swiss study of drug samples from Evolution found that while the advertised substance was generally accurate, the chemical purity differed from what the vendor indicated (Rhumobarbe, Staehli, Broséus, Rossy \& Esseiva, 2016). Cryptomarkets have obvious technological differences from conventional illicit drug markets, and these differences induce a blend of openness and secrecy. Further research is needed to determine if there are significant, measurable differences between the chemical properties of drugs from cryptomarkets and those from conventional markets.

Cryptomarket sales are different in nature to those that occur in conventional illicit drug markets. Aldridge and Décary-Hétu (2014) contend that cryptomarkets are not an 'eBay for drugs' with consumers making small purchases for personal use (cf. Barratt, 2012a). In an analysis of Silk Road listings, they found that a substantial volume of transactions could be characterised as business-to-business rather than business-to-consumer. Business-to-business sales accounted for $31-45 \%$ of Silk Road revenue for the period of analysis, suggesting that a core group of consumers are drug dealers sourcing illicit drugs for conventional dealing. Further, Aldridge and Décary-Hétu (2016b) assessed listings from Silk Road and found that wholesale revenue (orders over US\$1000) accounted for approximately $25 \%$ of overall revenue. Wholesale activity was most common for ecstasy-type drugs, as well as benzodiazepines and prescription stimulants (Aldridge \& Décary-Hétu, 2016b). There were also regional differences, as significant wholesale activity originated in China, the Netherlands, Canada, and Belgium (Aldridge \& Décary-Hétu, 2016b). Contrarily, EMCDDA (2017) research found that wholesale transactions were relatively uncommon, with most sales being for a low or medium volume of drugs, although it is certainly possible that the low-medium volume sales evidenced by EMCDDA (2017) were for social supply. In these cases, it is important to note that cryptomarkets concomitantly serve illicit drug users who are not direct customers of cryptomarkets, thus extending the drug-diffusing capacity of cryptomarkets and linking online and conventional illicit drug markets (Aldridge \& Décary-Hétu, 2016b).

Despite some contradictory findings on illicit drug purity, Aldridge and Décary-Hétu (2014) assert that cryptomarkets may play a pivotal role in the reduction of systemic violence in illicit drug markets, as they function in the virtual realm, reducing the need and ability for violence, territorialism, and intimidation which are commonly associated with drug dealing (Andreas \& Wallman, 2009; Goldstein, 1985; Reuter, 2009). They consider cryptomarkets to be a 
"transformative criminal innovation" as it is likely that they will influence the development and functioning of future illicit drug markets (Aldridge \& Décary-Hétu, 2014, p. 4). They argue that it is likely that low-level drug dealers will continue to use cryptomarkets to conduct their business, as cryptomarkets are associated with a low risk of detection and apprehension. Cryptomarkets also represent an internationalisation of illicit drug markets, and the significance of this should not be understated, as internationalisation allows individuals a means of accessing illicit drugs that are not available in their country of residence, as well as the ability to shop around for the best available price. The process of internationalisation also increases competition between vendors, in turn expanding the range of items available for purchase (Aldridge \& Décary-Hétu, 2014).

\section{Vendor Practices on Cryptomarkets}

Vendor practices on cryptomarkets are variable, but there are some common themes. Ormsby (2016) conducted several interviews with cryptomarket vendors. Her participants were mostly males aged in their twenties to forties, and many were former conventional drug dealers. However, for some, Silk Road was their first foray into drug dealing. Vendors reported motivations that overwhelmingly focused on the profitability of cryptomarket trading if they could establish a strong reputation for providing good service and high-quality drugs (Ormsby, 2016). In Kruithof et al.'s (2016) study, vendors were predominantly young males from English-speaking or European countries. They were generally well-educated, entrepreneurial, and possessed strong technical competence (Kruithof et al., 2016). Available evidence is limited due to the obvious need for vendors to maintain anonymity, but vendor demographics appear to be relatively similar to those of consumers (Barratt \& Aldridge, 2016).

Vendor reputation is maintained through cryptomarket rating and review systems. The ratings and feedback that vendors receive are vital in ensuring the continued success of their business (examples of vendor reviews are provided in Figure 1 and Figure 2 over the page). As is the case with conventional illicit drug markets, trust is central to the success of cryptomarket illicit drug businesses. Tzanetakis et al. (2016) stress that in conventional drug markets, dealers often sell only to known contacts. However, in cryptomarkets, vendors and consumers are not able to reliably establish the legal identity of those with whom they are trading, due to aliases, anonymising software, and the use of cryptocurrencies. While anonymity is a central feature of cryptomarkets, it can also make it difficult for vendors and consumers to develop trust between one another, as the opportunity to establish interpersonal relationships is reduced. Consequently, cryptomarket vendors must proactively establish a reputation of trustworthiness 
to increase sale volumes and attract a loyal customer base. Vendors bearing the burden of responsibility for proving their trustworthiness is a stark contrast to the functioning of conventional illicit drug markets, where closed market dealers do not usually sell to new customers unless they are introduced through a third-party who is already considered trustworthy. Similarly, systemic violence plays a role in maintaining conventional illicit drug markets, but violence and intimidation are mostly unrealised in cryptomarkets. Therefore, vendor reputation systems and escrow services provide a necessary foundation for cryptomarket trust and reliability (Tzanetakis et al., 2016).

Figure 1. Product Reviews for a New Zealand-based Vendor on Dream Market

\section{Feedback}

\section{Rating Comment}

(5) 29 Gram - 101.5 USD - SPECIAL AAA+WEED platinum kUsh INDOOR

5 stars!

40 Gram - 140 USD - SPECIAL AAA+WEED platinum kuSh INDOOR

(5) 455 Gram - 1137.5 USD - SPECIAL AAA+WEED plotinum kush INDOOR

(5) Everything good

50 Gram - 175 USD - SPECIAL AAA+WEED platinum kush INDOOR

(5) Gasssss 10/10 per usual

56 Gram - 196 USD - SPECIAL AAA+WEED platinum kush INDOOR

(5) Great stealth, shipping time, quantity

29 Gram - 101.5 USD - SPECIAL AAA+WEED platinum kush INDOOR

(5) Fast shipping, great bud for price!

29 Gram - 101.5 USD - SPECIAL AAA+WEED plotinum kUsh INDOOR

(5) Never a problem w WA. 5DD and .6 heavy. Very dependable

113 Gram - 339 USD - SPECIAL AAA+WEED platinum kush INDOOR

(5) Great shipping time, great smoke

29 Gram - 101.5 USD - SPECIAL AAA+WEED platinum kUsh INDOOR 


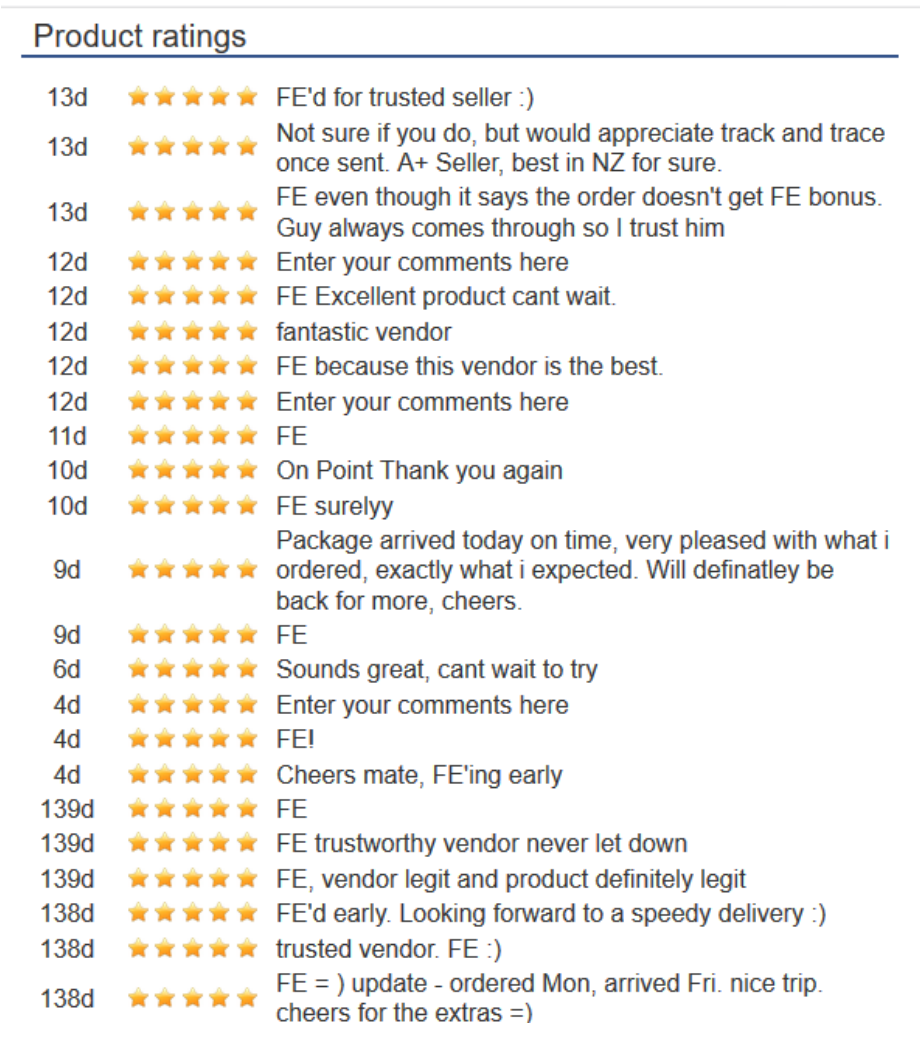

Despite differences in the establishment and maintenance of trust between cryptomarkets and conventional illicit drug markets, Paquet-Clouston, Décary-Hétu and Morselli (2018) stress that cryptomarkets are largely compatible with Reuter's (1983) pioneering analysis of organised crime markets, as their conflicting features mean that only a small minority of vendors thrive. Cryptomarkets are clearly not a utopia for all involved, and in the case of cryptomarket vendors, conflicting features include open access with high barriers to entry and successful sales, the tension of maintaining anonymity alongside the need for most vendors to engage in the street market to source illicit drugs, and the potential to reach a large volume of customers while being unable to control aspects of postal delivery (Paquet-Clouston et al., 2018). Paquet-Clouston et al.'s (2018) study of AlphaBay concluded that it was highly competitive and top-heavy. A minority were able to prosper and sustain successful businesses, but most vendors were relegated to the periphery as 'market spectators' with almost no sales. The disparity between successful and unsuccessful vendors was perpetuated by the promotional tactics of those who were successful, including advertising through posting a high volume of listings (Paquet-Clouston et al., 2018). Therefore, unsuccessful vendors are effectively pushed out of cryptomarkets. 
The unstable status of smaller, less successful vendors is supported by Nurmi, Kaskela, Perälä and Oksanen's (2017) analysis of Finnish cryptomarket Silkittie (now known as Valhalla) which found that vendors were active for an average of only 62.8 days. Similarly, Christin's (2013) early analysis of Silk Road over an eight-month period established that most vendors disappeared within three months of their arrival, though the dominant group of 112 vendors were present throughout the period of analysis. These studies confirm the existence of vendor hierarchies in cryptomarkets, with vendors competing for rank in a manner similar to that which has been observed in offline illicit drug markets (e.g., Adler \& Adler, 1983; Desroches, 2007; Hutton, 2005).

Cox (2016b) assessed the importance of vendor reputation, and the role of ratings, feedback, and reviews, concluding that reputation systems allow consumers to judge the quality of goods that vendors sell, as well as their reliability and responsiveness to customer enquiries and complaints. Vendors who develop poor reputations are "shunned by the cryptomarket community" and are unable to retain sufficient sales to survive in the competitive cryptomarket environment (Cox, 2016b, p. 49). Furthermore, feedback and rating systems may assist in harm reduction, as reviewers can report if they believe that the drugs that they purchased have been adulterated or mislabelled (Cox, 2016b). Consumers are, therefore, able to make informed purchasing decisions and avoid drug batches that have received bad reviews, potentially mitigating the harmful effects of poor-quality illicit drugs and increasing consumer confidence in vendors that receive consistently positive reviews.

Reputation systems are not infallible, however, as Cox (2016b) notes that they can be manipulated by vendors who wish to artificially inflate their ratings. Abuse of reputation systems can include vendors 'purchasing' illicit drugs from themselves using fake consumer accounts that they have created in order to leave positive feedback on their own vendor profiles, as well as suddenly changing their otherwise consistently good business practices to scam consumers out of Bitcoin by requiring them to finalise early, but then failing to send the purchased goods. Nurmi et al. (2017) report support for the importance of vendor reputation systems to vendor success, citing a positive relationship between vendor reputation and daily illicit drug sales, with the most successful vendors having both a high reputation and capacity for a large volume of sales. These findings further demonstrate the importance of developing trust between cryptomarket vendors and consumers. Nurmi et al. (2017) suggest that trustworthiness may be particularly important in recent times as the cryptomarket ecosystem is volatile due to enforcement operations and internal fraud. Risk-averse consumers may be 
particularly affected by this instability, as they are likely to avoid vendors with poor reputations (Nurmi et al., 2017). In practice, increasing trust and providing a good quality service to consumers can take several forms. Tzanetakis et al. (2016) describe methods such as providing a slightly higher volume of illicit drugs than specified in the listing, providing high-quality products, stealthy packaging, timely responses to customer enquiries, fast shipping, and an active presence on subreddits and darknet fora. Figures 3 and 4 below demonstrate examples of shipping information provided by vendors. ${ }^{9}$

Figure 3. Shipping Information Provided by a Vendor on a Dream Market Listing

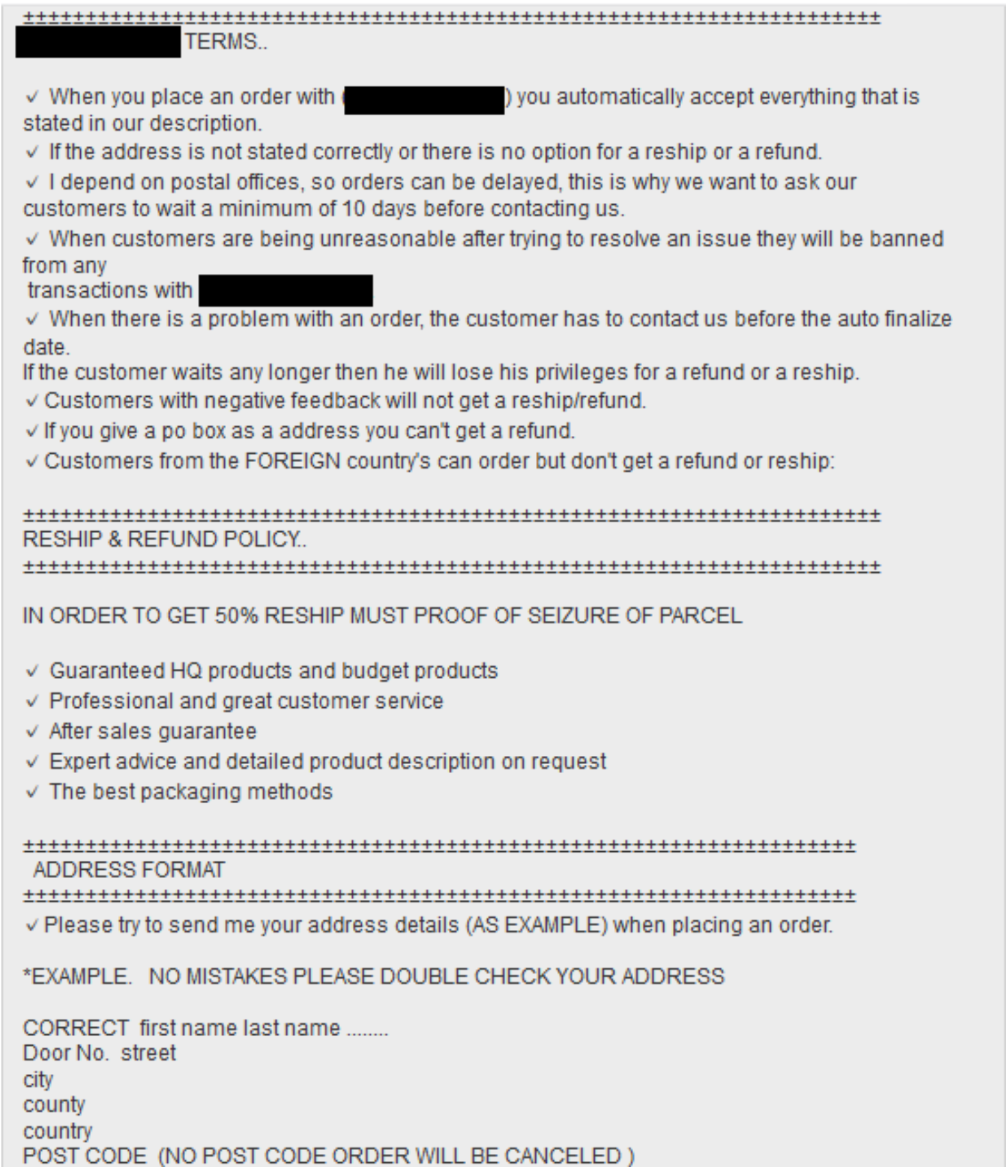

${ }^{9}$ All identifying details in the figures (e.g., usernames) have been redacted for confidentiality reasons. 
Figure 4. Shipping Information Provided by a Vendor on a Wall St Market Listing

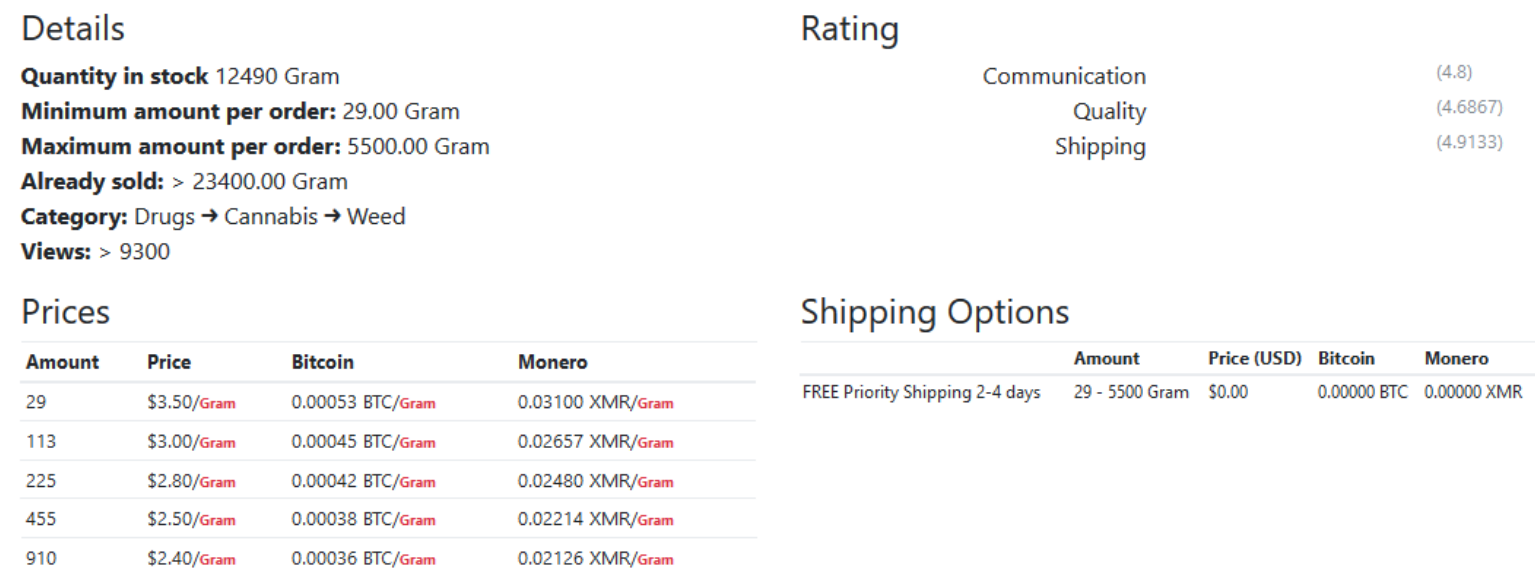

Further conveying the importance of vendor reputation, van Hout and Bingham's (2014) interviews with Silk Road vendors found that they characterised themselves as "intelligent and responsible" drug users who made informed and well-considered decisions to begin selling illicit drugs on cryptomarkets (p. 185). Vendors' decision-making narratives focused on the ease of establishing vendor accounts on Silk Road, as well as the attraction of operating within what they perceived to be a relatively low-risk and high-profit environment. Further, vendors reported that they valued the culture of harm reduction on Silk Road. They supported efforts to ensure that vendors took responsibility for the products that they were selling, through methods such as providing high-quality illicit drugs and drug advice to consumers, and showing professionalism and distance from street dealing, which they perceived to be more objectionable than cryptomarket dealing (van Hout \& Bingham, 2014). van Hout and Bingham's (2014) analysis of vendors' attitudes and behaviour demonstrates the extent to which vendors are invested in maintaining their reputation in the cryptomarket ecosystem.

\section{Consumer Practices on Cryptomarkets}

Consumer practices on cryptomarkets are also complex and nuanced. Existing research suggests that cryptomarket consumers are mostly males in their early to mid-twenties (Barratt \& Aldridge, 2016). Ormsby's (2016) Australian interview participants were mostly aged between their twenties and forties, but some reported 'rediscovering' illicit drugs through Silk Road when they were in their fifties and sixties after having consumed cannabis and psychedelics in their youth, but no longer having access to conventional illicit drug markets. Ormsby's (2016) participants were mostly recreational drug users, employed, technologysavvy, had disposable income, and had used illicit drugs prior to their introduction to Silk Road. Most interviewees first heard about Silk Road through their social networks, but some 
discovered it through media coverage or internet fora. Most were recreational users of MDMA and cannabis, but a few had purchased 'harder' illicit drugs such as heroin and methamphetamine (Ormsby, 2016). The recreational nature of much of the participants' drug consumption was underscored by the popularity of social supply, with some participants even reporting that they ordered drugs from cryptomarkets to their hotel address while on holiday, as they perceived this to be less risky than smuggling illicit drugs across international borders (Ormsby, 2016).

Similar findings are reported by van Hout and Bingham (2013a, 2013b) in their research on the motivations and experiences of cryptomarket drug consumers. van Hout and Bingham (2013b) undertook monitoring of darknet forum posts, as well as online interviews with 20 Silk Road consumers. The illicit drug use trajectories of their participants ranged from 18 months to 25 years, with few reporting experiences with online illicit drug purchasing prior to Silk Road. Drugs of choice included MDMA, nitrous oxide, ketamine, cannabis, cocaine, 2C-B, and mephedrone (van Hout \& Bingham, 2013b). ${ }^{10} 11$ Motivations for cryptomarket drug purchases centred on curiosity, concern about personal safety in conventional illicit drug markets and the quality of street drugs, the wide variety of products offered on cryptomarkets, anonymity, and ease of delivery. This was also reflected in forum posts on Silk Road, which addressed harm reduction information, trip reports, and reviews (Figure 5 over the page demonstrates how forum posts are organised on the Dream Market forum).

Vendor selection decisions were grounded in trust, the speed of transaction, stealth, and drug quality (van Hout \& Bingham, 2013b). Décary-Hétu and Quessy-Doré (2017) provide support for van Hout and Bingham's (2013b) findings, noting that, on average, repeat cryptomarket customers (of all listings, not just illicit drugs) make $60 \%$ of their purchases from the same vendor. Further, they found a positive correlation between customer loyalty and the quantity of information provided by vendors on their listings and profiles. Examples of vendor listings are provided in Figure 6, Figure 7, and Figure 8 (Décary-Hétu \& Quessy-Doré, 2017).

\footnotetext{
10 4-Bromo-2,5-dimethoxyphenethylamine (known as 2C-B) is a psychedelic drug with a relatively short duration of effect (“2C-B”, n.d.). In New Zealand, it is a Class B drug (Misuse of Drugs Act, 1975).

11 4-Methylmethcathinone (mephedrone) is a cathinone class NPS which a combination of empathogenic and stimulant effects ("Mephedrone", n.d.). In New Zealand, it is a Class B drug (Misuse of Drugs Act, 1975).
} 
Figure 5. Forum Posts on the Dream Market Forum

\begin{tabular}{|c|c|c|c|c|}
\hline 四 & $\begin{array}{l}\text { Sticky: VENODRS PLEASE READ THIS IMPORTANT INFORMATION ABOUT } \\
\text { STEALTH SHIPPING! by }[1 \underline{2} \underline{3} \ldots \underline{9}]\end{array}$ & 216 & 119,422 & Yesterday 18:04:51 by \\
\hline [1] & Bulk is looking for a Meth connection. by & 0 & 1 & Today 02:50:05 by \\
\hline [1] & Looking for vendors by & 0 & 2 & Today 02:48:13 by \\
\hline [1] & FORUM FRANCAIS by $[1 \underline{2} \underline{3} \ldots \underline{629}]$ & 15,702 & $2,525,093$ & Today 02:45:35 by \\
\hline Wit & $\begin{array}{l}\text { European Heroin review, multiple vendor test, reloaded by } \\
{[\underline{1} \underline{2} \underline{3} \cdots \underline{71}]}\end{array}$ & 1,764 & 467,566 & Today $01: 25: 36$ by \\
\hline III & $\begin{array}{l}\text { AUSSIE INTERNATIONAL THREAD AGAIN....AND AGAIN...AND AGAIN........ } \\
\text { by }[\underline{1} \underline{2} \underline{3} \ldots \underline{13}]\end{array}$ & 304 & 141,293 & Today $01: 20: 45$ by \\
\hline [11 & $\begin{array}{l}\star \text { COLOMBIAN COKE } \star \text { CANNABIS OIL } \star \text { INDICA } \star \text { SATIVA } \star \text { HYBRID } \star C O L O M B I A N \\
\text { COKE } \star \text { by }\end{array}$ & 1 & 12 & Today $01: 13: 41$ by \\
\hline 10 & $\star$ CANNABIS OIL $\star$ INDICA $\star$ SATIVA $\star H Y B R I D \star C O L O M B I A N ~ C O K E ~ \star$ by & 1 & 11 & Today 01:12:14 by \\
\hline [1] & CRAZY COLOMBIAN A+ COKE FROM WITH THE BEST PRICES by & 1 & 14 & Today 01:02:42 by \\
\hline [1] & A+ FISHFLAKE COLOMBIAN COKE FROM NEW LOW PRICES by & 1 & 11 & Today 00:59:58 by \\
\hline III & Any Dominican Vendors On Here?? by & 0 & 4 & Today $00: 42: 51$ by \\
\hline [1] & $\begin{array}{l}\text { MDMA Vendors Who are not scammina and do not ship from NL. 2nd post. } \\
\text { by } \square \underline{2} \underline{3} \ldots \underline{13}]\end{array}$ & 304 & 60,130 & Today $00: 42: 40$ by \\
\hline [1] & How long is too long for a international order to be in usa customs & 8 & 220 & Today 00:34:33 by \\
\hline 国 & Aussie ice (methamphetamine) - who's got the good stuff? by & 6 & 114 & Yesterday $23: 54: 21$ by \\
\hline Lat & by $\square[1 \underline{2} \underline{3} \ldots \underline{16}]$ & 390 & 91,404 & Yesterday $23: 27: 24$ by \\
\hline 1 & Energv Control Lab Tests - Dutchcokereviewers & 8 & 128 & Yesterday $22: 39: 25$ by \\
\hline [11 & $\begin{array}{l}\text { Cocaine Reviews- No Spam - No Bull Shit - Just reviews - ADVICE } \\
\text { by }[\underline{1} \underline{2} \underline{3} \ldots \underline{73}]\end{array}$ & 1,820 & 322,973 & Yesterday $21: 58: 07$ by \\
\hline 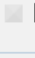 & $\begin{array}{l}\text { by COCAINE/SPEED/MDMA REVIEW \& FEEDBACK THREAD } \\
\text { by }[\underline{2} \underline{3}]]\end{array}$ & 53 & 14,475 & Yesterday $21: 28: 10$ by \\
\hline [il & aus meth vendor where are vou need ya back by & 0 & 8 & Yesterday $21: 20: 53$ by \\
\hline [1] & $\begin{array}{l}* * * * * \text { THE GOOD SPEED GUIDE (Paste, Powder, Crystal, Whatever) ***** } \\
\text { by [ } 1 \underline{2} \underline{3} \ldots \underline{2} \text { ] }\end{array}$ & 2,040 & 700,786 & Yesterday $19: 13: 59$ by \\
\hline
\end{tabular}

Figure 6. A Listing for LSD from a New Zealand-based Vendor on Dream Market ${ }^{12}$

\begin{tabular}{|c|}
\hline Browse by category \\
\hline $\begin{array}{l}\text { Drugs } 73356 \\
\text {, Psychedelics } 5385 \\
\text {, 2C } 604 \\
\text {, 5-MeO } 28 \\
\text {, DMT } 454 \\
\text { ' LSD } 3328 \\
\text {, Mescaline } 49 \\
\text {, Mushrooms } 488 \\
\text {, NB } 93 \\
\text {, Other } 106 \\
\text {, Salvia } 37 \\
\text {, Spores } 38\end{array}$ \\
\hline $\begin{array}{l}\text { Digital Goods } 59714 \\
\text { Drugs } 73356 \\
\text { Drugs Paraphernalia } \\
372 \\
\text { - Services } 6907 \\
\text { Other } 6894\end{array}$ \\
\hline Onion mirrors \\
\hline $\begin{array}{l}\text { 6qlocfg6zq2kyacl.onion } \\
\text { verified }\end{array}$ \\
\hline 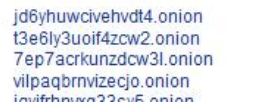 \\
\hline
\end{tabular}

\section{Teachers Gaze 99\%+155ug LSD}

$\begin{aligned} \text { Vendor } & \\ \text { Price } & \text { B0.01276 (\$83.2) }(4.99 \text { ) } \\ \text { Ships to } & \text { New Zealand } \\ \text { Escrow } & \text { No }\end{aligned}$

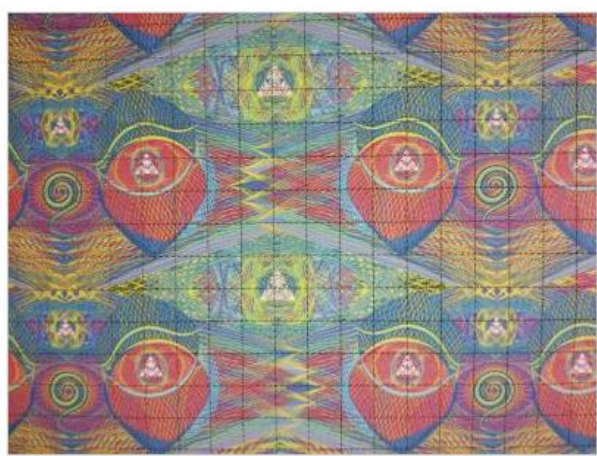

Product description

World Famous 155 ug Teachers Gaze $99 \%+$ LSD

Free shipping available

*Free shipping option does not qualify for refund or reship policy*

\begin{tabular}{|c|c|}
\hline \multicolumn{2}{|l|}{ Links } \\
\hline \multirow{2}{*}{\multicolumn{2}{|c|}{$\begin{array}{l}\text { ' Forum } \\
\text {, Help } \\
\text { - Conferences } \\
\text { - Vendor application } \\
\text {, Earn money } \\
\text { B Exchange }\end{array}$}} \\
\hline & \\
\hline $\begin{array}{l}\text { BTC } \\
\text { mBTC } \\
\text { BCH } \\
\text { XMR } \\
\text { USD } \\
\text { EUR } \\
\text { GBP } \\
\text { CAD } \\
\text { AUD } \\
\text { mBCH } \\
\text { BRL } \\
\text { DKK } \\
\text { NOK } \\
\text { SEK } \\
\text { TRY } \\
\text { CNH } \\
\text { HKD } \\
\text { RUB } \\
\text { INR } \\
\text { JPY }\end{array}$ & $\begin{array}{l}1.0 \\
1000.0 \\
12.8 \\
57.7 \\
6519.0 \\
5667.5 \\
5038.4 \\
8376.6 \\
9107.7 \\
12865.0 \\
26014.0 \\
42257.1 \\
53478.9 \\
58834.7 \\
39208.0 \\
45013.3 \\
51223.2 \\
427246.9 \\
477393.8 \\
744119.6\end{array}$ \\
\hline \multicolumn{2}{|l|}{ News } \\
\hline \multicolumn{2}{|l|}{ Dew forum } \\
\hline \multicolumn{2}{|c|}{$\begin{array}{l}\text { Downtime \& Recovery } \\
\text { 13/09/2017 }\end{array}$} \\
\hline Deposit del & \\
\hline
\end{tabular}

${ }^{12}$ Figure 6 displays an LSD tab listing from a New Zealand-based vendor on Dream Market. The vendor has provided a photo of the tabs, a product description, price, and shipping information. The vendor's overall rating is displayed next to their username. Along the left, the drug categories available on Dream Market are displayed. On the right, there are various links and details of the Bitcoin exchange rate. 


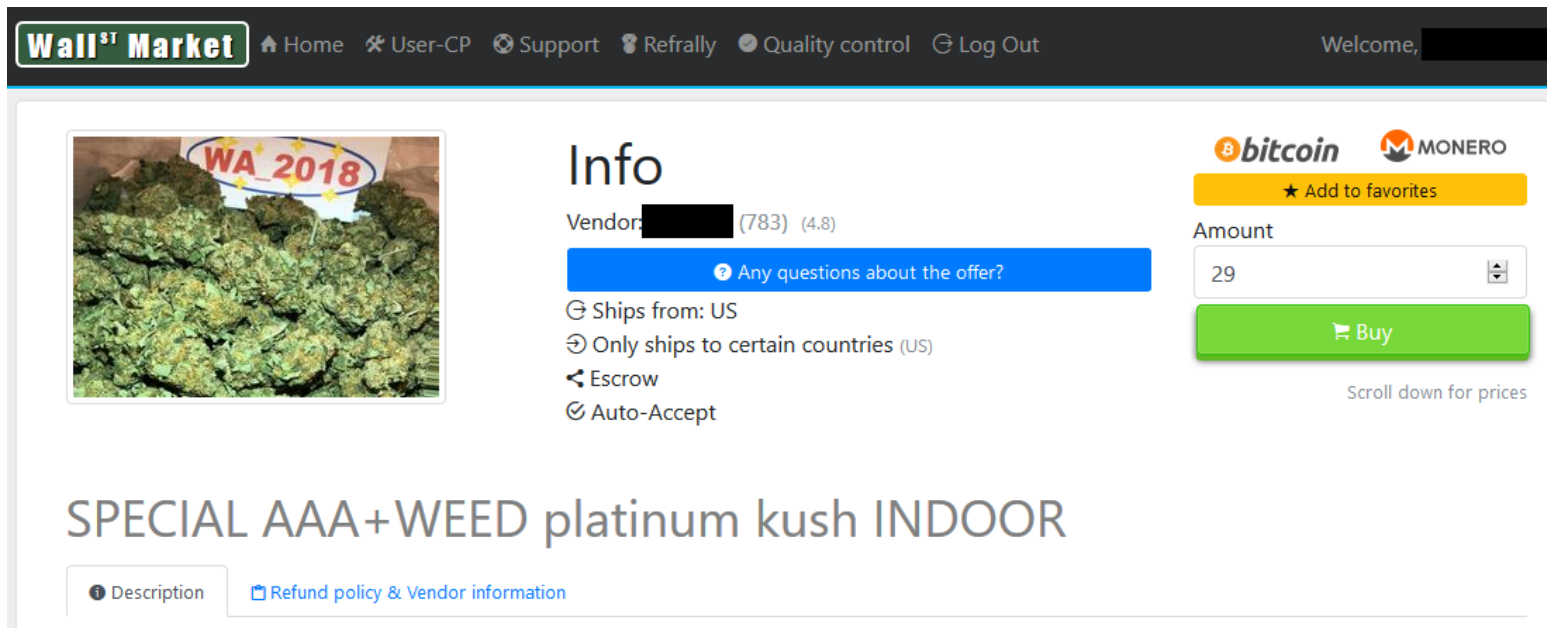

Platinum Kush is an indica-dominant strain that takes on a platinum-silver shade due to its thick coat of crystal resin. With purple hues and bright orange hairs, its buds grow dense with a sweet fruity and hashy aroma. Its THC content can measure up to about $18 \%$ with trace levels of CBD, and its buzz has been described as strongly cerebral and body-numbing.

NOTE:

NO seeds NO shake NO mold and enough weight

Figure 8. Illicit Drug Listings on Wall St Market ${ }^{14}$

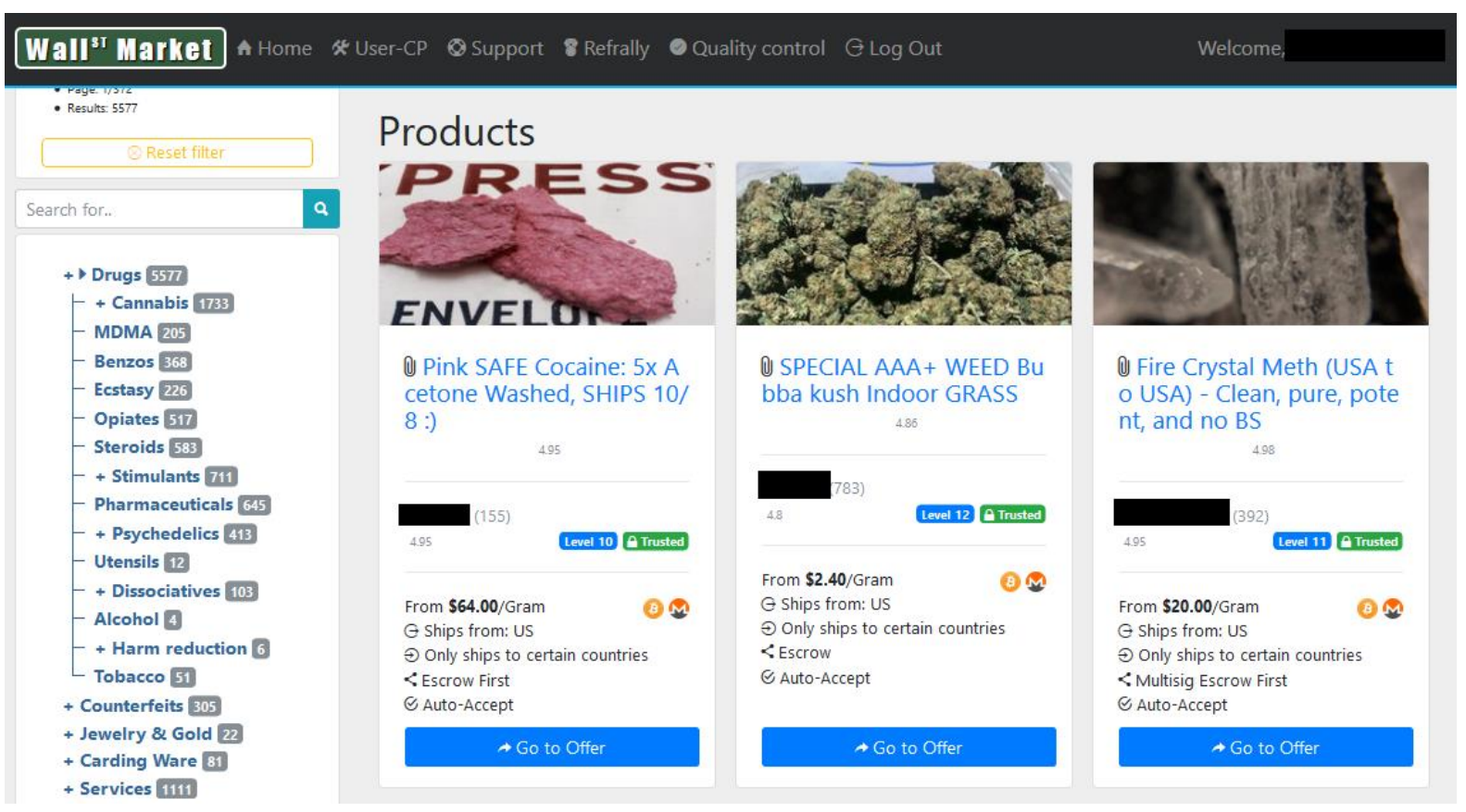

\footnotetext{
${ }^{13}$ Figure 7 shows a cannabis listing from a United States-based vendor on Wall St Market. There is a product photo, a description, and vendor, shipping and refund information.

${ }^{14}$ Figure 8 displays three drug listings on Wall St Market for cocaine, cannabis, and crystal methamphetamine. The product links can be clicked to provide more information about each listing. Vendor rating and shipping information is also provided, along with the payment information and the price per gram. Along the left side, the categories for drugs and other goods and service are displayed.
} 
Illicit drug 'quality' is frequently cited as a motivating factor for cryptomarket drug consumers. However, the term is vague, and researchers often fail to elaborate on what they mean when discussing 'quality'. Considering these issues, Bancroft and Scott Reid (2016) have attempted to disentangle the concept by investigating cryptomarket consumers' understandings of what drug quality constitutes. Using a combination of forum analysis and interviews, they propose that cryptomarket users consider several factors when assessing illicit drug quality, including predictability and reliability of effect, purity, and potency, as they "balanced various factors from expected to actual effect to comedown and how the drug interacts with other drugs" (Bancroft \& Scott Reid, 2016, p. 48). Participants drew on various forms of knowledge in making assessments of drug quality, such as embodied experience, craft, and chemical knowledge. These knowledge forms differed between users depending on the context and intent of their use, as well as their prior experiences of drug use. Consumers shared assessments of drug quality between one another through engaging in forum discussions, and Bancroft and Scott Reid (2016) emphasise that such discussions should be considered an important form of indigenous harm reduction on cryptomarkets.

Barratt and Aldridge (2016), among others, provide support for the notion that there are commonalities between cryptomarket users in terms of demographic information. However, cryptomarket consumers display diversity in their illicit drug use trajectories and experiences prior to cryptomarket engagement. The subtle nuances of cryptomarket consumer practices convey the extent to which consumers make rational and well-considered decisions to purchase from cryptomarkets.

\section{Harm Reduction on Cryptomarkets}

Harm reduction is a public health paradigm which focuses on pragmatic and non-moralising policies that are intended to reduce the harms associated with potentially risky human behaviours and lifestyle choices (Kellehear, Rumbold \& Hamilton, 1998; Pates \& Riley, 2012). In the context of drug use, it aims to reduce the harms associated with drugs, irrespective of their legal status. Lenton and Single (1998) provide a useful definition of the term within the context of drug harm. They contend that

the central defining characteristic of harm reduction is that it focuses on reduction of harm as its primary goal rather than reduction of use per se, secondly that strategies are included to reduce the harm for those who continue to use drugs, and thirdly that strategies are included which aim to demonstrate that, on the balance of probabilities, 
it is likely to result in a net reduction in drug related harm. (Lenton \& Single, 1998, p. 213, emphasis in original)

Harm reduction strategies typically focus on education about safer methods of drug consumption, as well as practices that reduce drug harm, including OST, naloxone, NSPs, and supervised injection facilities for PWID (Csete et al., 2016; Pates \& Riley, 2012). Although it was implemented in various forms throughout the $20^{\text {th }}$ century, harm reduction practices gained momentum and attention for their role in reducing the transmission of HIV/AIDS (and other blood-borne viruses) during the AIDS epidemic of the 1980s (Erickson, Riley, Cheung \& O'Hare, 1997). Ezard (2001) asserts that states have human rights obligations to provide access to harm reduction practices, and to reduce citizens' vulnerability and risk of experiencing harm from drug use. ${ }^{15}$

On cryptomarkets, indigenous harm reduction efforts predominantly focus on education, but seizures and closures of cryptomarkets and the resultant volatility of the cryptomarket environment pose challenges for the dissemination of harm reduction information (Barratt et al., 2016). Furthermore, the extent to which cryptomarkets are a form of harm reduction or can be used as a platform for harm reduction efforts, is debated. Aldridge, Stevens and Barratt (2017) reviewed the available literature on cryptomarkets and conclude that they have increased, and will continue to increase, the volume and range of illicit drugs that are accessible. However, these increases will not necessarily result in an increase in the net harm of illicit drugs, as cryptomarkets may reduce systemic violence and transnational conflict associated with the illicit drug trade. Overall harms will depend on the quality and safety of cryptomarket substances, as well as any harm reduction provisions that are implemented (Aldridge et al., 2017).

A different perspective is provided by Mounteney, Cunningham, Groshkova, Sedefov and Griffiths (2017), as well as Sumnall (2017), who argue that it is unclear if cryptomarkets will reduce drug harm, as, at present, there is not enough data to draw a conclusion. Sumnall (2017) predicts that it is unlikely that cryptomarkets will result in a net reduction in harm, as they comprise a very small minority of the international illicit drug trade. Further, cryptomarket-

\footnotetext{
${ }^{15}$ The harm reduction movement is not immune to critique. Critics of the paradigm argue that it cannot claim to be value-neutral or non-moralising because the process of categorising risks and harms necessitates moral judgements about the nature and severity of 'risky' human behaviours (Race, 2008). Additionally, Miller (2001) argues that harm reduction lacks sound theoretical underpinnings, and its reliance on epidemiological statistics is troubling as it fails to address the role of hegemonic discourse in the development and implementation of drug policy.
} 
related harm reduction benefits are likely to only affect some individuals who use some illicit drugs, especially as most illicit drugs sold on cryptomarkets are 'recreational' and considered to pose low risk of individual harm. Furthermore, the primary illicit drugs associated with cryptomarkets (e.g., MDMA, cannabis) are traditionally sold in conventional closed drug markets which are already associated with low levels of systemic violence (Martin, 2017a). Martin's (2017a) gentrification hypothesis posits that cryptomarkets are accessible to individuals who are technically competent and have disposable income to plan illicit drug purchases, but others who have existing vulnerabilities to systemic violence, such as those who experience unstable housing, social exclusion, and poverty, are effectively 'locked out' of cryptomarkets, and are, therefore, more likely to be subject to the systemic violence associated with conventional markets (Martin, 2017a). This inequality is troubling, and Sumnall (2017) warns that cryptomarkets may, in fact, increase harm-related inequalities between groups of drug users. This indicates that while cryptomarkets may reduce individual harm to some PWUD, they could expand harm-related social inequities.

In his pioneering work on the drugs-crime nexus, Goldstein (1985) conceptualised systemic violence as "the traditionally aggressive patterns of interaction within the system of drug distribution and use" in contexts where drugs are prohibited (p. 497). Individuals who engage in the drug trade cannot resolve disputes through the criminal justice system, so violence, threats, and intimidation are instrumental in maintaining order in illicit drug markets. ${ }^{16}$ However, traditional understandings of systemic violence are centred on face-to-face interactions between actors. Cryptomarkets do not necessitate face-to-face contact, instead facilitating anonymity and physical separation (Martin, 2017a). Therefore, order-maintaining regimes that exist within cryptomarkets must take a different form than those in conventional markets. For this reason, Aldridge and Décary-Hétu (2016a) propose that cryptomarkets may reduce the harms of the illicit drug trade, as the opportunity for physical violence is severely minimised, and vendor professionalism and customer service may have replaced systemic violence as a sufficient alternative disciplinary regime. This view is supported by Bakken et al. (2017) who note that the visibility of individual vendors on cryptomarkets increases competition between them. Increased inter-vendor competition requires that vendors exercise a high level of professionalism to achieve financial gain. This structurally efficient environment

\footnotetext{
${ }^{16}$ Though Goldstein's (1985) tripartite framework is considered a seminal work on the relationship between drugs and crime, it has been critiqued by several academics. In relation to Goldstein's (1985) concept of systemic violence, it should be noted that violence is not necessarily a common feature of illicit drug markets, and periods of high systemic violence are limited in both duration and location (Bowling, 1999; Reuter, 2009).
} 
formalises cryptomarket transactions in a manner that enforces cooperation between vendors and consumers, thus reducing the need for traditional expressions of systemic violence (Bakken et al., 2017).

Systemic violence may manifest in an alternative manner on cryptomarkets, including threats, damage to reputation, theft, fraud, cyberbullying, and doxxing. ${ }^{17}$ However, there have been no recorded instances of physical violence between cryptomarket vendors (Aldridge \& DécaryHétu, 2016a; Martin, 2017a). Barratt, Ferris and Winstock's (2016) comparison of conventional illicit drug markets and cryptomarkets using data from the GDS 2014 found that consumers reported threats to personal safety $(3 \%)$ and experiencing physical violence $(1 \%)$ less often when using cryptomarkets than conventional drug markets. Conflict management on cryptomarkets is complex, with strategies including tolerance, avoidance, ostracism, thirdparty intervention, negotiation, and threats (Morselli, Décary-Hétu, Paquet-Clouston \& Aldridge, 2017). The reduced possibility for physical violence on cryptomarkets may also have gendered implications, as Ormsby (2016) reports that her female interview participants felt that Silk Road was safer than purchasing illicit drugs through conventional markets. Furthermore, the vendors that Ormsby (2016) interviewed were pleased about not having to meet customers face-to-face and having more flexibility in processing orders when it was convenient for them instead of having to be available to consumers at all hours of the day. As cryptomarket research is currently in its infancy, conclusions about the effects of cryptomarkets on systemic violence should be regarded with caution, and the relationship between systemic violence and cryptomarkets certainly warrants further investigation. Findings tentatively indicate that cryptomarkets may transform or reduce systemic violence. For this reason, it is imperative to consider the relationship between systemic violence and cryptomarkets when designing and assessing harm reduction innovations. As Sumnall (2017) and Martin (2017a) stress, not all individuals are able to access cryptomarkets, and they may intensify systemic violence for those who are relegated to purchasing illicit drugs through conventional markets.

Alongside the potential to reduce systemic violence, cryptomarkets foster peer-to-peer indigenous harm reduction methods, with forum topics often focusing on harm reduction techniques (Figure 5 on p. 34 shows examples of posts on the Dream Market forum). Many darknet fora host 'drug safety' discussions, where conversations focus on product reviews, feedback, and trip reports (Caudevilla, 2016). Caudevilla (2016) notes that the internet has

\footnotetext{
${ }^{17}$ Doxxing is the act of maliciously publishing an individual's personal identifying information on the internet (Quodling, 2015).
} 
shifted the availability of health information, hosting many publicly-accessible health resources. This assertion is supported by Bancroft (2017) who argues that the internet has created knowledge communities which undermine the traditional lay/expert divide on drug harm knowledge. Bancroft (2017) determines that cryptomarket drug consumers engage in a delicate practice of 'responsible harm' where they utilise harm reduction practices but seek to control and take responsibility for the drug harm that they encounter. Consumers hold a dual consideration of illicit drug use as both risky and manageable, thus challenging expert discourses and forming alternative harm reduction knowledge and techniques (Bancroft, 2017).

The flip-side of online health resources is that incorrect or 'folk tale' drug-related health information disseminated on the internet can have negative consequences. However, Caudevilla (2016), a medical physician, has hosted 'Ask a Drug Expert about Drugs and Health' threads on darknet discussion fora since 2013. Anecdotally, he has found that the threads have been positively received, with appreciative and supportive feedback. The health questions that Caudevilla (2016) has received are varied and include topics of illicit drug effects, patterns of use, safe dosage, adverse effects, contraindications and interactions with other drugs, and illicit drug use during pregnancy. Caudevilla (2016) provides advice on an ad hoc basis, but he notes that internet-based health interventions have been successful for other health issues, including smoking cessation and anxiety, and there is no reason to believe that such efforts could not be applied to cryptomarket drugs. There are numerous possibilities for further development of public health and harm reduction initiatives on cryptomarkets, including information and service promotion, the presence of harm reduction organisations on fora, promotion of harm reduction information on vendor listings, promotion of drug testing services, and posting drug alerts on forum threads (Bancroft \& Scott Reid, 2016; Caudevilla, 2016; Cox, 2014). Beyond the obvious practical implications of reducing drug-related harm, harm reduction efforts on cryptomarkets may assist in the development of alternative antiprohibition drug harm knowledge paradigms, as well as the reframing of illicit drug use from a criminal justice issue to a health issue. Harm-reducing interventions could also be targeted to region-specific differences in cryptomarket activity as further insights come to light.

\section{International Cryptomarket Practices}

Several academic studies note country and region-specific differences in cryptomarket trading (e.g., Broséus et al., 2016; EMCDDA, 2017; Kruithof et al., 2016). Large variation exists in vendors' international shipping practices between regions. Echoing Aldridge and Askew (2017), and Décary-Hétu et al. (2016), Broséus, Rhumobarbe, Morelato, Staehli and Rossy’s 
(2017) geographical analysis of trading on Evolution found that trade in the United States and Australia was mostly domestic, but vendors in the Netherlands, Germany, and China were more likely to offer international shipping. They argue that American and Australian vendors may avoid international shipping due to the perceived high risk of parcel interception that results from concentrated border protection efforts, and, in the case of Australia, geographical isolation and lack of shared borders. Conversely, vendors in mainland Europe and China may find it worthwhile to offer international shipping due to its relative ease and low risk of detection. Therefore, the decision to offer international shipping appears to be informed by vendors' judgements about the risk and reward of doing so.

Broséus et al.'s (2017) spatial analysis also revealed country-specific variation in cryptomarket listings by drug type. For example, Indian and Chinese vendors seem to specialise in prescription drugs and NPS, respectively, and they argue that these geographical trends appear to be reflective of regional specificities in conventional licit and illicit drug markets. Their findings are corroborated by Dolliver, Ericson and Love (2018) and Kruithof et al. (2016). Dolliver et al.'s (2018) geovisualisation analysis of Agora found that heroin and cocaine sales were primarily from vendors in Australia, the Netherlands, and the United States, which they assert coincides with countries known for the consumption of these illicit drugs. Chinese vendors were the primary source of NPS, and prescription drugs were mostly from India, the United Kingdom, and the United States, all of which have well-established pharmaceutical industries. Most vendors were located across Australia, Canada, the Netherlands, the United Kingdom, and the United States (Dolliver et al., 2018). van Buskirk, Naicker, Roxburgh, Bruno and Burns (2016) provide further support for the prominence of these countries, as in their analysis of Agora, the top five countries by the number of listings were the United States, the United Kingdom, Australia, China, and the Netherlands.

The dominance of English-speaking countries on the darknet is further confirmed by Ciancaglini et al. (2015) who found that English was the main language on 62.4\% of darknet sites in their dataset. While the official language of the Netherlands is Dutch, $90 \%$ of the population speaks English and the Netherlands occupies a vital position in the European illicit drug trade as a producer of cannabis and MDMA, and a distribution hub for cannabis and cocaine (European Commission, 2012; Kruithof et al., 2016). Other European Union member countries are also prominent in the cryptomarket ecosystem. Between 2015 and 2017 when AlphaBay was the largest cryptomarket, vendors located in the European Union accounted for 
$28 \%$ of all drug sales, with Germany, the Netherlands, and the United Kingdom dominating among European Union countries (EMCDDA, 2017).

Outside of Europe and North America, Australia occupies a unique position in the cryptomarket ecosystem. Australia is over-represented in the number of vendors per capita, and Australians seem to generate the most revenue per vendor (Cunliffe, Martin, Décary-Hétu \& Aldridge, 2017; Kruithof et al., 2016; van Buskirk, Naicker, Roxburgh, Bruno \& Burns, 2016). Evidenced by regional variation in vendors willing to ship internationally, perceptions of border security influence the price of orders through factors like time taken for delivery, cost of international shipping, and parcel interception rates (Bakken et al., 2017; Broséus et al., 2017). Bakken et al. (2017) report that Australia and New Zealand are often not considered by international vendors to be worth shipping to due to the high rate of parcel interception at the borders of both countries.

The unique position of Australian cryptomarket vendors is possibly further explained by the expensive domestic conventional drug market. Ormsby (2016) affirms this, finding that Australians and New Zealanders in her research were able to purchase MDMA and LSD from overseas Silk Road vendors for a quarter of the price of the domestic market. The expensive domestic market leads to Australian cryptomarket vendors commanding a higher price per unit of drugs. As well as this, the over-representation of Australian vendors may be due to the high profits that are possible when selling domestically to Australian consumers. International vendors are dissuaded from shipping to Australia, but domestic Australian vendors are able to function without the added hurdle of interception by Australian border authorities and, therefore, can command a premium price, due to the scarcity of illicit drugs in the domestic market, and the reassurance that domestic shipping provides consumers (Kruithof et al., 2016; Phelps \& Watt, 2014; van Buskirk et al., 2016).

A logical corollary is that Australian vendors are unlikely to offer international shipping. They are not incentivised to do so, as international shipping is expensive and high-risk, and they are able to earn large profits by selling solely to the domestic market (Broséus et al., 2017; Tzanetakis, 2018). This is reflected in findings from Cunliffe et al. (2017), and Broséus et al.'s (2017) study of Silk Road 2.0 and Evolution between 2013 and 2015, which found that most Australian cryptomarket trade was domestic. Broséus et al. (2017) suggest that the domestic nature of Australian cryptomarket trading is supported by a high number of domestic clandestine illicit drug production laboratories, so drugs that can be manufactured within 
Australia (e.g., methamphetamine) are not commonly imported. Cunliffe et al. (2017) undertook an extensive analysis of 60,000 drug listings across eight cryptomarkets in 2016 and report that Australian vendors' illicit drug prices are comparable to the expensive conventional market, except for methamphetamine which is much cheaper on cryptomarkets. This finding supports Broséus et al.'s (2017) assertion about the domestic production of methamphetamine, and Cunliffe et al. (2017) suggest that the price of methamphetamine may be lower on cryptomarkets as online trading is less costly for vendors. They note that the methamphetamine market in Australia has a reputation for being particularly dangerous for dealers, due to its association with outlaw motorcycle gangs, and intense enforcement focus on disrupting supply chains. Australian border authorities' perceived effectiveness in intercepting illicit drug parcels has unintentionally increased Australian cryptomarket vendors' market share of the domestic illicit drug trade and inadvertently protected domestic organised crime groups so that they have a monopoly against overseas competition. Australian consumers are willing to purchase from expensive domestic cryptomarket vendors due to faster delivery times and the perception that domestic orders are significantly less likely to be intercepted (Cunliffe et al., 2017).

Barratt, Ferris and Winstock's (2014) analysis of the GDS 2012 reported that 7\% of Australian respondents had consumed illicit drugs that had been purchased through Silk Road. Further, Australian and American residents were more likely to use Silk Road than those in the United Kingdom, a finding that Barratt et al. (2014) link to inadequate illicit drug access in Australian and American conventional markets. Barratt et al. (2014) recorded country-specific variation in the types of illicit drugs that consumers purchased, reflective of specificities in local illicit drug trends. For example, Australian cryptomarket consumers purchased high quantities of cocaine and amphetamines, which Barratt et al. (2014) attribute to their low availability and high cost in the domestic conventional market. Broséus et al.'s (2017) findings support the prominence of amphetamine-type drugs and cannabis in the Australian market. Over half of the methamphetamine that was purchased through Silk Road 2.0 over the period of their analysis was sent to Australia, and Cunliffe et al.'s (2017) study found that over $25 \%$ of total methamphetamine cryptomarket sales were for methamphetamine that appeared to originate from Australia and sell within Australian jurisdiction.

The position of Australia in the cryptomarket community is fascinating, and somewhat of a departure from cryptomarkets' focus on 'soft' recreational drugs (Barratt \& Aldridge, 2016). There are several similarities between Australia and New Zealand which indicate that New Zealand may occupy a similar position to Australia in the cryptomarket ecosystem. Both are in 
Oceania, do not have any shared borders with other countries, have expensive and limited domestic conventional illicit drug markets, and have a reputation for stringent border control. These similarities underscore the importance of academic enquiry into the relationship that New Zealanders have with cryptomarkets. With this in mind, New Zealanders' positioning on cryptomarkets is analysed in Chapters 4,5 , and 6. 


\section{Chapter 3: Methodology and Methods}

\section{Methodological Framework}

The research project sought to synthesise and analyse rich data about the experiences of New Zealanders who have purchased illicit drugs on darknet cryptomarkets. Due to the exploratory nature of the project, qualitative semi-structured interviews were used to form a dataset. The interviews were transcribed and subjected to thematic analysis informed by constructivist grounded theory. This chapter provides an outline of the philosophical and epistemological underpinnings of the research, as well as discussion of the relevant ethical considerations, including those specific to digital research. Following this, an overview of the research process is presented, including the practical limitations of the dataset and personal reflections on the research process.

\section{Philosophical and Epistemological Underpinnings}

In all research, epistemological concerns must be interrogated to provide a foundation for the methodology that is selected. Epistemology broadly considers the way knowledge and understanding are formed, and it provides the foundation for the kinds of knowledge that are possible (Crotty, 1998; Maynard, 1994). There are multiple epistemological variants, with positivism and constructivism at opposite ends of the spectrum. Positivist epistemology claims that truth and meaning reside within entities themselves, whereas constructivist epistemology asserts that knowledge is not created through observable phenomena, but rather through individual subjectivity (Creswell, 2014; Crotty, 1998; Phillips, 1995; Schwandt, 1998). As epistemology is concerned with how knowledge is formed, it frames the basis of research design and is, therefore, embedded in the theoretical underpinnings, methodology, and methods of research. The project was informed by constructivist epistemology, which acknowledges that the social and political structures that form the current illicit drug landscape are not natural and should not be accepted as such. Rather, these structures are socially constructed.

Considering the epistemological basis of the research and the research aims, qualitative methods were selected. Noaks and Wincup (2004) note that qualitative methods are often preferred in criminological research as they enable researchers to access personal narratives and accounts of offending and related actions that do not come to the attention of authorities (Noaks \& Wincup, 2004). The data obtained from qualitative research is richer than that which can be obtained from quantitative research, allowing an extensive and nuanced understanding of the nature of criminological phenomena, and leading “to an 'appreciation' of the social world 
from the point of view of the offender, victim or criminal justice professional" (Noaks \& Wincup, 2004, p. 13). Further, semi-structured interviews often yield data that is "contextual, linguistic, narrative, and pragmatic" (Kvale \& Brinkmann, 2009, p. 18, cited in Hesse-Biber \& Leavy, 2011, p. 95).

The research was also informed by critical criminology. Critical criminology refers to a group of diverse criminological theories and perspectives that challenge mainstream approaches to understanding crime and social control (Friedrichs, 2009; McLaughlin, 2010; Ugwudike, 2015). Critical criminologists primarily utilise qualitative and inductive research methods, rejecting the positivist notion of the neutral observer that is common in mainstream and administrative criminology (Friedrichs, 2009). Critical criminology prioritises a commitment to social justice and human rights (Cohen, 1993; Schwendinger \& Schwendinger, 1970). It is understood that hegemonic power relations and social and political structures breed injustice, and critical criminology attempts to elucidate these power structures which thrive in their invisibility. Along with commitment to social justice and exposing state crimes and human rights injustices, critical criminology uses a broad definition of 'crime', considering not only criminal offences, but also multi-faceted harms. This school of thought focuses on the way institutions and structures reproduce and perpetuate these harms, and their immense cost and misery to humans. Thus, critical criminology is well-placed to critically interrogate illicit drugrelated harms and how cryptomarkets may serve to exacerbate or alleviate them.

\section{Methodological Approach}

The research utilised an inductive pathway of knowledge, whereby qualitative methods are used to pinpoint theories within the dataset that is generated, instead of a deductive pathway which tests a hypothesis against the dataset (Hesse-Biber \& Leavy, 2011). As an inductive approach was used, constructivist grounded theory was the most appropriate choice for the research methodology. Grounded theory refers to a method of research which involves obtaining and analysing qualitative data to form theories from the data itself (Charmaz, 2014). Theories are developed through a process of induction that requires the researcher to interact extensively with the dataset, alternating between data and analysis (Charmaz, 2014; HesseBiber \& Leavy, 2011). Grounded theory emerged from American sociological scholarship in the 1960s and is a favoured method for many qualitative researchers as it requires them to simultaneously engage in data collection and analysis processes (Charmaz, 2014; Glaser \& Strauss, 1967). This 'dynamic dance' between data collection and analysis promotes flexibility and the development of innovative ideas and theories (Hesse-Biber \& Leavy, 2011, p. 35). 
Constructivist grounded theory is a subtype of grounded theory methodology. It was developed by Charmaz $(2000,2014)$ and has a specific focus on flexibility and researcher reflexivity. Rejecting the assumption of the neutral observer, constructivist grounded theory recognises that research is not dispassionate and detached, therefore requiring researchers to examine how their positionality and privilege influence the research process and the inductive construction of theory (Charmaz, 2000). The reflexive approach offered by constructivist grounded theory links well with critical criminology and other critical perspectives, which generally use qualitative and interpretive methods (Friedrichs, 2009; Hesse-Biber \& Leavy, 2011). Constructivist grounded theory's focus on flexibility and reflexivity allows the data to 'speak for itself', thus aligning with critical criminology's commitment to prioritise the voice of those who are often silenced by hegemonic power structures and norms.

\section{Research Methods}

\section{Research design.}

The research project utilised a qualitative approach to investigate the experiences of New Zealanders who had ordered illicit drugs over the darknet. A qualitative approach with semistructured interviews was considered appropriate for this research, as it allowed interview participants to express, in their own words, their thoughts and perspectives on their engagement with cryptomarkets, as well as the potential significance of cryptomarkets for New Zealanders seeking illicit drugs. Semi-structured interviews facilitate the building of rapport with participants, and they allow the researcher an "understanding of the context of the project to facilitate alertness to significant themes" (Noaks \& Wincup, 2004, p. 79). Interviews were conducted through each participant's preferred method of contact - these included face-to-face meetings, Skype, instant messaging services with end-to-end encryption, and email. ${ }^{18}$ Building rapport with participants is recognised as a vital element of the qualitative research process (Seidman, 2006; Warren, 2011; Weiss, 1995). Therefore, it was necessary to allow participants to select a method of communication that they were comfortable with. As the interview topic involved the disclosure of sensitive information about criminal offending, it was important that participants were as comfortable as possible during the interview. If a participant elected to meet face-to-face for the interview, they were invited to select a semi-public location of their choice (e.g., café or university meeting room), and the researcher offered to buy them a coffee to build rapport and an atmosphere of warmth and friendliness. Ensuring participants engaged

\footnotetext{
18 The encrypted, untraceable instant messaging services that were used included Signal and the secret conversation function on Facebook Messenger.
} 
with the researcher on their own terms was vital for the interview process, as it allowed participants the freedom to discuss issues that they considered important and allowed pertinent issues to be explored in further depth. Comparable rapport-building methods have been used by researchers conducting internet-based research, including the use of humour and emojis in instant messaging, as well as time-checking with participants to convey that their time is valued (Barratt, 2012b; Barratt \& Maddox, 2016).

\section{Participants, data collection, and analysis.}

Data for the thesis were collected from interviews with people over the age of 18 who were based in New Zealand and had ordered illicit drugs from cryptomarkets or had been residing in New Zealand at the time that they had ordered illicit drugs from cryptomarkets $(n=12)$. Participants were offered an NZ\$30 supermarket voucher as a koha, however, some participants did not wish to accept the voucher, with one participant stating that he was motivated to participate "out of interest [and] not for reward." 19 The researcher initially intended to categorise interview participants according to whether they had engaged with drug dealing (either dealing drugs that they obtained from cryptomarkets, or dealing drugs as a vendor on a cryptomarket) or were solely consumers of cryptomarket drugs. However, when the interviews were undertaken, it was clear that the distinction between dealers and consumers was highly blurred, with some participants engaging in both personal use and social or 'minimally commercial' supply (Coomber \& Moyle, 2014). For this reason, the categorisation of participants was abandoned, and the interviews were instead treated as a single dataset.

Participants were recruited through a combination of advertising and snowballing. For the initial round of advertising, the researcher shared the research poster (Appendix A) on Vic Deals. Vic Deals is a Wellington-based Facebook group where members can trade goods and services and discuss Wellington-specific issues. There were over 110,000 members on Vic Deals when the research poster was first advertised on 11 May 2018. Most members of Vic Deals are university students and young people, and most participants were recruited through the Vic Deals post. One participant was recruited through snowballing, as they shared a mutual friend with the researcher and saw the advertisement as it had been posted by the mutual friend on their Facebook page. A second round of recruiting was undertaken in August and September 2018, and the poster was advertised in two Wellington-based medicinal cannabis Facebook

\footnotetext{
19 'Koha' is the Māori term for a gift that is offered in the context of reciprocity in social relationships (Te Aka, n.d.-a).
} 
groups with permission from the group administrators. A poster was selected as the advertising medium for the research, as it allowed potential participants the option to engage with the advertisement as much or as little as they wanted, and to consider the invitation to participate in their own time before deciding whether to contact the researcher. This was to ensure that participants were volunteering to participate, and to minimise the possibility of coercion, which is particularly important in sensitive research topics of this nature, as researchers need to be aware of the potential vulnerabilities of the population being researched and avoid exploitation (Liamputtong, 2007).

When the study was advertised on Facebook, the researcher received multiple messages from prospective participants who wanted further information about the research. On the Vic Deals post, the researcher offered to provide her public PGP key to anyone who wished to send encrypted messages to her. ${ }^{20}$ No one contacted the researcher using a PGP key, but one participant commented that the researcher's "discretion [was] very reassuring." Some individuals contacted the researcher with personal stories of being offered illicit drugs that had been obtained from cryptomarkets or experiences of obtaining illicit drugs from the clearnet, even if they did not meet the eligibility criteria to be interviewed. One participant contacted the researcher as he was interested in taking part in an interview, but only on the condition that he could meet and smoke cannabis with the researcher first. Presumably, this offer was intended to establish the trustworthiness of the researcher who would not be viewed as a potential 'nark' if she was willing to partake in illicit drug consumption. However, the researcher had to decline the prospective participant's offer and politely explained that she could not ethically consume illicit drugs with an interview participant. After contacting the researcher about their interest in the project, many prospective participants decided against being interviewed or did not respond to follow-up messages. Interviews were undertaken with individuals who replied to the researcher and retained an interest in the research. Participants were made aware that they could withdraw from the project or amend their contribution at any time prior to 1 September 2018.

Researchers need to be aware of the potential exploitation of participants and take steps to ensure that ethical standards are maintained (Noaks \& Wincup, 2004). Informed consent is vital in avoiding participant exploitation. Before the interviews commenced, participants were provided with an information sheet and consent form (Appendices B \& C). Face-to-face

\footnotetext{
${ }^{20}$ A PGP key is a message encryption method used to improve security (Zimmerman, 1995).
} 
interview participants were required to sign the consent form. Other participants were not required to sign the form but were asked to confirm, verbally or in writing, that they consented to the interview. Participants were asked if they had any questions about the research or the interview process, with the researcher making specific mention of the confidentiality of the interview, and what would happen to the interview data if the researcher was called on by the New Zealand Police or other authorities.

Interviews that were conducted via instant messaging or email were spread out over weeks or months, as the researcher had sustained dialogue with these participants, and there was often a large amount of time between messages and replies. The researcher found face-to-face and Skype interviews easier than the instant messaging and email interviews as they occurred within the confines of an hour or two, as opposed to being stretched across time. There was a delicate balance between the ethical need to maintain the physical safety of all parties and the privacy and confidentiality of the participants, especially considering that the interview covered sensitive topics and the disclosure of criminal offending. University meeting rooms allowed participants to speak freely about their experiences with minimal fear of being overheard, and café interviews were scheduled at mutually convenient times, mostly outside of peak hours to minimise the likelihood of other patrons overhearing the conversation. The interviews that were audio-recorded (those that occurred face-to-face or through Skype) ranged in length from 40 minutes to one hour and 50 minutes, with a mean of 59 minutes. Questions were posed using a semi-structured interview schedule (Appendix D). Maintaining a 'traditional' semi-structured format for the email interview was challenging. In this case, the researcher attempted to maintain as much of a semi-structured interview as possible by sending follow-up questions in response to the participant's answers to the original questions.

The researcher referred to the interview schedule throughout the interview to ensure that important topics were covered, but the conversation sometimes deviated to subjects that were not strictly included in the schedule (e.g., participants' prior interactions with the police, perspectives on drug prohibition outside of the cryptomarket context). In these cases, the researcher allowed the conversation to proceed naturally. This flexibility, one of the advantages of qualitative methods, allowed participants to prioritise the expression of perspectives and issues that were significant in their lived experience and often led to rich and detailed insight which would not have been uncovered if the interview had been rigidly structured. 


\section{Participant demographics.}

Participants' demographic information is displayed in Table 1 (over the page). There were a total of 12 research participants. Most of the participants were male $(n=11)$ with one female participant. Of the 12 interviews, two were conducted via instant messaging, one was conducted via a combination of instant messaging and face-to-face, four interviews were conducted face-to-face, four via Skype, and one via email. Participants were invited to indicate their age in whatever form they preferred. Most participants were in their late teens to early twenties, with the two oldest participants describing themselves as being ' 36 or 37' and 'middle-aged'. Three participants identified themselves as Caucasian, two as British, two as white, two as New Zealand European, one as Pākehā/New Zealand European, and one as halfFilipino and half-Kiwi. ${ }^{21} 22$ The single female participant identified as United Kingdom Jamaican. Though the sample size was small, the participant demographics are largely aligned with previous research which indicates that cryptomarket users are predominantly young, white, and male (Barratt \& Aldridge, 2016; Ormsby, 2016). The types of substances that participants were accessing (see Table 1) are also congruous with those indicated in previous research, with cannabis, LSD, and MDMA being particularly popular (Barratt, Ferris \& Winstock, 2016).

\footnotetext{
${ }^{21}$ The term 'Pākehā' refers to a New Zealander of European descent, not of the indigenous Māori ethnic group (Te Ara, n.d.-b).

22 'Kiwi' is a colloquial term used to refer to a person from New Zealand.
} 
Table 1

\begin{tabular}{|c|c|c|c|c|c|c|c|}
\hline Participant & $\begin{array}{l}\text { Gender } \\
(\mathrm{M} / \mathrm{F})\end{array}$ & Age & Ethnicity & $\begin{array}{l}\text { Markets accessed (if } \\
\text { mentioned) }\end{array}$ & Drugs accessed & $\begin{array}{l}\text { Criminal } \\
\text { convictions } \\
\text { due to orders } \\
(\mathrm{Y} / \mathrm{N})\end{array}$ & $\begin{array}{l}\mathrm{PDU} \\
(\mathrm{Y} / \mathrm{N})\end{array}$ \\
\hline Adam & M & 20 & NZ European/Pākehā & AlphaBay & $\begin{array}{l}\text { 2C-B, 4-AcO-DMT, LSD, MDMA, various } \\
\text { unspecified 'obscure' psychedelics }{ }^{23}\end{array}$ & $\mathrm{~N}$ & $\mathrm{~N}$ \\
\hline Andrew & M & 23 & Caucasian & $\begin{array}{l}\text { Various New Zealand- } \\
\text { based markets }\end{array}$ & Cannabis, LSD, MDMA & $\mathrm{N}$ & $\mathrm{N}$ \\
\hline Alice & $\mathrm{F}$ & 25 & $\begin{array}{l}\text { United Kingdom } \\
\text { Jamaican }\end{array}$ & - & Cannabis, MDMA & $\mathrm{N}$ & $\mathrm{N}$ \\
\hline Anon & M & Middle-aged & Caucasian & Agora, Silk Road & Amphetamines, LSD & $\mathrm{N}$ & Y \\
\hline Jackson & M & Early twenties & $\begin{array}{l}\text { New Zealand } \\
\text { European }\end{array}$ & $\begin{array}{l}\text { A vendor-run shop } \\
\text { (name redacted) }\end{array}$ & MDMA & $\mathrm{N}$ & $\mathrm{N}$ \\
\hline James & M & 20 & British & $\begin{array}{l}\text { Silk Road 2.0, an } \\
\text { unnamed Australia and } \\
\text { New Zealand-based } \\
\text { market }\end{array}$ & Cannabis seeds, MDMA & $\mathrm{N}$ & $\mathrm{Y}$ \\
\hline John & M & 19 & British & - & LSD, MDMA & $\mathrm{N}$ & $\mathrm{N}$ \\
\hline Kyle & M & 19 & Caucasian & $\begin{array}{l}\text { AlphaBay, Dream } \\
\text { Market, an unnamed }\end{array}$ & 2C-B, cannabis, LSD, MDMA & $\mathrm{N}$ & $\mathrm{N}$ \\
\hline
\end{tabular}


New Zealand-based

market

$\begin{array}{lllll}\text { Lucidity } & \text { M } & 19 & \text { White } & \text { Dream Market }\end{array}$

2C-E, alprazolam, cocaine, DOM, DMT,

Y

hydrocodone, ketamine, LSD, MDMA,

zopiclone 2425262728

Agora, Dream Market

LSD, MDMA, methamphetamine

Y

Y

Cocaine, diazepam, DMT, LSD, MDMA

$\mathrm{N}$

and - AlphaBay,

and its variants, methamphetamine ${ }^{29}$

Heroin, ketamine, methamphetamine,

Y

unspecified psychedelics

${ }^{23}$ 4-Acetoxy-N,N-dimethyltryptamine (4-AcO-DMT) is a tryptamine class NPS with effects similar to psilocybin (“4-AcO-DMT”, n.d.). In New Zealand, it is a Class A drug (Misuse of Drugs Act, 1975).

${ }^{24}$ Alprazolam (Xanax) is a benzodiazepine that is commonly prescribed as a short-term anxiety medication (“Alprazolam”, n.d.). In New Zealand, it is a Class C drug (Misuse of Drugs Act, 1975)

25 2,5-Dimethoxy-4-methylamphetamine (DOM) is an amphetamine class psychedelic drug with a combination of psychedelic and stimulant effects ("DOM", n.d.). In New Zealand, it is a Class A drug (Misuse of Drugs Act, 1975).

${ }^{26}$ N,N-Dimethyltryptamine (DMT) is a psychedelic substance with a short duration of effect ("DMT", n.d.). In New Zealand, it is a Class A drug (Misuse of Drugs Act, 1975).

${ }^{27}$ Hydrocodone is an opioid painkiller ("Hydrocodone", n.d.). In New Zealand, it is a Class B drug (Misuse of Drugs Act, 1975).

${ }^{28}$ Zopiclone is a non-benzodiazepine hypnotic drug that is commonly prescribed to treat insomnia ("Zopiclone", n.d.). In New Zealand, it is a prescription medication (BPAC NZ, 2018).

${ }^{29}$ Diazepam (Valium) is a benzodiazepine that is commonly prescribed as a short-term anxiety medication ("Diazepam", n.d.). In New Zealand, it is a Class C drug (Misuse of Drugs Act, 1975). 
Attempting to classify participants according to the nature of their use and engagement with illicit drugs quickly becomes challenging, as there is significant blurring between various categories. Two of the participants had convictions relating to cryptomarket drug orders. In both cases, their convictions were managed through community sentences (home detention, community service, and probation). It is difficult to differentiate between participants who were dealing illicit drugs and those who were not, as many participants engaged in small-scale social supply or minimally commercial supply (Coomber \& Moyle, 2014) ${ }^{30}$ Aside from Anon, all participants personally consumed at least some of the drugs that they ordered. ${ }^{31}$ Seven participants (Adam, Jackson, James, John, Kyle, Lucidity, and Michael) indicated that they had profited financially from drug dealing, although this dealing often involved minimal financial gain. Most participants shared drugs with friends in some capacity, and these instances of sharing may meet the legal criteria for supply charges under the Misuse of Drugs Act (1975), even when financial gain was not involved.

Of the participants who indicated that they profited from drug dealing, three entered cryptomarket ordering with the explicit primary intention of dealing (Jackson, Lucidity, and Michael). The other four participants who profited from their orders initially accessed cryptomarket drugs for personal use and later started dealing. Of the dealing that occurred, most participants supplied primarily to friends and acquaintances, but one participant (Michael) sold methamphetamine to local lower-level drug dealers. ${ }^{32}$ Most participants had not made recent orders at the time of the interview, but several reported future intentions to make further orders or would not rule out the possibility $(n=4)$. Four participants (Anon, James, Michael, and Sam) indicated that they considered, or had previously considered, their drug use to be problematic (e.g., referring to oneself as an 'addict' or disclosing that they had engaged with drug treatment because of problematic drug use (PDU).

\section{Data analysis.}

Audio recordings from interviews were transcribed verbatim by the researcher. Interviews that did not require audio recording (those conducted via instant messaging or email) were saved in a Word document. Transcription of audio-recorded interviews was a time-consuming and arduous process. However, the transcription process is important as it allows researchers to

\footnotetext{
${ }^{30}$ Due to this difficulty, Table 1 does not attempt to classify participants according to their drug supply status.

${ }^{31}$ All participants are referred to using pseudonyms to protect confidentiality.

${ }^{32}$ It is possible that the research did not attract more commercial-scale drug dealers as they would not want to disclose their activities to a researcher and risk detection or apprehension.
} 
develop familiarity with their data and note emerging themes (Noaks \& Wincup, 2004). Once interviews had been transcribed, participants who had indicated their interest to do so were invited to comment on and make any amendments to their transcript. This process formed an important aspect of informed consent, allowing participants to have the final say over their contribution to the research project and how their data would be used.

Considering the philosophical and methodological underpinnings of the research, thematic analysis through grounded theory was selected to analyse the data. Thematic analysis is a data analysis tool for "identifying, analysing and reporting patterns (themes) within data" (Braun \& Clarke, 2006, p. 79). It involves data coding to develop themes, with emphasis on academic rigour and high-quality analysis to systematically develop and refine codes (Braun \& Clarke, 2006; Clarke \& Braun, 2017). Thematic analysis offers a flexible approach, appropriate for qualitative research, and it is compatible with the constructivist epistemology that provided the foundation for the research project (Clarke \& Braun, 2017). Furthermore, thematic analysis can be utilised within a critical framework, such as that of critical criminology, to interrogate the meaning and significance of data (Clarke \& Braun, 2017).

Thematic analysis processes were applied to the interview transcripts. The researcher initially intended to use NVivo for coding and analysis. However, this was abandoned in favour of manual coding using coloured pens and pencils, as the researcher found this process significantly easier (see Appendix E for example). Once initial coding was completed, the researcher checked the codes, refined them, and undertook additional coding where appropriate. The process of initial codes followed by more specific refined codes is wellaligned with thematic analysis that is informed by constructivist grounded theory (Charmaz, 2014). The themes that emerged from the analysis are discussed in Chapters 4, 5, and 6.

\section{Advertising and personal challenges.}

During the recruitment process, numerous individuals reached out to the researcher through Facebook comments and messages, or email. Some who made contact were prospective participants who wished to find out more about the research. However, many individuals were clearly uninterested in participating in the research, instead acting as 'trolls' or sharing their personal opinions about illicit drugs and the darknet. ${ }^{33}$ As illicit drugs and drug use are

\footnotetext{
${ }^{33}$ Internet trolling is "the deliberate provocation of others using deception and harmful behaviour on the Internet which often results in conflict, highly emotional reactions, and disruption of communication in order to advance the troll's own amusement" (Sest \& March, 2017, p. 69).
} 
controversial topics, it was anticipated that there would be some debate about drug-related issues in responses to the research poster. However, the degree of some inflammatory comments about the research was unanticipated. The initial advertisement on Vic Deals in May 2018 generated over 100 individual comments, with one person commenting that the research was undertaken "So you can nark people to the dirty cunt pigs...fuk off criminology cunt with your nark project," and "Let's put more people in jail for smoking a joint...fuken cunt laws." While some comments expressed genuine interest in the research, others indicated that they believed that the recruitment was a ruse by the authorities to apprehend people purchasing from cryptomarkets, with one individual writing "Nice try cops" and another posting a photo of a pig in police uniform. ${ }^{34}$ Some people tagged the official Facebook pages of the New Zealand Police and Jacinda Ardern in the advertisement. It was intriguing that many of the comments mistakenly assumed that, as a criminologist, the researcher was supportive of drug prohibition. However, the researcher did not find being referred to as a "criminology cunt" particularly distressing and chose not to engage with trolls or commenters who did not seem to be genuinely interested in participating in the research.

\section{Ethical Considerations and Research Challenges}

All research involving human subjects must adhere to strict ethical standards. These standards are particularly important when researching sensitive topics and stigmatised populations (Liamputtong, 2007). The research was conducted in accordance with the Victoria University of Wellington's Human Ethics Policy. An application for ethical approval was made to the Human Ethics Committee (\#0000025896) and approval was granted on 4 May 2018. Due to the sensitive nature of the research topic, the Committee raised several queries, but these were relatively minor and easily resolved with further discussion between the researcher and the Committee. The Committee's primary concerns included the protection of participants' identities if the researcher was subpoenaed and whether the safety of the researcher could be adequately protected if she was interviewing drug dealers in public locations. As a result, the researcher included a disclaimer in the information sheet and consent form to advise participants of the limits of confidentiality if she was subpoenaed or otherwise called on by the authorities (Appendices B \& C). This was also discussed with participants prior to each interview, and they were asked not to provide details of events and individuals that could possibly be identifying. The researcher also agreed to take a fully charged mobile phone to each face-to-face interview and notify someone of her whereabouts at the start and end of each

\footnotetext{
34 'Pig' is a derogatory slang term sometimes used to refer to police officers.
} 
interview so that they could take appropriate action if she failed to contact them. There were no incidents in the face-to-face interviews that compromised the physical safety of the researcher or the participants.

There is some debate over what constitutes 'sensitive' research (Lee \& Renzetti, 1990; Liamputtong, 2007). Wellings, Branigan and Mitchell (2000) argue that a research topic is sensitive "if it requires disclosure of behaviours or attitudes which would normally be kept private and personal, which might result in offence or lead to social censure or disapproval, and/or which might cause the respondent discomfort or distress" (p. 256). Some theorists understand sensitive research to involve vulnerable populations, such as "social groups who have an increased relative risk or susceptibility to adverse health outcomes," including individuals who are subject to stigma and discrimination (Flaskerud \& Winslow, 1998, p. 69, cited in Liamputtong, 2007, p. 3). If these definitions are used as criteria, then drug research can certainly be considered 'sensitive', as stigma and discrimination experienced by illicit drug users is well-documented, and drug research can include the disclosure of harm and criminal offences (Ahern, Stuber \& Galea, 2007; Room, 2005; van Boekel, Brouwers, van Weeghel \& Garretsen, 2013). When conducting sensitive research, it is necessary to consider the impacts on both the researcher and participants and take measures to ensure that the safety needs of those involved are met (McCosker, Barnard \& Gerber, 2001). With this in mind, the researcher was attentive to the needs of participants throughout the interview process by providing an empathetic ear and compiling a list of support services to provide to participants if necessary.

Although there is growing recognition of the effects of sensitive research on researchers, ethics committees tend to focus on the minimisation of harms to participants (Dickson-Swift, James, Kippen \& Liamputtong, 2007; McCosker et al., 2001). Dickson-Swift et al. (2001) assert that it is vital for researchers to be mindful of how the research process affects them in the face of "ongoing challenges such as dealing with developing attachments, hearing untold stories, feelings of guilt, vulnerability and exhaustion" (p. 344). Issues of emotionality are intertwined with those of researcher reflexivity. Reflexivity refers to awareness of, and reflection on, one's positionality as a researcher and how that positionality with its privileges and biases might affect the research process and findings (Berger, 2015). In acknowledging the importance of researcher reflexivity, it was necessary for the researcher to consider her positioning as a young, middle class, Pākehā, queer woman. To encourage reflexivity and introspection, the researcher kept a journal of her emotions and experiences throughout the data collection process. 
There are additional challenges to conducting drug-focused and internet-based research (Barratt \& Aldridge, 2016; Barratt \& Lenton, 2010; Barratt \& Maddox, 2016; Martin \& Christin, 2016). During and after the interviews, several participants asked the researcher about her own experience with illicit drugs. Such questions were posed in the spirit of curiosity and seeking to find common ground, but they were accompanied by a degree of discomfort. ${ }^{35}$ Despite this vulnerability, it felt unreasonable to expect participants to discuss their own illicit drug use with the researcher without some level of reciprocal openness. For this reason, the researcher answered personal questions as openly and honestly as possible. Other unexpectedly emotional experiences for the researcher involved participants expressing the stigma that they had encountered and the legal consequences of their engagement with cryptomarkets. Some participants also spoke of their struggles with PDU. While emotional reactions were sometimes unanticipated, the researcher drew on emotionality to empathise and connect with participants at these moments in the interview process. While she had never personally ordered cryptomarket drugs, the researcher approached the interview process as an 'involved outsider' who felt deeply disturbed by the harms and injustices of drug prohibition (Stanley, 2012).

\section{Practical Limitations}

The age, ethnicity, and gender of participants in this study (displayed in Table 1) was broadly consistent with the demographics of participants in similar research (Barratt \& Aldridge, 2016; Ormsby, 2016). The sample mostly comprised of males $(n=11)$, with only one female participant. Most participants identified themselves as either white, British, Pākehā, or Caucasian, and they were aged between their late teens and 'middle-age'. Despite the similarities between the participant demographics in this sample and comparable research, it would be premature to suggest that the sample is representative of the population of drug cryptomarket users, as research into cryptomarket users is still in its infancy. Ideally, there would have been more gender, age, and ethnic diversity among the participant population. It would have been advantageous to recruit Māori participants, as they are disproportionate recipients of drug-related convictions and are the indigenous ethnic group in New Zealand (New Zealand Drug Foundation, n.d.). Additionally, economic class was not a specific focus of interviews, and information on participants' class background would have contributed to the depth of insight that could be achieved (for example, in relation to Martin's (2017a) gentrification hypothesis). Neither of the participants who had criminal convictions for their

\footnotetext{
${ }^{35}$ It is not uncommon for qualitative researchers to grapple with the appropriateness of personal disclosures during interviews (Dickson-Swift et al., 2001).
} 
cryptomarket orders $(\mathrm{n}=2)$ had served a custodial sentence. Completing an interview with a participant who had served a custodial sentence would have allowed the researcher to gain additional insight into the effects of criminal justice system sanctions on the lives of New Zealand cryptomarket users. ${ }^{36}$ Finally, participants were recruited through the clearnet rather than through the darknet, and this may have influenced the dataset.

Despite the admitted limitations, representativeness and generalisability were not specific goals of this research project, in part due to the constraints of a Master's thesis, but also because the project was exploratory and intended to provide a broad overview of the positioning of drug cryptomarket users in New Zealand. Although the researcher would have preferred to recruit 15-20 participants for a larger dataset, it would not have been feasible for a project of this size. In total, 12 participants were interviewed, a number comparable with previous qualitative cryptomarket studies (Barratt, Lenton, Maddox \& Allen, 2016; van Hout $\&$ Bingham, 2013b, 2014). The 12 interviews formed an appropriate dataset for a qualitative Master's thesis. The following chapters describe and analyse pertinent themes that emerged from the dataset, and clearly demonstrate that further research into New Zealanders' engagement with drug cryptomarkets is warranted.

\footnotetext{
${ }^{36}$ Although the researcher liaised with an individual who had served a custodial sentence for his convictions, an interview did not eventuate as he did not contact the researcher to organise a time to meet, despite her following up with him twice.
} 


\section{Chapter 4: Cryptomarkets - Insights, features, and risks}

[I have found cryptomarkets] very convenient and empowering. There's something to be said about not conforming to societally engineered morals and norms. - Richard, 30

The value of exploratory research lies in its ability to discover new phenomena, provide cutting-edge insights, and establish further lines of enquiry (Stebbins, 2001). This chapter will discuss some of the cryptomarket insights, features, and risks that were gathered from interviews.

Participants discussed various steps that they took to reduce the risk of apprehension when ordering from cryptomarkets. Approaches included ordering solely from New Zealand-based vendors, refraining from ordering large quantities of drugs, refraining from ordering cannabis plant, using drop-sites and pseudonyms, and utilising various forms of technology. ${ }^{37}$ Some participants also relayed lived experiences of being apprehended for their cryptomarket orders. An order failing to arrive was a relatively common experience, but 'close calls' were memorable.

\section{Perceptions of Risk and Apprehension}

Risk is a concept that has been discussed thoroughly in academic research on cryptomarkets. Despite this, few authors have defined risk within the parameters of their work. A useful general definition is provided by Garland (2003) who interprets risk as "a measure of exposure to danger, of the likelihood and the extent of loss" (p. 2, cited in Décary-Hétu et al., 2016, p. 70). Within drug research, risk is predominantly understood in terms of the risk of arrest and imprisonment, particularly in relation to its influence on drug prices (Caulkins \& Reuter, 1998, 2006; May \& Hough, 2004). The following section will focus on participants' perceptions of risk, highlighting techniques that they consider reduce the risk of apprehension and exploring lived experiences.

\section{Reducing the risk of detection and apprehension.}

Techniques that participants used to reduce the risk of detection and apprehension can be divided into two categories - actions taken when making an order, and those taken in relation

\footnotetext{
${ }^{37}$ A 'drop-site' or 'drop-point' refers to the address that some participants would use to have their orders delivered to. As they did not want orders to be traced to their legal identity, some participants would use pseudonyms for the name on their orders and use an address that they were not otherwise associated with for the delivery so that it would be difficult for authorities to link parcels to them if they were intercepted. As participants chose delivery addresses that they were not otherwise associated with, the addresses were often quite a distance from their home address, and it was time-consuming to travel to check their drop-site addresses regularly.
} 
to delivery. Both categories are aimed at reducing the likelihood of detection during the postal handling and delivery phase of the order, as this is widely considered to be where detection is most likely to occur (Aldridge \& Askew, 2017). Participants gathered knowledge of these techniques from various sources. Many cryptomarkets and related websites (on both the darknet and the clearnet) contain guides on avoiding detection, but some of the techniques that participants used were 'common sense' and not learnt from any particular source (Aldridge \& Askew, 2017; Martin, 2014).

Participants discussed ensuring appropriate operational security when accessing cryptomarkets as one of the most basic methods of reducing the risk of detection and apprehension. Sensible operational security decreases the risks involved in purchasing cryptomarket drugs in two ways. Firstly, it means that if an individual's property is searched, it would be difficult for authorities to find evidence of their use of cryptomarkets. Secondly, it allows individuals to maintain their anonymity when using the darknet, resulting in a reduced likelihood of authorities accessing their personal details if a market is seized. Discussions of operational security centred on two key elements - Tails and cryptocurrency practices. Tails (The Amnesic Incognito Live System) is an operating system that is designed to run from a read-only flashdrive that leaves no digital evidence that it has been used (Abraham, Silva, Decourcy \& Cardon, 2017; Dawson \& Cárdenas-Haro, 2017). Tails is useful when ordering from cryptomarkets, as it does not leave evidence that Tor has been accessed. Kyle enjoyed using Tails "because of the ease factor" and:

If anything went wrong it was just so easy to throw a USB away, and [the authorities] could search your laptop all [they] wanted [and not find any evidence of Tor]. - Kyle, 19

Cryptocurrency practices were another important element of operational security. Though cryptocurrency such as Bitcoin is difficult to trace, as noted in Chapter 2, it is possible to link Bitcoin purchases to an individual's legal identity by examining the publicly-accessible Bitcoin ledger and utilising blockchain analysis (Cox, 2016c; Narayanan et al., 2016). Bitcoin activities can be obscured using Bitcoin tumblers, but although participants were aware of the effectiveness of Bitcoin tumblers, they did not utilise them (Cox, 2016c). Security practices that some did use, however, included buying Bitcoin with cash, so that their purchases would not be associated with their bank account or credit card. 
There was a belief among some participants that parcels from New Zealand-based vendors were less likely to be intercepted. This is a logical assumption, as domestic parcels do not have to pass through Customs clearance, and the checks that occur in the domestic postal process are likely to be significantly less rigorous than those utilised by Customs. ${ }^{38}$ The reasoning was apparent in interviews, and Kyle said:

The rate of people getting caught domestically is so stupidly low, there's just no real [risk]. - Kyle, 19

Participants believed that New Zealand's border security measures were highly effective. The notion of effective border security was supported by reports that some cryptomarket vendors had restrictions and separate policies for New Zealand delivery addresses. Similar findings have been documented regarding the Australian market, and existing literature has pinpointed international shipping as a particularly risky area in the cryptomarket drug trade (Bakken et al., 2017; Broséus et al., 2017; Décary-Hétu et al., 2016).

Adam and Andrew made orders solely from New Zealand-based cryptomarket vendors, as they both felt that the risk of detection was too high to consider ordering internationally:

I actually didn't import any internationally. It was always domestic because I didn't want to mess around with Customs. [...] I would never [place an order with an international vendor], just because in Australia and New Zealand, we have the tightest Customs in the world and I just don't want to mess with them. [...] I'm not a big risktaker. Not that big, anyway. - Adam, 20

The thing is, I've never made an order from overseas. I would only ever do domestic [orders] because I don't see much of a risk. - Andrew, 23

John originally used international vendors when he started purchasing from cryptomarkets and then switched to solely New Zealand-based vendors when he learnt about the penalties for importation under the Misuse of Drugs Act (1975):

I think the first one was from the Netherlands, and then from then on, [I] mostly got it from the States, and then, later on, switched to a New Zealand provider just to avoid the whole importing thing from things getting tracked in Customs. [...] If it's just in the

\footnotetext{
${ }^{38}$ Section 5 of the Postal Services Act (1998) permits postal operators to open and examine postal articles that they have reason to suspect may contravene the Misuse of Drugs Act (1975). However, there is, understandably, no publicly available information on the frequency of such examinations.
} 
post then it's way less risk than it coming through on a plane, or you know, particularly if it's in a package [as opposed to an envelope]. - John, 19

Similarly, Lucidity, who at the time of his interview had not made any cryptomarket orders since he was convicted, said that he would consider using a New Zealand-based vendor if he were to start making orders again in the future. Ordering from New Zealand-based vendors was not without its disadvantages, however, as participants reported that it restricted them to a small range of drugs, a small number of vendors, and higher price. John commented on the constraints of purchasing solely from New Zealand-based vendors:

We sort of split from international vendors to New Zealand vendors, purely for the risk factor, but the acid we got from the States was far, not superior, but there was just more to choose from like there was only one vendor that we really wanted to go with in New Zealand. It was fine, like it was good stuff [from the New Zealand vendor], but you couldn't get the variety of concentration and stuff [that you could get from overseas vendors], we could only get 180 microgram tabs [from the New Zealand vendor], whereas we could get like 200 [or] 250 [microgram tabs] from the States if we wanted to. - John, 19

For Michael, ordering from New Zealand-based vendors was inconceivable, because "their prices are ridiculous," and his connections meant that he could "go get it cheaper fucking 200 metres down the road." Another technique to avoid apprehension was to restrict each individual order placed to small drug quantities. There was a perception that small quantities of drugs were less likely to be detected by Customs, especially if they were packaged in envelopes instead of bags or boxes, due to the assumption that letters are less conspicuous because they are used to transport paper documents only. Consequently, drugs that could fit in an envelope with a discreet profile, such as MDMA or LSD tabs, were viewed as easier to import without detection:

I notice that the low amounts tend not to get intercepted, so like ten to 20 grams [of MDMA], or five to ten [grams], probably five to ten grams have made it through the most. The times I have ordered 20 or 30 [grams], they've actually been intercepted. Jackson, early twenties

Parallel to the perception of small quantities as less detectable was the assumption that authorities would be less likely to pursue charges under the Misuse of Drugs Act (1975) if an intercepted parcel contained only a small amount of a substance. Kyle asserted that if an 
intercepted parcel was "below certain thresholds" then Customs would seize it and send the intended recipient a warning letter instead of initiating court proceedings, though he did not state what he thought the threshold for this course of action would be or how he had come to that conclusion.

Moreover, if an order was seized by Customs or failed to arrive, participants considered that it would be foolish to order subsequent parcels to the same address, as authorities may have flagged the delivery address as suspicious, and be holding seized parcels to build a case for pursuing charges if subsequent parcels were intercepted:

From what I've heard, Customs tends to let the first few [parcels] through or sometimes they'll just start stopping [them] until they can build a case. - Jackson, early twenties

Jackson is correct, as Section 12 of the Misuse of Drugs Act (1975) permits Customs officers to allow the delivery of unlawfully imported drugs for the purposes of detection of the importer and the building of a criminal case. Kyle added:

I think you'll find most of the people who've been properly caught and stuff would be either having one package seized and then ordering another, or having two [orders] that are being shipped out at the same time. - Kyle, 19

The scenario provided by Kyle is consistent with the manner in which criminal cases were built against both Lucidity and Michael. However, as there were only two participants in the study that had incurred criminal convictions due to their engagement with cryptomarkets, it should not be inferred that this is the case with most cryptomarket-related apprehensions in New Zealand.

It was considered prudent to avoid ordering from cryptomarket vendors who were in 'highrisk' countries. Such countries included those in South America and Central and Eastern Europe, as those regions were thought to be subject to additional Customs checks due to being associated with drug production. As it was obviously desirable to avoid scrutiny from Customs, some participants avoided ordering from countries that they associated with drug production and trafficking. Kyle said:

If [an order] comes out of Germany or the Netherlands, then it's got a mark on it through Customs. [...] The Netherlands is probably the worst for MD[MA] and stuff. Pretty much, I'd imagine any package from the Netherlands is probably x-rayed pretty hard. - Kyle, 19 
It is interesting that participants linked some countries with increased scrutiny at the border. As Customs' internal processes are largely unknown to the public, it is not possible to say whether mail items from countries in the regions that participants labelled are in fact subject to more intense inspections. However, as Kyle noted, the Netherlands is recognised as a key MDMA producer, and a significant proportion of cryptomarket vendors reside in the Netherlands, so it makes sense for participants to avoid purchasing from there (Aldridge \& Décary-Hétu, 2016b; Dolliver et al., 2018; EMCDDA, 2017; Kruithof et al., 2016).

Regarding actions taken during delivery, use of a drop-site and a pseudonym was another important step in avoiding detection and apprehension. Not all participants used drop-sites, but those who did selected addresses that they were not otherwise associated with. Participants who used drop-sites would also use pseudonyms for the delivery name on their order. This meant that if an order was intercepted by Customs, it would be difficult for authorities to link the parcel with the legal identity of the intended recipient:

Obviously using a drop-site [reduces the risk of getting caught]. [...] [If you are] using a drop-site, and no names or anything, and not an address that was associated with you, then it would be very hard to get caught. - Kyle, 19

The process of choosing a drop-site varied between participants. Some used the addresses of friends or acquaintances, while others chose addresses further afield. Michael used the houses of acquaintances for his deliveries, and in exchange, he provided them with some of the methamphetamine from each order. He would ask them to give him the name of a previous tenant from mail that was received at the address so that he could use that name for the delivery details. He instructed his acquaintances to sign for the parcel when it was delivered, and then leave it on the front porch. Michael would then 'steal' the parcel by uplifting it from the front porch. If the police were to find the methamphetamine at the houses of his acquaintances before he had the chance to uplift it, Michael coached them to avoid incriminating themselves. He advised acquaintances to tell police that they had signed for the parcel without knowing its contents, realised that it was addressed to someone else, and had been going to contact the courier company to advise them of the error.

A common method for selecting a drop-site was to browse unoccupied rental properties and houses for sale on websites such as Trade Me: ${ }^{39}$

\footnotetext{
${ }^{39}$ Trade Me is a popular New Zealand auction website, similar to eBay.
} 
The trick is to use some kind of real estate website and check for a house that hasn't been inhabited for about two years that's on the market. So, then after that, you check if someone's there or not, if not [you] empty the mailbox, and then there you go, you've got your drop[-site]. [...] I'm yet to read an article where [someone's drug purchasing has] been linked to the darknet and it's not [due to] making simple mistakes like sending it to your own house and having your own name on the parcel and whatnot. - Jackson, early twenties

Once a promising property was found, the address would be visited to inspect it for nearby neighbours, whether the mail was being collected regularly, and ease of access to the letterbox. If the property was appropriate, then it would be used as the delivery address for orders. As participants chose delivery addresses that they were not otherwise associated with, their dropsites were often quite a distance from their home address, and it was time-consuming to travel and check them regularly. Some participants had multiple drop-sites at any one time, and it was considered good practice to change drop-sites frequently to minimise the possibility of detection. Once on bail, Lucidity chose drop-sites along a hill in the city that he lived, and he would walk the route of his drop-sites to check for deliveries "at least 15 times within a week." A common method of selecting pseudonyms was to use the name of previous tenants at the drop-site address.

Correct use of drop-sites and pseudonyms meant that it was unlikely that participants' activity could be connected to their legal identity. There was a perception among participants that, when drop-sites and pseudonyms were used appropriately, the worst that could happen if a parcel was intercepted would be loss of product or money. Michael even included the rate of parcel interception in his business costs. Not all participants used drop-sites and pseudonyms, however. John and his friend had to use their legal names on their orders, due to the constraints of living in a hall of residence. Kyle had orders sent to his family home while he was a high school student, and he used his legal name for the delivery because he had read online that it was safer to use your own name if ordering to your own house:

Probably not so much in New Zealand, but in some places, if mailmen are real onto it and they see a different name coming up that isn't associated with the address, they can get kind of suss. - Kyle, 19

Overall, participants utilised numerous techniques to reduce the risk of detection and apprehension, both when accessing and ordering from cryptomarkets, and in their delivery- 
related actions. Not all techniques were widely or consistently used by participants, but they were aware of risk-reducing practices and reported that discussions about safety and security were common on cryptomarket fora. Those who utilised them found that drop-sites and pseudonyms provided significant peace of mind, creating a barrier between their legal identities and their drug purchasing activities, and reducing the possibility of authorities linking them to intercepted parcels.

\section{Lived experiences of detection and apprehension.}

Academic scholarship on drug cryptomarkets is still in its infancy. Due to this, there have been no peer-reviewed academic publications investigating cryptomarket consumers' lived experiences of detection and apprehension by authorities. The following section gives voice to two participants who received criminal convictions because of their cryptomarket orders, highlighting their experiences of detection, apprehension, and the subsequent criminal justice process.

Participants expressed that it was relatively common for an order to be intercepted or fail to arrive. The rate of successful orders varied significantly between participants, with Jackson reporting that "maybe like 50 percent" of the orders that he made were successfully delivered to him. The delivery success rate also fluctuated between vendors and the type of parcel packaging used. For example, Lucidity, who had made dozens of orders, commented that he had never had any issues with one vendor who used particularly stealthy packaging, a combination of flat-pack envelopes and moisture barrier bags so that "you could not distinguish [the drugs] from a thick bank statement."

Though having some unsuccessful orders was considered normal, incidents that were deemed 'close calls' for detection or apprehension were memorable. Jackson spoke of a friend who was teaching him how to make cryptomarket orders. His friend used his residential address for the delivery, and the parcel was intercepted by Customs which led to a police detective knocking on his door:

So, foolishly, my friend who was getting me in on [drug cryptomarkets] ordered it to his own house, and even more foolishly, he wasn't very smart about the name he put on it. As a result, there were some investigations later on about the package arriving. [...] They weren't able to incriminate him ... - Jackson, early twenties 
Fortunately for his friend, the matter was not pursued any further, but Jackson said the incident was a "big lesson" for him regarding the importance of using drop-sites and pseudonyms. James told a similar story:

My mate's brother tried to buy a whole ounce [of cannabis] off the deep web, and Customs officers turned up to his house and spoke to his mum and that and [she said to them], "Oh, must be the wrong address, sorry." - James, 20

Such stories contributed to perceptions that authorities were unable to build a criminal case if cryptomarket consumers were uncooperative with their enquiries, thus adding a further layer of protection from apprehension. However, two participants, Lucidity and Michael, incurred criminal convictions because of their illicit drug importation from cryptomarkets.

Lucidity began ordering illicit drugs from cryptomarkets in late 2015 when he was 17 years old. His main drugs of choice were LSD and MDMA, but he also purchased various others (see Table 1, Chapter 3, p. 52 for details). His orders were initially for personal use, but later evolved into social supply for friends and acquaintances, and he estimates that he made between 50 and 60 orders in total. Lucidity's drug importation was detected as he made orders in his legal name to his residential address, a decision that he now regards as foolish:

I would send [orders] to my name and change a letter and claim, "It's not legally my name," in my head, "that will work in court." [laughs] It doesn't make sense. I know it doesn't make sense, but at the time, it seemed to. - Lucidity, 19

Over time, several of his orders failed to arrive. Lucidity assumed that he had been scammed by the vendor, but the parcels had actually been intercepted by Customs. Customs amassed over a dozen parcels, which formed the basis for the search warrant that was later executed on his flat. He had been making orders for approximately one year at the time that he was arrested, and he continued to make orders while on bail for a period of about six months. He acquired a total of six convictions - three counts of importation of MDMA with intent to supply, one count of possession of MDMA with intent to supply, one count of possession of cocaine with intent to supply, and one count of cultivation of cannabis. Customs misplaced the intercepted parcels that had been used to obtain the search warrant that was executed on his flat, so the drugs from those parcels were not included in court proceedings. He was initially sentenced to three-anda-half years in jail, but his sentence was reduced because of his young age and an early guilty plea, so instead he was sentenced to home detention for a period of ten months, as well as six months' post-detention conditions and mandatory drug counselling. Lucidity found home 
detention was very difficult, as he was unemployed at the time and felt isolated from the outside world. Although five of his six convictions were supply-related, Lucidity stated that financial gain was not a motivation or priority for him, and most of his dealing took the form of social supply:

I would sell [MDMA] at 20 [dollars] a point, or if it was, like, a party at my house, like a token drink just so I'm not giving you free drugs. - Lucidity, 19

He estimates that he made between NZ\$7000 and NZ\$8000 in profit through drug dealing from his cryptomarket orders, but that he could have made between NZ\$100,000 and NZ\$200,000 if he had sold drugs at the market rate.

Michael's cryptomarket activities also resulted in criminal convictions. Over a six-month period, he imported large quantities of methamphetamine from a United States-based vendor in a joint effort with an associate. Unlike Lucidity, Michael and his associate had a sophisticated set-up, selling methamphetamine to local lower-level drug dealers. Michael reported that they made about NZ $\$ 6000$ profit per week, as well as each retaining approximately 3.5 grams of methamphetamine per week for their personal use. Michael and his associate initially established careful practices to avoid detection, including separation of duties, drop-sites, and the use of burner cell phones. However, his associate failed to follow the protocol consistently and, like Lucidity, had been making orders for personal use to his own residential address. When a search warrant was actioned and his associate was apprehended, police obtained Michael's details, thus uncovering part of their operation. As Michael retold this story in the interview, his frustration and resentment were palpable:

[My associate's] job, because he was the internet guy and he knew how to do it, was to order it and just take care of that side of things. I would arrange where [the parcels] got dropped, and I would arrange getting rid of [the methamphetamine]. [...] He wanted to sell more and fucking, you know, have more [methamphetamine] and things like that, and I said no, so he ended up ordering another package to his house, but [a previous order that he had made] had been picked up by Customs and so his address was red-flagged, and then when the second package went through Customs, obviously [because] his address was red-flagged they found [the drugs] in there. [...] They actioned a search warrant [on his property]. I'd given him a tablet to do all the ordering and that on, which was a $4 G$ tablet, and said, "Don't use it for anything else, just go for a drive [to use public internet] and do your ordering, and keep it in a snap- 
lock container and fucking stash it somewhere," so that it was never [at his house]. When [the police] came and knocked on the door with the search warrant, he goes and opens the door, "Oh, police!" What's sitting on his fucking coffee table in the lounge? That tablet, open, already logged in to one of the [cryptomarket] sites. [...] The dumbass had my name and one of my burner phones. He had my full name saved under it. [...] [The police] linked it back to me. - Michael, 36-37

Michael initially faced 14 charges of intent to supply methamphetamine and one charge of conspiracy to import. However, he said that, in the end, he was "actually very lucky" as he was convicted for slightly under three grams of methamphetamine. He was sentenced to 12 months' home detention and 250 hours of community service. Although Michael found home detention "fucking annoying" he was able to find appropriate employment which made the sentence easier to cope with as he was able to leave the house regularly. He was confident that his convictions would not negatively impact his future job prospects, and, at the time of the interview, he had a new job lined up to commence once his home detention was completed.

Experiences of apprehension, detention, and 'near misses' were varied. Only two participants had sustained criminal convictions due to their cryptomarket drug orders, so their experiences should not be considered representative. Despite this, it is noteworthy that neither Lucidity nor Michael received custodial sentences for their actions. The following sections move to discuss the various forms of supply and drug-sharing that participants engaged in. Participants' perspectives on drug laws and criminal charges are discussed in further detail in Chapter 6.

\section{Supply: Social, Commercial, and 'something in between'}

Despite predatory 'pusher myths' of drug dealers' greed and reckless disregard for wellbeing, academic research has consistently demonstrated that drug markets and dealers are not homogeneous (e.g., Adler \& Adler, 1983; Coomber, 2006; Jacques \& Wright, 2015; Measham $\&$ Moore, 2009; Taylor \& Potter, 2013). Not all drug trading is motivated by financial gain. Coomber and colleagues assert that social supply and 'friend suppliers' are common phenomena within drug markets (Coomber, 2006; Coomber \& Moyle, 2014; Duffy, Schaefer, Coomber, O’Connell, \& Turnbull, 2008; Parker, Aldridge \& Measham, 1998).

The concept of 'social supply' encompasses drug trading between friends and acquaintances that is not financially motivated (Coomber \& Moyle, 2014). A significant portion of drug trading falls under the umbrella of social supply, with non-financial motivations including friendship, gift-giving, and leisure (Coomber \& Turnbull, 2007; Hough et al., 2003). Another 
category, 'minimally commercial supply', has been suggested by Coomber and Moyle (2014) to encompass trade between 'addicted user-dealers' and other PWUD that does not have profit as its primary driver. Rather, it is used to provide income to support the user-dealer's own drug use. Social supply networks are also recognised as an important element of cryptomarket drug trading (Barratt, Ferris \& Winstock, 2016; Demant, Munksgaard \& Houborg, 2018). It has been suggested that legislative responses to social supply are excessively punitive, as drug laws often fail to distinguish between social and commercial supply (Coomber \& Turnbull, 2007; Duffy et al., 2008; Law Commission, 2011). In the words of Lucidity:

[The law] is made for your millionaire from South America shipping freighters of cocaine, not for a teenager with some money. - Lucidity, 19

This section will discuss the various forms of drug supply and trading that participants engaged in, including supply without financial gain, supply with financial gain, and social supply.

As detailed in Chapter 3, 11 participants personally consumed at least some of the drugs that they obtained from cryptomarkets. Sharing drugs with friends and acquaintances was also very common, and Sam was the only participant who reported that he did not share drugs from his cryptomarket orders with anyone else. The remaining 11 participants had shared drugs with friends and acquaintances in various forms, including trading and gifting, with various monetary arrangements governing their drug-sharing.

Seven participants (Adam, Jackson, James, John, Kyle, Lucidity, and Michael) indicated that they had profited financially from drug dealing. Of these seven, only three entered cryptomarket ordering with the explicit primary intention of dealing - Jackson, Adam, and Michael. Adam had recently moved to New Zealand from a country in the Persian Gulf, where illicit drug use was severely punished. He wanted to experiment with illicit drugs and thought that becoming a drug dealer would be a good way of making money, as he needed income to support himself while he was studying in New Zealand. He chose to order from a New Zealandbased cryptomarket vendor, to reduce the likelihood of detection and apprehension:

I did it to make money because I had just come in from overseas and I didn't have a job and I needed to make money somehow, so that's how I did it, and it worked out really well. - Adam, 20

Aside from Jackson, Adam, and Michael, participants who profited from their orders initially accessed cryptomarket drugs for personal use without any intention to start dealing, but later 
transitioned into drug supply. The dealing that occurred was primarily to friends and acquaintances, but one participant, Michael, sold methamphetamine to local lower-level drug dealers. He chose to supply to lower-level dealers rather than the end-consumer because he found it easier to keep his drug importing operation secret and control his interactions with lower-level dealers:

I didn't like selling to the end-user, because they're high-key, you know, they're the ones that knock on your door at fucking some ungodly hour or something like that, so I liked dealing to dealers because they like to keep their hook-up a little bit more quiet, a little bit safer... - Michael, 36-37

Michael and his associate earned significant profits from their cryptomarket-related drug dealing. However, aside from Michael, participants who were engaged in illicit drug supply generally made relatively small dollar amounts. For example, Jackson estimated that he made NZ\$2500 to NZ\$3000 profit across approximately five orders. James estimated that he made about NZ\$6000 in total from selling the cannabis that he grew, and Adam estimated that he made upwards of NZ\$12,000 selling mainly MDMA and psychedelics over the course of about 18 months. Lucidity indicated that he could have earned between NZ\$100,000 and NZ\$200,000 from his dealing if he had sold at street prices, but he instead sold at well under the market rate and made between NZ\$7000 and NZ\$8000 before being apprehended by police.

Several participants who engaged in dealing reported that they were not motivated by profit but wanted to have some small financial reward for the risk that they were taking by placing orders, thus explaining why they sold drugs at significantly below the market rate. Kyle mainly sold LSD and MDMA and did so at below the market rate because he needed "some risk-toreward kind of factor" to justify the risk that he was taking by importing illicit drugs from overseas. Kyle's dealing falls under the category of social supply, as he made a small profit by sourcing drugs for his friends for special occasions:

I would say [it was] not like conventional dealing [to] make a profit or something like that, [it was more like] if we were going to go out somewhere, everyone could just put in money and I could get it for them, sort of thing. - Kyle, 19

Other participants' dealing arrangements also fell under social supply. Lucidity would trade MDMA for a "token drink" if he was hosting a party "just so I'm not giving [people] free drugs." Likewise, Andrew's supply arrangements varied according to the context and to whom he was supplying drugs. Like Kyle, he wanted to make a small profit because of the risk that 
he was taking by ordering cryptomarket drugs, but he also frequently gave LSD tabs away at cost price:

I don't [make orders] for drug dealing or anything, I do it just for myself and a couple of friends, really. It's not like I'm making a business [out of it] or anything and having it as a job, it's just kind of for fun, in a way. [...] I'm not going to give my drugs away [for free] if I've spent all that money. [laughs] I give quite a lot of it away though, to be fair. I guess I probably make them pay maybe three or four more dollars [than the cost price] if I'm selling a tab, but then I give quite a lot of it away as well. Half the time I'll just give [my friends a tab]. - Andrew, 23

Social suppliers had numerous non-financial motivations for dealing. These included being able to give friends and acquaintances the drugs that they sought and wanting their friends to have access to drugs that they perceived to be safer than those from the domestic conventional market. For example, Richard stated that his cryptomarket drug orders were for:

Personal use and at one stage to supply friends, never for financial gain though. I was more concerned that friends were trying random street variants available in NZ, which never contained what they thought they'd contain, or what they were sold as. - Richard, 30

Profit was not a motivator for Richard. Rather, he felt that it was safer for him to order cryptomarket drugs for his friends who wanted them than it was for them to take potentially dangerous "random street variants" available in the New Zealand conventional market. ${ }^{40}$ Others, such as Jackson, only sought supplementary income from their drug dealing:

It was definitely supplementary money that I got. I've got two jobs, I'm pretty hardworking, but if you can get the drugs in and make some money from it on the side of everything else every now and then, what's the harm if you're being as safe as possible about it? - Jackson, early twenties

James did not intend to sell the cannabis that he grew. However, the yield from his plants was so high that he had excess cannabis that he could not consume himself:

\footnotetext{
${ }^{40}$ If cryptomarket drugs are stronger and purer than "street variants" then it is possible that the risk of harm or overdose could increase if those consuming them are accustomed to weaker, less potent drugs in the domestic conventional market. However, some participants acknowledged this possibility and gave harm reduction advice to those that they supplied with drugs.
} 
I had more weed than I knew what to do with, so I had to give it away, I had to sell it. I just had too much. [...] I just sold it to people for the regular price and just made them a massive bag or whatever. [...] I was smoking for free for years though, because of it, and I was giving it away and I was selling it as well. I eventually didn't have to work anymore because I had unlimited weed, which was all I worked for in the first place. [...] I probably made about $\$ 6000$ maybe, in the whole time of doing it. - James, 20

As cryptomarket prices tended to be well below prices in the expensive domestic conventional market, participants who were dealing could make a profit while simultaneously providing inexpensive product to consumers. Furthermore, cryptomarket drugs were of a superior quality than those in the domestic conventional market, so consumers were pleasantly surprised that they did not have to pay exceedingly high prices for them. John described the prices that he and his friend set for LSD tabs:

We did end up making quite a bit. Buying direct from the supplier in larger quantities we could get LSD for $\$ 10$ a tab and we'd sell them for closer to the street price at around \$40 each so we'd make \$30 off each tab. [...] [The LSD] was quite good quality as well, so friends would be expecting to pay 50 [or] 60 bucks because it's quite strong tabs, and then they're like, "Oh, you're doing me a deal [because] it's only 40 [dollars]," but we're still [making a profit]. [...] With the acid, yeah, people were always pretty pleased with it and most of the people we were selling to were repeat buyers, so we had lots of friends who were like, "Yo, that was great! I'll have another one." - John, 19

Likewise, because of the cheap price of cryptomarket drugs compared to the domestic conventional market, Adam said that his dealing was "pretty much always mates' rates," with LSD tabs being sold at approximately half the street price:

Because I was able to get so much [product] so cheaply, I was able to make a lot of profit and still sell the product to other people for a low price as well, you know? [...] Usually, if you don't know the person you're buying off, for LSD, per tab it'd be 35 to 40 dollars. I was able to source them for seven-and-a-half [to] eight dollars [each] and then I sold them for 20 [dollars]. - Adam, 20

Along with various forms of social and for-profit supply, participants who engaged in supply displayed genuine concern for the wellbeing of those that they were supplying to, again contradicting the notion of the predatory drug dealer (Coomber, 2006). This was especially 
evident in the ways that they promoted harm reduction practices, including drug testing and dosage advice. Adam sampled drugs from every order that he made because he wanted to ensure that he was selling a safe product to consumers:

[I always tested drugs before selling them because] I just wanted to more know that it was exactly what it was advertised [as]. [...] [For example], it was advertised as LSD, but it could have been 25I-NBOMe, which would have been terrible. ${ }^{41}$ I would have wanted to know that before I put myself out there, because if I sold [25I-NBOMe] to someone and someone had taken three of them and died, then I would have been in jail. - Adam, 20

Adam demonstrated an awareness of the drugs that he was supplying to others. He was knowledgeable about the potential adverse health effects of 25I-NBOMe, especially when mistaken for LSD (Andreasen et al., 2015; Gee, Schep, Jensen, Moore \& Barrington, 2016; Kueppers \& Cooke, 2015; Morini et al., 2017). Adam was not able to confirm the purity or contents of the drugs that he was supplying by personally testing them, as such information can only be obtained through scientific analysis. However, he used his knowledge and experience of drug effects when testing drugs that he ordered. Drug sampling provided him and his consumers with some peace of mind that what he was selling was consistent with his prior experiences of a given drug. By personally sampling the drugs from each order, Adam displayed care for the wellbeing of those that he was dealing to. His concern for consumers was not purely altruistic, as he noted that he would be liable if "someone had taken three [25INBOMe] and died," but Adam arguably put himself at risk by sampling each batch, and his actions represent a significant departure from the myth of drug dealers' reckless disregard for the safety and wellbeing of those to whom they sell (Coomber, 2006).

Harm reduction practices adopted by participants also extended to dosage advice. Several participants provided dosage advice, particularly if they knew that it was a friend or acquaintance's first experience with a drug. Jackson advised individuals that he dealt to that he packed his pills with slightly more MDMA than the average dose (approximately 110mg instead of the standard 100mg), and he was careful to "let people know to be hesitant if they're quite small or they don't weigh much, " as he felt that it was important that people had a good time and stayed as safe as possible when taking MDMA that he had supplied. Most of Andrew's

\footnotetext{
${ }^{41} 25 \mathrm{x}-\mathrm{NBOMe}$ is the general form of the NBOMe series of phenethylamine class NPS that produce psychedelic effects ("25x-NBOMe", n.d.). In New Zealand, NBOMe series substances are Class B drugs (Misuse of Drugs Act, 1975).
} 
friends were experienced with drugs, so he did not feel that he needed to provide them with guidance, but he would give advice if asked. John provided harm reduction and dosage advice when dealing LSD tabs:

I sort offelt like it was my duty to make sure they were doing it safely and understanding what they were doing. [...] If it was a particularly strong tab, I'd say, "Maybe just do half a tab if it's your first time," and that kind of thing. [...] People were generally pretty responsive to that. - John, 19

Along with dosage advice, Adam gave harm reduction tips on managing bad psychedelic trips, and he also taught his customers about supplements that they could take to reduce the potentially harmful effects of MDMA. Another social supplier, Kyle, was also knowledgeable about supplements, and visited health stores to buy them. He made up packs for his friends to take before, during, and after MDMA use. The supplements that Kyle provided included vitamin C, alpha-lipoic acid, magnesium, and 5-hydroxytrytophan. He learnt about which supplements might be helpful by researching safer ways to take MDMA and visiting an MDMA education website called RollSafe, which provides harm reduction tips and sells supplement kits (RollSafe, n.d.). There is some evidence to suggest that pre and post-loading of supplements may be effective in reducing neurotoxicity and related harms from MDMA (Aguirre, Barrionuevo, Ramírez, Río \& Lasheras, 1999; Kelly, 2009; Sprague, Huang, Kanthasamy \& Nichols, 1994). Like others, when asked why he chose to provide supplements, Kyle's response demonstrated genuine concern for others and awareness about his potential liability for adverse outcomes:

Just for general safety. If I had access to it, then why not? [...] It's in your best interests to make sure everyone keeps safe as well. [...] There's a certain amount of liability if something ever happened to someone. It's better to keep people safe. - Kyle, 19

Eleven of the 12 participants engaged in some form of trading of the illicit drugs that they purchased from cryptomarkets. Trade arrangements included sharing, gifting, social supply, and supply for profit. A significant portion of drug trading fell under the category of social supply, with only Jackson, Adam, and Michael entering cryptomarket ordering with the explicit primary intention of drug dealing. Numerous participants drifted into social supply without intending to or provided drugs to friends and acquaintances on an ad hoc basis, echoing previous research from Murphy, Waldorf and Reinarman (1990) about the process of becoming a cocaine dealer. Actions and behaviours associated with supply contradicted popular 'pusher 
myths', with participants demonstrating care and concern for those to whom they supplied drugs. Several participants were aware of, and passionate about, harm reduction practices including safe dosage advice and use of harm-reducing supplements.

\section{Gentrification Hypothesis}

Researchers have presented various perspectives on the harm-reducing potential of drug cryptomarkets. As they currently represent a minuscule portion of overall drug trading and are mostly associated with the sale of drugs that have low harm potentials, Mounteney et al. (2017) and Sumnall (2017) assert that cryptomarkets are unlikely to make any substantial alteration to drug-related harms. However, Aldridge et al. (2017) note that cryptomarkets may reduce systemic violence, with their overall effect depending on the quality and safety of available drugs as cryptomarkets grow. Forming the basis of Martin's (2017a) gentrification hypothesis is the argument that cryptomarkets are only accessible to some drug users. Barriers to accessing cryptomarket drugs include the ability to plan drug purchases, technical competence, and disposable income. Such obstacles can impede cryptomarket access for those with vulnerabilities like PDU, poverty, and homelessness. For this reason, the rising popularity of cryptomarkets may intensify harm-related inequalities between vulnerable drug users and those who are more privileged (Martin, 2017a; Sumnall, 2017).

Four participants indicated that they were, or had previously been, problematic drug users. ${ }^{42}$ Only one of those participants, Sam, indicated that he was no longer using any drugs. James and Michael both continued to use drugs in more moderated ways, and Anon did not specify whether he had continued to use drugs. The remaining two-thirds of the sample did not identify themselves as problematic drug users. Additionally, all but one participant was male, all were under the age of 40 with most being in their late teens and early twenties, most described their ethnicity as some form of white, and all were very eloquent, technically competent, and had various levels of disposable income. In comparing the sample to Martin's (2017a) gentrification hypothesis, participants displayed few social or economic vulnerabilities aside from one-third indicating varying forms of PDU. As stated in Chapter 3, it is not possible to deduce whether the demographic makeup of the sample is representative of New Zealand cryptomarket users more generally, as the sample size is small, and recruitment was heavily centred on the university environment. However, three participants disclosed that they had purchased methamphetamine from cryptomarkets, and Broséus et al. (2017) and Cunliffe et al.

\footnotetext{
${ }^{42}$ Participants indicated PDU in various ways, including referring to themselves as 'addicts' or labelling their drug use as 'addiction'. Participant demographics are provided in Table 1, Chapter 3, p. 52).
} 
(2017) found a high volume of methamphetamine transactions between Australian cryptomarket vendors and consumers. This belies Barratt and Aldridge's (2016) assertion that recreational drugs with low harm potentials dominate cryptomarkets. Given the noted similarities between drug markets in Australia and New Zealand, it is possible that methamphetamine occupies a similarly prominent position in New Zealand cryptomarket trading. Further research in this area is needed, as it conceivable that the unique global positioning of New Zealand would influence which groups of New Zealanders use cryptomarkets, and the type of drugs that they access.

\section{Summary}

As is often the case with exploratory research, participants provided novel and unanticipated insights about their engagement with cryptomarkets. These insights included methods that they used to reduce the risk of detection and apprehension by authorities, and various forms of drug supply and trading. The insights and features discussed by participants often created more questions than they answered, emphasising the need for further research on how and why some drug users access cryptomarkets. Chapter 5 will compare participants' experiences of conventional drugs markets and drug cryptomarkets and analyse the factors that attracted participants towards cryptomarkets as a means of accessing the illicit drugs they desired. 


\title{
Chapter 5: Comparing the New Zealand domestic conventional illicit drug market with illicit drug cryptomarkets - Push and pull factors
}

\author{
[Comparing New Zealand street dealing to cryptomarkets is] like [comparing] apples to \\ oranges, eh. - Jackson, early twenties
}

Illicit drug cultures are surreptitious and can be difficult for researchers to access. Despite this, there is a rich history of ethnographic and qualitative research focusing on illicit drug markets and the cultures that surround them (Ritter, 2006). Early examples of such studies include Becker's (1953) seminal work on becoming a 'marihuana user', and Preble and Casey's (1969) investigation of New York heroin markets. More recently, Coomber and colleagues have undertaken substantial interview-based research with drug consumers and dealers, investigating matters such as organisation, social supply, adulteration, and pricing in drug markets (Coomber, 1997a, 2006, 2015; Coomber \& Maher, 2006; Moyle \& Coomber, 2015). In New Zealand, similar research has been relatively scarce but has focused on the experiences of users of club drugs (Hutton, 2010), BZP-party pills (Cohen \& Allison, 2015; Sheridan \& Butler, 2007, 2010) and methamphetamine (Sheridan, Butler \& Wheeler, 2009).

Within the realm of drug cryptomarket studies, qualitative interview-based research has explored conceptualisations of drug quality (Bancroft \& Scott Reid, 2016), satisfaction with anonymous online interactions (Bancroft \& Scott Reid, 2017), harm trajectories (Barratt, Lenton, Maddox \& Allen, 2016), the type and range of illicit drugs available to Australian cryptomarket users (van Buskirk, Roxburgh, Bruno, Naicker, Lenton, Sutherland, Whittaker, Sindicich, Matthews, Butler \& Burns, 2016), and consumer and vendor experiences more broadly (van Hout \& Bingham, 2013a, 2013b, 2014). Among others, Aldridge and DécaryHétu (2014) and van Hout and Bingham (2013a, 2013b, 2014) suggest that cryptomarkets have the potential to transform international illicit drug markets and associated harms. However, there have been no extensive attempts to make direct comparisons between conventional illicit drug markets and cryptomarkets.

Drawing on insights gained from participant interviews, Chapter 5 will compare participants' experiences of New Zealand's conventional drug market and drug cryptomarkets. Comparing participant experiences across the two is crucial in developing an understanding of how and why some New Zealanders choose to access drug cryptomarkets. This chapter will commence by discussing issues that participants raised in relation to the functioning of the domestic conventional illicit drug market, with attention paid to border security, access, quality, and 
price issues that arise from New Zealand's geographical positioning. Secondly, the chapter will examine the positive aspects of illicit drug cryptomarkets as described by participants. The negative elements of the domestic conventional market and the positive elements of drug cryptomarkets will be discussed as 'push' and 'pull' factors, respectively, that act to attract some New Zealanders to cryptomarkets. ${ }^{43}$ Following this discussion, Chapter 6 will explore the negative aspects of drug cryptomarkets, as reported by participants, as well as their perspectives on New Zealand's drug legislation.

\section{Push Factors: Constraints of the Conventional Illicit Drug Market in New Zealand}

International and country-specific data on illicit drug markets are incomplete. Economic analyses of illicit drug markets are difficult to undertake, as findings are often based on deductions about the structure and dynamics of illicit drug markets which are vulnerable to error. Difficulties are particularly associated with obtaining accurate data on price, quality, consumers, and dynamics of illicit drug use (Ritter, 2006). Research on supply-side and demand-side drug market economics has been undertaken internationally. ${ }^{44}$ Within New Zealand, similar research has been limited to a small number of studies on cannabis prices (Wilkins, Bhatta \& Casswell, 2002; Wilkins \& Casswell, 2003; Wilkins, Reilly, Pledger \& Casswell, 2005) and the prohibition of BZP-party pills (Wilkins, Sweetsur \& Parker, 2014). However, they do not provide insight into the social and cultural factors that influence New Zealand's conventional illicit drug market. Commenting on similar issues within the Australian context, Dwyer and Moore (2010) argue that "future studies of illicit drug markets require indepth qualitative and ethnographic data on the social, cultural, economic and political processes and contexts that produce and sustain drug markets" (p. 91).

As discussed in Chapter 2, Australia and New Zealand are somewhat aberrant within the international cryptomarket context. Australia is overrepresented in the number of vendors per capita, and Australians generate the largest revenue per vendor (Cunliffe et al., 2017; Kruithof et al., 2016; van Buskirk, Naicker, Roxburgh, Bruno \& Burns, 2016). A similar environment has been suggested in relation to New Zealand, with a logical explanation being that the scarcity

\footnotetext{
43 The concept of push and pull factors was introduced by Lee (1966) in his theory of migration. In human geography, push factors refer to the forces that 'push' an individual to leave the area in which they reside. Conversely, pull factors denote the forces that attract an individual to migrate to a destination. Though Lee's (1966) concept is generally applied within migration studies, it has also occasionally been utilised in social sciences and related disciplines (e.g., Vanwesenbeeck, 2013).

${ }^{44}$ For example, see Caulkins and Reuter (1998, 2006), and Reuter and Greenfield (2001). The UNODC also releases a yearly World Drug Report which provides extensive analysis of global drug markets (e.g., UNODC, 2018c).
} 
and expense of illicit drugs within the domestic conventional market encourages Australians and New Zealanders who use illicit drugs to access them via cryptomarkets (Ormsby, 2016; Phelps \& Watt, 2014). However, as Bakken et al. (2017) and Broséus et al. (2017) note, perceptions of the stringency of border security influence international vendors' shipping decisions. The perception of Australia and New Zealand as having rigorous border security may mean that international vendors are less inclined to ship to those countries because of concerns about parcel interception. Due to international vendors' hesitance to ship to Australia and New Zealand, there has been a proliferation of domestic vendors in both countries who can charge more than international vendors, with prices that are more aligned with the expensive domestic conventional market, and assurances that consumers can avoid the hurdles of border clearance (Ormsby, 2016). Australian and New Zealand-based cryptomarket vendors are unlikely to provide international shipping, as their primary customer base is domestic (Tzanetakis, 2018). The behaviour of cryptomarket consumers and vendors indicates that conventional illicit drug markets in Australia and New Zealand are constrained. Although some research has been undertaken on the choices of Australian drug cryptomarket consumers in relation to this positioning, little has been suggested about the constraints of the New Zealand domestic conventional market and its influence on New Zealand drug users. Border security, availability and quality, authenticity and purity, price, and market violence were raised by participants as factors which constrain New Zealand's domestic conventional market, reflecting similar findings from van Hout and Bingham (2013b) which were detailed in Chapter 2.

\section{Effective border security.}

Participants perceived the issues that they encountered in the domestic conventional market to be at least partially attributable to border security factors. New Zealand is a geographically isolated country which has a reputation for having stringent border security. Not only is New Zealand's border guarded by a 'wall of water', but it is also a significant distance from its closest neighbouring country, Australia, and is small in both area and population. ${ }^{45}$ Due to its geographical isolation and relatively recent history of human occupation, New Zealand is home to a large number of endemic flora and fauna species which have not evolved defences to foreign pests and disease (Ministry for Primary Industries, 2016). The high degree of endemism displayed by New Zealand's flora and fauna is reflected in their cultural significance,

\footnotetext{
${ }^{45}$ The most recent available census data measured New Zealand's population as 4,242,048 (Statistics New Zealand, 2013).
} 
particularly for Māori. As such, environmental protection features prominently in New Zealand's social and cultural norms. Sustaining New Zealand's environment is also an important factor in maintaining economic prosperity, as the economy relies heavily on primary industries such as agriculture, forestry, and fishing (Ministry of Business, Innovation and Employment, 2014).

Considering these factors, there is a strong emphasis on biosecurity, which can be defined as "the exclusion, eradication or management of pests and diseases that pose a risk to the economy, environment, cultural and social values" (Ministry for Primary Industries, 2016, p. 4). This is reflected in the Biosecurity Act (1993) and the prominence of biosecurity, biodiversity, and conservation in the 2018/19 Budget, with Customs commanding an operating budget of NZ\$230 million for 2018/19 (New Zealand Government, 2018; State Services Commission, 2018). It is further underscored by the popularity of Border Patrol, a reality television show which has spanned ten seasons and describes Customs, Immigration New Zealand, and the Ministry for Primary Industries as the "crucial layer of defence" between New Zealand and "drugs, illegal goods, biosecurity risks, and animal disease" (Peacocke, 2018). Participants were keenly aware of the significance of biosecurity in New Zealand:

We're so fucking far from everything. [laughs] [...] I feel like the hard part about getting [drugs into the country] is because we've put a lot of effort into our Customs because of [biosecurity]. ${ }^{46}$ [...] I think that's where a lot of it comes from, we just already have the systems in place [for biosecurity] so it's not too hard to [use those systems to intercept drugs]. - Lucidity, 19

They felt that the processes in place to protect biosecurity were also conveniently well-placed to intercept illicit drugs entering the country, with Adam and Andrew remarking that:

[New Zealand's conventional drug market is limited and expensive] because we are so isolated from the rest of the world and also because our Customs are so tight, it's very difficult to get any large amount of drugs through the borders. [...] Customs know what they're looking for and [drugs are] still very, very difficult to get through. - Adam, 20

New Zealand and Australia have some of the strictest Customs in the world, so it's so hard to get [drugs] into New Zealand. We're covered by sea every way. [...] All of the drug stuff comes through with [biosecurity]. [Customs are] looking for other things,

\footnotetext{
${ }^{46}$ Responsibility for biosecurity also falls on the Ministry for Primary Industries (“Our strategy”, n.d.).
} 
but if they find drugs and whatnot, they're going to pick it up a lot of the time, because of the other systems that are in place. - Andrew, 23

There are inherent difficulties in attempting to estimate the proportion of illicit drugs that Customs successfully intercepts compared to the quantity that pass through the border undetected, as the undetected quantity is a dark figure. Despite this, valuable information, albeit limited, can be gleaned from Customs publications. Customs report that in a 12-month period across 2017/18, they intercepted illicit drugs with a total street value of NZ\$345 million, compared with NZ\$329 million in 2016/17 (New Zealand Customs Service, 2017a, 2018). The perceived stringency of Customs was also reflected in some participants reporting that international vendors would sometimes refuse to ship to New Zealand because of the high likelihood of orders being intercepted. Adam said:

I did browse some of the international listings from time to time and quite a few of them said they would never, ever even ship to Australia or New Zealand because of the likeli[hood] of getting caught for the vendor and the buyer. Obviously, the overseas vendors were still very wary of the condition of the borders of Australia and New Zealand. - Adam, 20

Some vendors shipped to New Zealand, under the condition that refunds would not be provided for products that failed to arrive, therefore eliminating the profit loss that would occur if reimbursement was provided for undelivered parcels:

I definitely remember seeing 'New Zealand market [means] no refunds'. I think that's probably because our Customs must be stricter than other countries. - Jackson, early twenties

New Zealand society and culture has a palpable focus on biosecurity and environmental protection, as evidenced by the priority afforded to such issues in legislation, policy, and practice. The fact that New Zealand is "so fucking far from everything" and "covered by sea every way," has simultaneously fostered many endemic species which require protection from foreign pests and diseases and produced numerous practical hurdles to the importation of illicit drugs. Such measures, and whether New Zealand's border security mechanisms are more effective than those of comparable countries, are of limited practical value in this case, as there is a clear perception among participants that New Zealand border security is rigorous, and it is this perception, regardless of its accuracy, that influenced participants' behaviour. 
The perception that New Zealand is highly effective at intercepting illicit drugs had several implications for participants. Firstly, they partly attributed the constraints of the conventional illicit drug market to border security. Additionally, they reported that cryptomarket vendors were averse to sending orders to New Zealand due to the perceived risk of detection. Some vendors had separate policies for New Zealand consumers, sometimes requiring higher prices or refusing refunds for undelivered orders. These findings are largely consistent with the literature on Australian drug cryptomarket consumers, particularly in terms of the perceived risk of parcel interception, and the judgement of New Zealand as a futile shipping destination (Bakken et al., 2017; Broséus et al., 2017). Estimations of border security, and associated difficulties in the conventional market, pushed participants towards cryptomarkets. Yet, participants also felt that the reputation of New Zealand border security constrained their options as consumers within the cryptomarket environment, limiting the range of vendors that were willing to sell to them. Participants were pushed out of the domestic conventional market by the effects of border security, but they also struggled to find a niche within the risk-averse, profit-driven cryptomarket environment.

\section{Poor availability and quality.}

Participants associated their understanding of New Zealand's border security with the poor availability and quality of illicit drugs in the conventional market. Richard did not realise the full extent of New Zealand's illicit drug scarcity until he moved overseas:

Living in Germany, [the] Netherlands and now settling in the UK has helped me realise Kiwis (including myself) naivety to drugs and drug culture. [...] [New Zealanders are] skeptical [sic] of any drugs we'd buy outside of weed - because we just don't have the consistency and quality available in larger countries. - Richard, 30

Lucidity echoed Richard's statements, stating that living in New Zealand had made it difficult to explore his interest in illicit drugs:

I've always had, sort of, an interest in drugs, I guess, but it's not a very easy thing to explore in New Zealand. It's not like we have cocaine just rolling down the streets... Lucidity, 19

Although attempts to make direct comparisons between datasets are fraught with difficulty and should be regarded with caution, data from the UNODC (2018a) indicates that New Zealand has relatively low annual prevalence rates for use of illicit drugs such as cocaine compared to 
other countries such as the United Kingdom. A logical explanation for this is that illicit drugs are more difficult to access in New Zealand. Though it is now over a decade old (therefore predating the emergence of drug cryptomarkets), the 2007/08 New Zealand Alcohol and Drug Use Survey (NZADUS) reported lifetime prevalence of ecstasy consumption at $6.2 \%$, and lifetime prevalence of cocaine consumption at 3.6\% (Ministry of Health, 2010). ${ }^{47}$ Comparatively, the 2014-15 Crime Survey for England and Wales reported lifetime prevalence of consumption of ecstasy $(9.2 \%)$ and cocaine $(9.8 \%)$ at significantly higher rates (Home Office, 2015). ${ }^{48}$ Like New Zealand, the British Isles do not share land borders with other countries. However, they are close to countries in mainland Europe that are major producers and importers of illicit drugs, possibly explaining increased availability, and therefore, consumption, of illicit drugs in England and Wales (EMCDDA, 2018).

Participants were keenly aware of the difficulties that they experienced accessing illicit drugs through the domestic conventional market. These difficulties acted as a push factor, nudging them away from the domestic conventional market and attracting participants to drug cryptomarkets, which often offered the only means of accessing the illicit drugs that they desired. For example, the scarcity of MDMA within the conventional market led Kyle to order MDMA from a cryptomarket, and John found himself in a similar situation when he wanted to access LSD:

A friend and I wanted to get our hands on some LSD, we knew it would be hard to get in [city] and didn't feel like we could trust [city] dealers to provide itfor a decent price and that it wouldn't be tainted with anything dangerous. [...] The main benefit of the dark web here is to be able to order things from overseas [that you can't access in New Zealand]. [...] Particularly things like LSD are far harder to come across from street dealers than things like weed and such [in New Zealand]. - John, 19

John and several other participants commented that cannabis was far more readily available to them than other drugs in the domestic conventional market. The relative accessibility of cannabis in New Zealand is supported by the 2007/08 NZADUS which reported that cannabis was the most widely consumed illicit drug, with a lifetime prevalence of $46.4 \%$ and past-year prevalence of $14.6 \%$ (Ministry of Health, 2010). Cannabis consumption was slightly lower in the 2012/13 New Zealand Health Survey, which reported lifetime prevalence of $42.0 \%$ and

\footnotetext{
${ }^{47}$ Among those aged 16 to 64.

${ }^{48}$ Among those aged 16 to 59.
} 
past-year prevalence of $11.0 \%$ (Ministry of Health, 2015). ${ }^{49}$ Previous research has noted that the cultivation of illicit cannabis crops is widespread in numerous regions throughout New Zealand, underpinning the dominance of cannabis in the domestic illicit drug trade, presumably as it does not need to be imported (Wilkins \& Casswell, 2003).

Similar factors may explain the popularity of methamphetamine (sometimes referred to as ' $\mathrm{P}$ ') in New Zealand. The 2009 methamphetamine government action plan described methamphetamine as a "unique problem" in New Zealand (Department of the Prime Minister and Cabinet, 2009, p. 1). Numerous media reports have focused on the 'P scourge' ostensibly affecting some New Zealand communities in 'epidemic' proportions since the early 2000s (Bradley, 2018; Collins, 2016; Hunt \& Stewart, 2018). The high prevalence of past-year methamphetamine consumption (2.0\%) compared to international standards was attributed by the Department of the Prime Minister and Cabinet (2009) to New Zealand's geographical isolation and subsequent scarcity of other illicit drugs. Methamphetamine was characterised as the only domestically manufactured illicit stimulant, aided by the ready availability of pseudoephedrine, its pre-cursor substance (Department of the Prime Minister and Cabinet, 2009). Methamphetamine, therefore, may be a rational choice for New Zealanders who desire stimulants, but are unable to access alternatives in the domestic market, thus explaining its relatively high past-year prevalence. Michael, who purchased methamphetamine in the domestic conventional market as well as drug cryptomarkets, cited lack of local access to good quality MDMA as one of the factors that led to his heavy methamphetamine use:

It would have been started probably about seven years ago [when the quality of MDMA in New Zealand city] started to really start to turn to shit, and then you're still a drug taker and you like taking drugs so it's like, "Fuck, what else is there now? Oh well, [I'll take] crack. ${ }^{50}$ Yep, let's jump back on that again." - Michael, 36-37

In a similar vein to John's concern about not being able to find LSD "for a decent price" which "wouldn't be tainted with anything dangerous," Michael raised concerns about illicit drug quality. Participants linked drug inaccessibility with poor overall quality in the domestic conventional market. As noted by Bancroft and Scott Reid (2016), 'quality' in this context often referred to an illicit drug's perceived "reliability, purity, potency, and predictability of effect" (p. 42). Although he did not elaborate on what he felt caused the quality of domestic

\footnotetext{
${ }^{49}$ Among those aged over 15 .

${ }^{50}$ Not to be confused with crack cocaine, 'crack' is sometimes used in New Zealand as a slang term for methamphetamine.
} 
MDMA to "turn to shit," Michael echoed several other participants who voiced frustration and concern about poor accessibility and quality of the illicit drugs that they wanted to use. It is not possible to pinpoint New Zealand's geographical isolation and associated matters as causal factors in the access and quality issues reported by participants, but comparisons between New Zealand and the available international evidence suggest that such factors could plausibly influence New Zealand's domestic conventional illicit drug market, and further research in this area is sorely needed. Regardless of the actual causes of poor illicit drug access and quality, participants reported that access and quality constraints pushed them away from the domestic conventional market and towards cryptomarkets.

\section{Poor authenticity and purity.}

Intertwined with assessments of quality and its constituents were participants' understandings of illicit drug authenticity in New Zealand's conventional market. Numerous participants indicated that they considered inauthentic or 'fake' drugs to be an issue within the domestic market. Inauthentic drugs were presumably cheaper to produce and less risky to import, so subsequently had high availability:

I've heard all sorts of stories about people buying acid off a street dealer and it's someone who is stuck for money so they've cut up a cereal box and they're selling that. - John, 19

The stories that John had heard did not involve drug users being sold alternatives to LSD. Instead, they were sold squares of cardboard that did not contain any psychoactive substances at all. More serious issues arose when illicit drugs were substituted with less desirable alternative substances and subsequently passed off as authentic. Several participants reported that they, or mutual friends, had experienced this with LSD and MDMA:

[I knew] a mate's sister's friend who ended up getting [NBOMe] somehow when he was trying to get [LSD] tabs in New Zealand. [...] I've only had one experience of myself getting, from someone I didn't really know that well, an MD[MA] product off the street which wasn't [authentic] and [the dealer] didn't really know either, so they were kind of getting ripped off as well. It was just a cheaper version [of MDMA] which 
[has] more comedowns, different product. ${ }^{51}$ [...] I'm pretty sure it would be BKMDMA... which wasn't illegal in China so they used to produce quite a lot and then it just kind of became, through New Zealand, a cheaper alternative. ${ }^{52}$ Since it was kind of seen as a similar [drug], unless you really knew what you were taking, people wouldn't notice. But then also, the dosage for it is kind of a lot higher and it doesn't last as long, the effects aren't as strong, so that would generally lead to people taking more without waiting for it to come up [and take effect]. [...] I think it's got quite a bad comedown. I remember, personally, when I knew it was [BK-MDMA], I didn't give it to anyone or anything like that, just because I didn't feel it was worth it. - Kyle, 19

Synthetic alternatives to drugs such as LSD and MDMA enter the market because the those that they are attempting to emulate are inaccessible. There have been numerous media reports detailing the emergence of alternatives such as NBOMe and BK-MDMA in New Zealand over the past several years (Cooke, 2016; Ensor, 2016; "Five people hospitalised after using 'NBomb"”, 2015). Alongside the issue of drug inauthenticity is the parallel issue of adulterating, or 'cutting', drugs with other substances to reduce their production cost and enhance profits. Although beliefs about the ubiquity of drug adulteration are commonly held, Coomber and colleagues assert that the practice is less widespread than is popularly believed (Cole et al., 2011; Coomber, 1997a, 1997b, 2006; Coomber \& Maher, 2006). Authenticity concerns raised by participants are obviously anecdotal. Thus, it is impossible to definitively prove or disprove that their experiences involved counterfeit or adulterated drugs. The availability of research on illicit drug purity in the New Zealand market is poor (UNODC, 2018b). However, drug testing social enterprise KnowYourStuffNZ reported that of 445 drug samples that they tested over the summer of 2017 and 2018, 21\% were not what the consumer believed them to be ("Our results", n.d.).

As Kyle observed, in some cases, it is reasonable to assume that the dealer was acting in good faith and was unaware that they were selling (what the consumer perceived to be) an inauthentic product. Regardless, misunderstanding about the actual contents of a drug can have serious health consequences that sometimes prove fatal. For example, in recent years, adverse health

\footnotetext{
51 A 'comedown period' refers to the acute unpleasant adverse effects associated with drug withdrawal, particularly MDMA withdrawal. Adverse effects can include heightened emotions, irritability, involuntary facial movements, paranoia, and heart palpitations (Degenhardt, Bruno, \& Topp, 2010; McElrath \& O’Neill, 2011).

52 3,4-Methylenedioxy-N-methcathinone (also known as BK-MDMA or methylone) is a cathinone class entactogenic and stimulant ("Methylone", n.d.). It is not explicitly mentioned in the Misuse of Drugs Act (1975), but it is "substantially similar" to a Class B drug, methcathinone, and, therefore, falls under the Class C schedule.
} 
impacts have been particularly well-documented in relation to the NBOMe family (Andreasen et al., 2015; Kueppers \& Cooke, 2015; Morini et al., 2017), including publication of New Zealand-specific cases (Gee et al., 2016).

Similar issues arise when drugs are more potent than consumers anticipate. Individuals may inadvertently take an overdose if they are accustomed to being supplied with weaker substances and do not adjust the amount consumed when the potency of a substance increases (Aldridge et al., 2017). The emergence of 'super-strength' ecstasy pills, which contain three to four times the average dose of MDMA, have highlighted the issue of illicit drug potency in recent years (DrugScope, 2014; Power, 2015; Usher, 2017). Pill batches are sometimes linked to adverse effects and hospitalisations, as high doses of MDMA are associated with medical emergencies such as serotonin syndrome, and cardiac, kidney, and liver issues (Davies, English \& Grundlingh, 2018). Media reports have indicated that super-strength pills have been found in New Zealand (Stewart \& Hunt, 2018; Workman, 2018). These reports are supported by Jackson, who stated that his friends had negative experiences with high-dose ecstasy pills:

I mean, like with the blue Louis V's [strong ecstasy pills] that were going around, my friends had, like, a handful of those pills and it really fucked them up, eh. - Jackson, early twenties

Authenticity and purity concerns articulated by participants were complex and multi-faceted. Participants spoke of issues such as being supplied with counterfeit drugs that contained no psychoactive substances, the prevalence of synthetic drugs as undesirable alternatives to their inaccessible counterparts, drug adulteration, and inconsistencies in strength and purity. They were wary of authenticity and purity in New Zealand's conventional market, and the risk of adverse health outcomes that unknown authenticity and purity represented. Due to these issues, participants were 'turned off' by the prospect of accessing illicit drugs through the domestic conventional market.

\section{High price.}

Another factor pushing participants towards drug cryptomarkets was the high cost of drugs in the conventional market. Accessibility issues notwithstanding, the domestic drug market is expensive, both by international standards and when compared with cryptomarket prices. It is difficult to obtain accurate price figures for illicit drugs due to their underground trading, but the GDS provides some of the most rigorous available data on illicit drug prices 
internationally. ${ }^{53}$ According to the most recent GDS (2018) findings, New Zealand had the highest mean price for a single pill containing MDMA at $€ 20.40$ (approximately NZ\$34.00) compared with a global average of $€ 9.60$ (approximately NZ\$16.00). Additionally, New Zealand had the highest average price of one gram of cocaine at $€ 211.70$ (approximately NZ\$353.00), and had the fourth highest mean price for a single LSD tab at $€ 10.82$ (approximately NZ\$18.00) compared with the global average of $€ 8.14$ (approximately NZ\$13.60). ${ }^{54}$ The cost of illicit drugs in the domestic conventional market was at times prohibitive for participants, who were acutely aware that prices were exorbitant in comparison to international standards:

Ifeel like we're just stuck down here [in New Zealand] with what we've got, so people try to make it better by outsourcing. [...] People in New Zealand [order drugs from the darknet] because there's no other option, really. - Lucidity, 19

A simple tab of LSD would be $\$ 40$ on the street and it wouldn't be very potent, it wouldn't be very good quality, it might not even be real. However, you go on the darknet and a hundred tabs for a hundred dollars, and it's high, high, high quality, and it's cheap. It's high quality and it's cheap, and it's a much, much, much better product than anything you'd get off the bloke down the road in the house on the corner, you know? - Adam, 20

Even when interpreting the available price data with caution, there are indications that illicit drugs in the New Zealand conventional market are very expensive. Considering the fundamental economic laws of supply and demand, it is indisputable that the high price of illicit drugs in New Zealand is linked with their availability being outstripped by demand. Additional influences, including push factors such as stringent border security and geographical isolation, are likely to also contribute to the expensive domestic market, although it is not possible to disentangle each of these factors and isolate their effect on drug prices. Despite this ambiguity, high prices featured prominently in participant interviews, as a deterrent to engaging with the domestic conventional market, pushing them to seek an alternative in drug cryptomarkets.

\footnotetext{
${ }^{53}$ The GDS uses a purposive sample, not a representative one, so price data should be treated with caution. Only countries with 100 or more past year user respondents were included in the GDS (2018) international price analysis.

${ }^{54}$ Though the New Zealand illicit drug prices detailed in the GDS (2018) findings are significantly higher than the reported global averages, participants stated that they were paying even higher amounts than the average New Zealand prices reported in the GDS. For example, participants reported paying approximately NZ\$40 for an LSD tab, and NZ\$40-NZ\$50 for a cap (unpressed powder) containing 0.1 grams of MDMA.
} 


\section{Risk of violence.}

As discussed in Chapter 2, systemic violence is a well-documented phenomenon in illicit drug markets, occurring within the context of drug prohibition, as actors in the illicit drug trade cannot rely on the police to enforce order. Systemic violence consists of violence, intimidation, and threats that are instrumental in resolving disputes and maintaining the rules of engagement' within illicit drug markets (Goldstein, 1985). Systemic violence within the domestic conventional market was noted as a push factor by participants, some of whom had experienced violence, or threats of violence, or knew others who had. Jackson and Kyle recalled serious incidents of violence associated with the New Zealand illicit drug market. In Jackson's case, a mutual friend required hospitalisation for injuries sustained after a drug deal went sour:

I had some friends of my flatmates [who] were trying to buy some weed off some dude, and apparently he got dragged down the road by a car just recently, and ended up in the hospital. Like, that's always a possibility when you're meeting face-to-face with someone, in New Zealand especially, because I feel like a lot of drug dealing is done by gang members and things like that, although it's done a lot by just other people [too], but I definitely think there's a certain element of personal danger that could be inflicted. - Jackson, early twenties

Kyle recalled an incident where some acquaintances were robbed and threatened at gunpoint due to encroaching on the territory of a local gang:

Some people were dealing off a property that was quite close to a [well-known New Zealand motorcycle gang] headquarters, so they got a not-so-friendly visit from them kind of asking them to stop which also lost them a motorbike. [laughs] [...] I would say [they were] robbed at gunpoint, sort of. - Kyle, 19

Both Jackson and Kyle's accounts involved gangs. Academic literature has indicated that there is a significant presence of criminal gangs and other organised crime groups within New Zealand's conventional drug market (Wilkins \& Casswell, 2003). New Zealand is not unique in this regard, with parallel findings in other countries (Reuter, 1983; van Duyne \& Levi, 2005). However, in New Zealand there has been extensive media and political focus, and academic discussion on the involvement of ethnic and motorcycle gangs in the illicit drug trade in recent years, particularly in relation to the manufacture and supply of methamphetamine (e.g., Black, 2014; Department of the Prime Minister and Cabinet, 2009; Wilkins \& Casswell, 2003). It is 
possible that such media coverage has contributed to a fear of systemic violence perpetrated by gangs. John reported that purchasing cannabis from gang members was "quite scary":

When I first came to [city] last year, we were buying pot from a tinny house, which is fully gang-run and stuff, and it's like, that's quite scary to be dealing with gang members on a regular basis. - John, 19

Participants' experiences with, and perceptions of, systemic violence deterred them from accessing drugs through the domestic conventional market. Their perspectives and experiences were linked with perceptions about the involvement of criminal gangs. Several participants relayed experiences of physical violence and intimidation in the conventional market, and these incidents were push factors, prompting them to access drug cryptomarkets where they felt that the risk of violent victimisation was significantly lessened.

\section{Pull Factors: Positive Aspects of Illicit Drug Cryptomarkets for New Zealanders}

Accompanying the pull factors that deterred participants from accessing illicit drugs through the domestic conventional market, there were perceived benefits of drug cryptomarkets that 'pulled' participants towards using them to access the drugs that they desired. Low price, trustworthy rating and review systems, high quality, and the wide range of products, convenience and low chance of violence were cited by participants as advantages of drug cryptomarkets. The negative push factors that dissuaded them from the domestic conventional market combined with the favourable pull factors of drug cryptomarkets, influencing participants to purchase drugs through cryptomarkets.

\section{Low price.}

Many participants indicated that cryptomarket drugs were significantly cheaper than the conventional market. As discussed in the section on push factors, illicit drugs in New Zealand's conventional market command significantly higher prices than the international average, particularly in the case of MDMA, LSD, and cocaine, for which New Zealand has some of the highest average prices (GDS, 2018). The lure of cheaper prices on drug cryptomarkets was a significant temptation for participants, who compared the high cost of the domestic conventional market with the relative inexpense of drug cryptomarkets. This was particularly notable in the case of MDMA, which was widely used by participants: 
You could pay online, $\$ 40$, get a gram of really good molly and not have to see anyone [face-to-face], versus here you pay $\$ 40$, you might get half a point and it will be cut to shit with meth. You get what I mean? It's no contest for me. ${ }^{55}$ - Lucidity, 19

For many participants, the cheaper price of cryptomarket drugs was inseparable from their perceived superior quality. As discussed previously, participants' assessments of authenticity and purity in the domestic conventional market were generally poor, and this was partly attributed to the importation difficulties associated with New Zealand's geographical isolation and rigorous border security practices. Logically, increased quality and purity of illicit drugs would be associated with higher market prices. However, participants were pleasantly surprised to discover that shifting to cryptomarkets resulted in a decrease in price and an increase in quality, compared to substances that they had previously accessed through the domestic conventional market. For drug users in countries with a more bountiful domestic market, the price and quality offered by cryptomarkets may not be significantly superior to the domestic market and, therefore, may not act as a push factor. Lucidity summed this up:

We actually get decent drugs out of [ordering from cryptomarkets]. For [people in] other countries, it's better for you [to order drugs through the darknet in order] to avoid dealers or it's slightly cheaper maybe, [whereas] for us it's like ten percent of the [street] price and actually the drug [that is advertised]. - Lucidity, 19

Cryptomarkets are a relatively recent phenomenon in drug trading, representing a minute portion of all international illicit drug sales (Aldridge, 2012; Aldridge \& Décary-Hétu. 2016a; Bakken et al., 2017). Their long-term impact remains unclear, but participants were optimistic about the transformative potential of cryptomarkets in broadening New Zealand's conventional market in a manner consistent with their interests. Jackson stated:

I think [cryptomarkets] will, in the end, have a positive effect on the New Zealand drug market ... there'll be more drugs in the country at a cheaper price, and they'll be more available for everyone. - Jackson, early twenties

Though possibly not a significant influence in other countries, the relatively low prices offered by cryptomarket vendors were a pull factor for participants in the New Zealand context, and price discussions featured prominently in most interviews.

55 'Molly' is a slang term for MDMA. A 'point' is 0.1 grams of MDMA. 


\section{Trustworthy rating and review systems.}

Participants found that the overall quality of cryptomarket drugs was high, partly due to the review system that is built into marketplaces (Cox, 2016b; Tzanetakis et al., 2016; van Hout \& Bingham, 2014). Product ratings and reviews increase consumer confidence, allowing cryptomarket users to assess the quality and reliability of available listings, and make informed decisions about which products they wish to purchase and which vendors they wish to purchase from. Unlike in the conventional market, vendors are compelled to proactively establish and maintain positive reputations in order to succeed, as consumers choose not to purchase from vendors who have negative reputations or bad reviews. Participants were keenly aware of the self-regulating capacity of rating and review systems, with several comparing cryptomarkets to clearnet e-commerce sites that have similar in-built systems:

No one's going to buy [a drug] again unless it's good, and the whole market relies on it being good, so it kind of automatically in some ways regulates itself, to an extent. [...] It's just adding technology, the same type of technology that we get from Airbnb or Trade Me or whatever, to the black market. - Anon, middle-aged

Rating and review systems contributed to the perception of drugs sourced from cryptomarkets as trustworthy. Specifically, participants thought that cryptomarket drugs were more likely to be what they were advertised as. They also felt that vendors were motivated to respond to issues in a constructive and timely manner (e.g., replying to messages, providing refunds for lost orders) as they did not want to risk damage to their reputation that would result from negative feedback. Andrew appreciated that vendors provided detailed product descriptions on each listing, so he knew what to expect when ordering. Reviews left by previous consumers often compared their personal experience with the drugs that they had purchased to the claims made by the vendor in the product description, and participants reported that reviews were a significant aspect of the process of selecting which vendors to purchase from:

Probably the biggest part of the decision-making process is definitely just checking the reviews because there are good reviews and bad reviews as well, and there's loads of them, so it builds a certain sense of trust as well, knowing that people are actually buying this and placing feedback. - Jackson, early twenties

Vendors' businesses could fail if they did not act in accordance with the expected behaviour of the marketplace. Cryptomarket rating and review systems tip the consumer-vendor power dynamic in favour of consumers, so that they can exercise more control over their interactions 
with vendors than they would be able to in the conventional market setting. Participants were aware of the power that they had in leaving reviews and ratings. Kyle observed:

With the whole review system and stuff like that on the darknet, it's a lot easier to trust and people actually have a reason to not rip [their customers] off. [...] [Vendors] can easily get pretty much their whole business destroyed by that [if they rip people off]. Kyle, 19

Cryptomarket rating and review systems were a pull factor for participants and contributed to their understanding of cryptomarkets as a trustworthy and safe place to access drugs. Rating and review systems are self-regulating, as vendors who behave poorly or provide bad product fail to thrive in the cryptomarket arena. Vendors are, therefore, compelled to provide highquality goods and services to their customer base, and participants welcomed the predictability and quality that this afforded them.

\section{High quality.}

As was the case with push factors in the domestic conventional market, it is not possible to disentangle each individual pull factor and its unique influence on participants' behaviour. However, participants' satisfaction with the affordable nature of cryptomarkets was enhanced by their assessment that cryptomarket drugs were generally of a noticeably higher quality than those in the New Zealand conventional market. They also linked the apparent high quality of cryptomarket drugs to the regulatory capacity of rating and review systems, the trustworthiness of which is a separate pull factor in and of itself. Participants noted that the quality of cryptomarket LSD and MDMA was far superior to that of the domestic conventional market, which they reported was also expensive and often difficult to access. ${ }^{56}$ Descriptors of illicit drug quality were varied. Adam stated that he paid attention to the intensity and clarity of a drug, as well as how "dirty” it felt, while Kyle assessed the quality of cryptomarket-purchased LSD through the "cleanliness" of the high that it produced:

It was quite noticeably different just because of the fact that [the vendors] even labtested what percentage it was as well. [...] Just the cleanliness of the whole experience and stuff like that. [...] I think you find you feel more euphoric and it seems like it would be hard to have a bad time. - Kyle, 19

\footnotetext{
${ }^{56}$ Anecdotal reports of the costliness of LSD and MDMA in New Zealand's conventional market are supported by the findings of the GDS (2018).
} 
Kyle described high-quality MDMA as requiring a lower than average dose to achieve the desired effect. As well as this, high-quality MDMA lacked a 'comedown period'. He explained that the high-quality MDMA that he bought from cryptomarkets was "a smooth roll sort of thing, not like you're shaky or someone's jaw's chewing their face off. "'57 Similarly, Michael provided a detailed description of the methamphetamine that he obtained from a cryptomarket, saying that it was "fucking better than anything [he'd] had before." He went on to say:

The first time we got it, I'd already been up for about three or four days, and like, when you smoke [methamphetamine], after three or four days [of being on it] and you have a smoke, it doesn't give you a zing like it does when you've first woken up or whatever. We had [the cryptomarket methamphetamine] and that was it, it was just like, "Boof!" you know? It was just like it just hit you, and even after, like I said, we'd been up on it for three or four days already, and then we got that package and it was just like it just gave us a big kick, and it was just like, "Holy shit!” - Michael, 36-37

In addition to accounts of high-quality LSD, MDMA, and methamphetamine, several participants observed that cryptomarket-purchased cannabis was far superior to that available in the conventional market. They especially enjoyed being able to access various cannabis strains (sativa, indica, and hybrids) from cryptomarket vendors:

You can get brilliant [strains], like fucking Pineapple Express and stuff, and it's really nice and untreated, good quality, whereas here you don't know what sort of fly spray or anything is on it. - John, 19

Participants' accounts illustrated a stark difference between the quality of cryptomarket cannabis and that which was available through the domestic conventional market. These findings are fascinating because, as mentioned previously, there is a high rate of cannabis consumption and cultivation in New Zealand (Degenhardt et al., 2008; Ministry of Health, 2010, 2015; Wilkins \& Casswell, 2003). However, participants consistently characterised local cannabis as poor-quality, with high-quality cannabis only available to the select few who were 'in the know' and had the social capital and contacts required to obtain it. John even went as far as to say that, with standard domestic cannabis, “you don't even know what sort of fly spray or anything is on it." Despite its relatively wide availability in New Zealand, participants

\footnotetext{
${ }^{57}$ Kyle is referring to 'gurning' which describes acute "involuntary facial movements and muscle spasm," such as tooth grinding, cheek biting, and tongue and jaw motions that can result from MDMA consumption (Cant \& Cunliffe, 2017, p. e131).
} 
valued being able to access clearly-labelled cannabis strains and hybrids from cryptomarket vendors, as well as different forms of cannabis (e.g., oil, resin).

Previous research supports the popularity of cannabis on drug cryptomarkets, including among Australian consumers (Barratt \& Aldridge, 2016; Barratt, Ferris \& Winstock, 2016; Broséus et al., 2017). The popularity of cannabis is somewhat incongruous with other findings of cryptomarket consumers' caution when considering the risk of parcels being detected by authorities, as cannabis products are characterised by a potent and distinct aroma which may be difficult to conceal during transit. Considering this difficulty, and to get the best value for money with his orders, James opted to order cannabis seeds from a cryptomarket, which he then gave to an acquaintance to grow in a greenhouse. In exchange for using some of the greenhouse space, James gave a portion of the yield to his acquaintance to sell. This arrangement worked well for James, who described himself as a heavy cannabis smoker and 'addict', and he found that it was far cheaper for him to buy cannabis seeds from a cryptomarket than continually purchase bags of dried cannabis from a dealer. James' acquaintance was an experienced cannabis grower, and the seeds produced high-quality crops. He compared the quality of the greenhouse-grown cannabis to beer with a high alcohol content:

You know when you have a beer, and you can taste if it's a ten percent beer? [...] It's got stronger taste [...] There's lots of indicators, the stickiness of it, how crystally it looks. If it's shining when you turn it around in the light, it's probably good. [laughs] - James, 20

Parallel with high quality as a pull factor was the perception that cryptomarket drugs were safer than those obtained through the domestic conventional market. As detailed in the discussion of push factors, participants felt that illicit drugs in New Zealand's conventional market were of poor overall quality and authenticity, and this was linked to the subsequent assumption that they were unsafe. Counter to this, participants felt that cryptomarket drugs were likely to be safe because of the in-built rating and review systems. If drug safety is synonymous with drug purity, then the assumption that cryptomarket drugs are safer may be misguided. Recent research has had conflicting findings, and further research on cryptomarket drug purity is warranted. van der Gouwe et al. (2017) found no major differences in drug purity between online and offline samples that they analysed, while Caudevilla et al. (2016) found that most of the cryptomarket drug samples that they analysed were of high purity, and Rhumobarbe et al. (2016) reported that cryptomarket samples were generally consistent with the advertised 
substance, but the purity of drugs differed from the vendor's claims. Here, participants' conceptualisations of 'quality' and 'safety' cannot be easily distinguished from one another. As Kyle asserted, the high quality of cryptomarket drugs made them safer, because cryptomarkets have got:

... a better product, which keeps people safe as well. People aren't out there trying to get stuff that's going to get them real fucked up. [...] If there's whack stuff on the streets and there's good stuff on the darknet, you'd obviously choose to buy it from there.Kyle, 19

Safety, albeit a concept that is contestable and open to interpretation, is an important element of the high-quality goods and services that vendors are incentivised to provide to their customer base, due to the regulatory function of the rating and review systems. Consumers who felt that they had received unsafe drugs from vendors would leave negative reviews. Thus, vendors are compelled to provide drugs that meet community expectations of safety. ${ }^{58}$ In addition, cryptomarket trading is likely to appeal to drug dealers who can comply with the behavioural norms of the marketplace, are willing to provide high-quality drugs (of which safety is a factor), and for whom providing high-quality drugs is a point of pride. This echoes Kyle's statement that:

The connections [you need to have to be a successful cryptomarket vendor are] a bit more than your street dealer. [...] I'd generally just say it's kind of smarter people that are [cryptomarket vendors], with not as much intention to rip you off. - Kyle, 19

High quality was not only a substantial influence when purchasing easily-concealable drugs, such as LSD and MDMA, it remained a notable factor when participants recalled various forms of cannabis that they had purchased from cryptomarkets. In examining positive assessments of cryptomarket drug quality, it is necessary to simultaneously consider participants' experiences of sub-standard quality in the domestic conventional market. When both are evaluated, it is apparent that the push factor of poor domestic drug quality is inseparable from the pull factor of the superior quality of cryptomarket drugs. The finding that cryptomarket drugs were of high quality is consistent with previous research, as was the vocabulary that participants used to describe what the concept of 'quality' meant to them, with descriptions focusing on purity, potency, and "predictability of effect" (Bancroft \& Scott Reid, 2016, p. 42; Décary-Hétu \&

\footnotetext{
${ }^{58}$ How cryptomarket consumers conceptualise drug 'safety' and its constituents is not a specific focus of this research. Further enquiry in this area is warranted.
} 
Aldridge, 2016a). Although illicit drug quality has featured as a prominent element of cryptomarket research internationally, it is conceivable that high quality presented as a pull factor in participants' interviews to such a great degree because they felt the constraints of New Zealand's conventional market so intensely. Therefore, the superior quality offered by cryptomarkets was a stark contrast to the relatively poor quality of the domestic conventional market.

\section{Wide range, convenience, and low chance of violence.}

Further pull factors that were peripheral features of interviews included the wide range of illicit drugs that participants were able to access from cryptomarkets, along with convenience and low chance of violent victimisation. Regarding the range of drugs accessible through cryptomarkets, Adam said:

You get access to a very wide range on there. [...] Instead of going to multiple people that sell individual types of drugs, you can just go [to cryptomarkets]. It's like a onestop shop for anything and everything you would ever need. - Adam, 20

Participants reported that the range of illicit drugs available on cryptomarkets was far wider than the range in the domestic conventional market. This was also highlighted by the number of different substances that participants purchased from them (see Table 1, Chapter 3, p. 52 for details). For instance, Lucidity, who had very limited experience with illicit drugs before accessing cryptomarkets, reported buying 2C-E, alprazolam, cocaine, DOM, DMT, hydrocodone, ketamine, LSD, MDMA, and zopiclone from Dream Market. Adam, who had no experience with drugs prior to cryptomarkets, purchased 2C-B, 4-AcO-DMT, LSD, MDMA, and various 'obscure' psychedelics in the course of his engagement with AlphaBay. Furthermore, a few participants linked their cryptomarket orders with the onset of PDU or felt that their engagement with cryptomarkets was fuelled by their PDU. The range of drugs available on cryptomarkets allowed Sam to access heroin, a drug which he could not obtain in the domestic conventional market. Similarly, James, who considered himself a cannabis 'addict', bought cannabis seeds from a cryptomarket, because it was cheaper for him to grow his own plants than purchase large quantities of dried cannabis from local drug dealers:

You either smoke to live or you live to smoke, and I was the latter [...] It was just awful. It got to the point where my whole world and thinking was centred around getting more and using more, really. It was my only escape from reality and I abused the shit out of 
it. [...] I was just an addict looking for a cheap way to fuel my addiction, really. James, 20

As discussed previously, the poor availability of illicit drugs in the domestic conventional market was a push factor for participants. Considering the context of New Zealand's constrained conventional market, it is apparent that the range of drugs offered on cryptomarkets contributed to their allure for New Zealand drug users. Convenience was another minor pull factor. Ease of access was one facet of the convenience of cryptomarkets, as participants liked that they were able to access all the substances that they wanted in one location, rather than having to contact numerous drugs dealers with no guarantee that the substance that they were seeking would be available. Andrew said:

It's so easy. You don't need to, you know, text a bunch of people or try and sort something out, you just can do it at your own time and whatever time of the day. The ease, the price. [...] It would be weird going up to a stranger and asking them for drugs. - Andrew, 23

Participants could order from cryptomarkets whenever was convenient for them, bypassing the need to organise a time to meet with a local drug dealer. Secondly, the convenience of cryptomarkets extended to avoiding potentially awkward social interactions with drug dealers. John said that, combined with the reliability and high quality of cryptomarket drugs, he appreciated that:

...you avoid having to deal with potentially violent or awkward-slash-annoying drug dealers, it's convenient, you do everything from your laptop in your house and you don't have to be running around trying to message people and walking up to wherever you have to go. - John, 19

Social interactions involved in face-to-face drug purchases have the potential to be awkward. The awkwardness and uncertainty of these interactions are exacerbated when purchasing drugs from an individual with whom the consumer is unacquainted, as both parties 'size each other up' and assess the potential for violent victimisation or apprehension by the police. Participants discussed the discomfort that they felt when purchasing drugs face-to-face in the domestic conventional market as a push factor. This was especially evident in the context of tinny houses and gang-controlled operations, with John reporting that he found it "quite scary to be dealing with gang members on a regular basis, " and Kyle retelling an incident where an acquaintance was robbed at gunpoint by members of a local motorcycle gang. Understandably, the lack of 
physical contact between cryptomarket vendors and consumers, and the subsequently reduced risk of systemic violence, was a pull factor for participants, regardless of their personal experience with violent victimisation in the domestic conventional market.

There was a perception among participants that the worst possible outcome in cryptomarket consumer-vendor interactions would be "los[ing] out on some money if you come across a dodgy dealer," as Richard contended, but that "you will never likely lose your life or come out with a bruised or broken body. " Low opportunity for physical violence has been a prominent feature of academic discussions about cryptomarkets' harm reduction potential (Aldridge et al., 2018; Aldridge \& Décary-Hétu, 2014, 2016a; Bakken et al., 2017; Buxton \& Bingham, 2015; Martin, 2014, 2017a; Moeller et al., 2017; Tzanetakis et al., 2016). Also featured in academic scholarship has been the wide range of drugs (Aldridge et al., 2017; Aldridge \& Décary-Hétu, 2014, 2016a), and convenience offered by cryptomarkets (Ormsby, 2016; van Hout \& Bingham, 2013b). Although these issues were secondary to the major pull factors discussed in interviews, they remain an important aspect of the attraction of cryptomarkets for participants.

\section{Summary}

This chapter identified push factors in the domestic conventional market and pull factors associated with drug cryptomarkets, as told by participants. Participants expressed frustration with what they perceived to be a constrained conventional drug market in New Zealand. They found that border security and New Zealand's geographical positioning contributed to poor drug availability, quality, authenticity, and purity. These issues resulted in high domestic drug prices compared to international averages. In addition, several participants expressed that they were fearful of violent victimisation when purchasing drugs face-to-face, with Kyle and Jackson retelling stories of friends and acquaintances who had previously experienced violence in the domestic conventional market. Regarding the pull factors of drug cryptomarkets, participants discussed low price, trustworthy rating and review systems, and high quality. More peripherally, wide range, convenience, and low chance of violence contributed to their attraction. Push and pull factors were intertwined. Due to this, they should not be considered in isolation from one another. Additionally, many individual push and pull factors were overlapping. For example, participants' assessments of drug 'quality' often included other elements like authenticity and purity. It is difficult to disentangle and isolate the pushing and pulling effects of each individual factor. Nevertheless, the findings are compelling, revealing participants' dissatisfaction with the constraints of New Zealand's conventional illicit drug market, and the relative luxuries of drug cryptomarkets. 
Chapter 6 will explore the issues related to drug cryptomarkets further by examining participants' perceptions of the negative aspects of purchasing from them, including the paper trail, time commitment, and perspectives on the law and criminal charges that can result from cryptomarket-related drug importation. 


\title{
Chapter 6: Out of the fire and into the frying pan - Negative aspects of cryptomarkets
}

\author{
I suppose there's a bit more of a trail if things turn to custard... - Michael, 36-37
}

Low price, trustworthy rating and review systems, high quality, wide range, convenience, and low risk of violence were discussed in Chapter 5 as pull factors which contributed to the attraction of drug cryptomarkets. However, participants' experiences with drug cryptomarkets were not all positive. Although cryptomarkets were a welcome alternative to the frustrations of the domestic conventional market, participants discussed their negative aspects, along with personal experiences and anecdotes of cryptomarket drug purchases that had gone sour.

Academic research has largely focused on the positive, transformative elements of cryptomarkets, assessing whether they are likely to result in a net reduction in drug-related harms (e.g., Aldridge et al., 2017; Mounteney et al., 2017; Sumnall, 2017). The significance of harm-reducing features of cryptomarkets should not be understated, as research has suggested that cryptomarkets potentially lessen the possibility of coercion, violence, and arrest, when compared to conventional illicit drug markets, and may also promote the circulation of harm reduction information (Aldridge \& Décary-Hétu, 2014; Buxton \& Bingham, 2015; Lavorgna, 2016). However, less attention has been afforded to consumers' viewpoints on specific cryptomarket harms. This chapter will attempt to respond to this gap in the literature by discussing participants' accounts of the negative features of cryptomarkets.

\section{Paper Trail}

Detection by authorities was a key feature of participants' concerns about cryptomarkets. As noted in Chapter 2, the anonymising technology that facilitates the establishment and maintenance of cryptomarkets is a significant stumbling block for enforcement operations (UNODC, 2013). Intervention and detection efforts typically focus on conventional investigation techniques (e.g., surveillance and undercover operations), postal detection and interception, online detection and data analysis, and online disruption of cryptomarket communities (EMCDDA, 2017; Kruithof et al., 2016; Lewman, 2016; Pompidou Group, 2013; van Slobbe, 2016). Such techniques represent a departure from traditional efforts to dismantle illicit drug markets, which have typically focused on retail-level drug supply (Martin, 2014). Reliance on postal services is considered the riskiest aspect of the cryptomarket drug supply chain, as it is the only step which occurs outside of the virtual realm. International shipping is considered especially risky, because of the potential for parcels to be intercepted at the border 
(Aldridge \& Askew, 2017; Décary-Hétu et al., 2016). Despite the best attempts of border authorities, however, illicit drug parcels can be characterised as 'needles in a haystack', due to the massive volume of mail that crosses international borders every day (Martin, 2014). Additionally, cryptomarket vendors and consumers alike are aware of authorities' efforts to intercept parcels, and they demonstrate proficiency in concealment methods (Aldridge \& Askew, 2017). Even when parcels are successfully intercepted, authorities are tasked with identifying the intended recipient, and this can prove difficult because savvy consumers use aliases and alternative addresses for delivery.

Encryption and anonymity pose obvious difficulties for enforcement operations. Despite this, operations have had some success, evident in manoeuvres such as Operation Onymous and, within New Zealand, Operation Tiger and Operation Garden (Afilipoaie \& Shortis, 2015; New Zealand Police, 2017, 2018). However, it has been suggested that such operations may have had unintended effects, as cryptomarkets have consistently demonstrated resilience to attacks, evolving in response (Décary-Hétu \& Giommoni, 2017; EMCDDA, 2017; van Buskirk et al., 2017). Additionally, the media attention surrounding enforcement operations may increase public awareness of, and engagement with, cryptomarkets (van Buskirk et al., 2014). Participants were aware of authorities' focus on cryptomarkets, and their concerns about detection were exacerbated by the fact that there is, understandably, little publicly available information regarding the methods that have been used in previous efforts to intercept parcels, and infiltrate and bring down vendors and markets. Some participants felt that, for casual recreational drug users, cryptomarket orders were riskier than buying from a conventional dealer due to the strength of incriminating evidence potentially available to authorities. If sensible operational security, anonymity, and encryption processes are not adhered to, then the volume of available evidence is significantly higher than that which results from a discrete drug transaction in the conventional market. Kyle captured this by saying:

The easier side of a street deal is that unless the police catch you in the act or something, there's no transaction history, there's no link to anything [such as] if you've bought Bitcoin - there's no links back. If you've done [cryptomarket ordering] on your laptop, then that can be kind of traced as well, to a point. [A street dealer] doesn't have your address. [...] And generally, if you're buying from a street dealer, even if [the police] had texts and stuff [for you] as well, they probably have to catch you in the act or be surveying you to get a real conviction on you. - Kyle, 19 
Obviously, possession charges could be laid if illicit drugs were found on an individual or their property regardless of whether they were obtained through a cryptomarket or the domestic conventional market, but the drawn-out nature of waiting for cryptomarket orders was extremely anxiety-inducing for some participants. This was compounded by the quantity of evidence that police could obtain. For example, John commented that if he was to be apprehended, police would be able to see evidence of "a paper trail, because we were transferring each other quite large amounts of money." As well as this, authorities may be able to obtain evidence of Tor access, cryptocurrency purchases, transactions, and seized parcels linked to an individual's legal identity if proper precautions were not taken. Anxiety surrounding authorities' activities was exacerbated by not knowing exactly what information they could or could not glean, or whether their online activities would even be of interest to authorities. John said:

[A guy I knew who was selling cannabis] handled things in cash, he'd get on his motorbike [to] go and meet up with a grower [and] buy ounces off him. [...] [For him, there was] almost no paper trail. Whereas with us, even though we were very careful, it would be unavoidable to have no paper trail, because it's all online. - John, 19

Internationally and in New Zealand, police operations to quell cryptomarkets and associated drug trading have garnered significant media attention. Academics have suggested that the high-profile nature of such operations may increase the popularity of cryptomarkets as a method of accessing illicit drugs (van Buskirk et al., 2014). However, participants also reported that the media attention afforded to police operations contributed to their anxiety about the elements of operations that were unknown to them. Understandably, there is significant secrecy surrounding how authorities have gained access to cryptomarkets in the past. Participants were aware that cryptomarkets were a focus of anti-drug operations, but they were uncertain how much information authorities were able to access, and what level of interest they would take in their individual, relatively small-scale cryptomarket drug orders.

\section{Time}

The time taken for orders to arrive contributed to participants' anxieties about paper trails that could be accessed by authorities. The period between ordering and receiving drugs was especially drawn-out for participants who ordered from overseas vendors and had to wait for lengthy international transit. Jackson described the waiting period between placing orders and their arrival as "the most stressful times in [his] life" because: 
The feeling of knowing that someone could knock your door in, or if you get caught with it on you in town or whatever, then that could be it, that could be all over, seven years in jail or something ridiculous like that, [you] can never leave the country again [because of a criminal conviction]. - Jackson, early twenties

At the time of his interview, Jackson had recently re-evaluated the risk that he was taking by ordering drugs from cryptomarkets. He felt that it was no longer worth the risk of a criminal conviction, as he had been offered a career opportunity that he did not want to jeopardise. For Jackson, other time-consuming aspects of cryptomarket ordering included having to check his drop-site regularly to see if orders had been delivered. Although he disliked the uncertainty of waiting for an order to arrive, upon reflection, Jackson noted that buying drugs in the domestic conventional market would not be any more favourable because "you don't know if it's going to be the right product as well." He recalled an incident that was "pretty intense to see" where a friend ordered drugs from a cryptomarket and experienced severe anxiety due to the fear of apprehension:

Pressures from the fear of being caught importing drugs through the darknet [have] driven one of my close friends to extreme anxiety, not wanting to leave the house, not being able to sleep at night, substance abuse as a result, because they had a close call and then were just terrified that the government was watching his phone and all these different things. - Jackson, early twenties

Though an extreme example, the unease and paranoia experienced by Jackson's friend demonstrates concerns about leaving a paper trail, time, and apprehension by authorities. Another participant, John was living in a hall of residence during the time that he bought LSD and MDMA from cryptomarkets and sold it to friends and acquaintances. ${ }^{59}$ As there were hundreds of students living in the hall of residence, mail that was delivered to the hall would be sorted by staff who would then send an email to each student that had received a letter or parcel so that they could collect it from the main office. Due to this system of receiving mail, John had to provide his legal name on the delivery information to ensure that staff notified him when mail arrived. Combined with the waiting period, providing his legal name on cryptomarket orders proved to be a significant source of anxiety for John and the friend who he made orders with:

\footnotetext{
${ }^{59}$ Halls of residence provide accommodation for first-year university students who have moved from other regions.
} 
There's the waiting period of "Any day now I'm either going to get an email that I've got the package [awaiting collection] or I'm going to have the police knocking on my door, " and it's quite unnerving to be in that situation, so it's nice to avoid that [by purchasing drugs face-to-face]. [...] [A downside of ordering from cryptomarkets is] the paper trail because [of] all of your transactions [...] the paranoia, the extended sort of period of arrival... - John, 19

When parcels were delayed in transit, it created additional stress, as participants wondered if their orders were going to arrive at all, or if they had been intercepted at the border. One of James' orders took about two months to arrive. He also had to wait for the cannabis to grow and be harvested, which was a long process:

It's a lot slower [than buying cannabis from a dealer in the domestic conventional market]. [laughs] You're literally watching grass grow. - James, 20

Keeping up-to-date with cryptomarket issues was time-consuming, as was developing the knowledge required to make cryptomarket orders successfully. Alice articulated this difficulty by saying:

It 's just annoying and you have to constantly keep updated with who's shut down who's tracked who's moved and finding reliable sellers. Like it's far from ideal from a consumer perspective. You also have to know the basics of cryptocurrency in order to actually trade and then your product may just not show up. - Alice, 25

In various ways, time was associated with anxiety for participants. Waiting for orders to arrive was stressful. Some participants were nervous that orders had been intercepted, and that authorities would be able to link their orders with their legal identities. Two participants, Jackson and John, discussed their anxieties at length. Jackson described waiting for orders to arrive as among the most stressful times in his life, and due to his living situation, John had to provide his legal name on his orders. The stress of waiting for orders to arrive was linked with the paper trail that participants noted was also a consequence of cryptomarket ordering, as they were concerned that authorities may be able to access evidence of their orders to use for criminal proceedings. Additionally, learning how to access cryptomarkets and order from them safely was time-consuming, as was keeping abreast of cryptomarket developments, specifically which markets and vendors were considered reliable. 


\section{Perspectives on the Law and Criminal Charges}

Participants voiced many concerns that tied back, either directly or indirectly, to the illegality of their activities. Section 6(1) of the Misuse of Drugs Act (1975) sets out the provisions for 'dealing' offences. These include importing and exporting, producing and manufacturing, supplying and administering, offering to supply or administer, selling and offering to sell, and possession with intent to supply or sell. Specifically, Section 6(1)(a) states that no person shall "import into or export from New Zealand any controlled drug." The penalties, set out in Section 6(2) and 6(2)(a) are severe, with life imprisonment for offences relating to Class A drugs, imprisonment not exceeding 14 years for Class B drugs, and imprisonment not exceeding eight years for controlled substances other than Class A or B. Additionally, the penalties for conspiring to commit a Section 6(1) offence include imprisonment not exceeding 14 years for Class A drugs, imprisonment not exceeding ten years for Class B drugs, and imprisonment not exceeding seven years for controlled substances other than Class A or B (Misuse of Drugs Act, 1975).

Of significance for cryptomarket cases, the provisions of Section 6(1) result in drug importation carrying the same penalties as production, manufacture, and supply offences, even if the drugs are intended for personal use only. ${ }^{60}$ By contrast, Section 7(1) of the Act sets out regulations relating to the possession and use of controlled drugs, for which the penalties are notably less severe. Under Section 7(1), it is an offence to possess or consume any controlled drug, and also to supply, administer, or offer to supply or administer, any Class $\mathrm{C}$ drug to another person. The penalties, recorded in Section 7(2), include imprisonment not exceeding six months, or a fine not exceeding NZ\$1000, or both, for Class A drugs, and imprisonment not exceeding three months, or a fine not exceeding NZ\$500, or both, for drugs other than Class A. Additionally, Section 7(1) offences carry a presumption against custodial sentences for Class C possession and use offences, unless indicated by previous criminal convictions or exceptional circumstances (Misuse of Drugs Act, 1975). The penalties for possession and consumption offences are significantly more lenient than those for Section 6(1) offences. Consequently, individuals who are apprehended for ordering drugs from international cryptomarket vendors face much severer consequences than would normally result from regular possession charges.

\footnotetext{
${ }^{60}$ Further, the decision in Arthur $v R$ [2005] NZCA 51 warned at [27] that manufacture or import of Class A drugs is likely to incur significantly higher sentences than straightforward supply cases, because "they are responsible for actually bringing the illegal substance into existence or into the jurisdiction."
} 
Participants were knowledgeable about New Zealand's drug legislation. One participant, Lucidity, who was also a drug dealer, kept a printed copy of the Act to refer to if he needed. Participants were aware of the severe penalties associated with importation, which they understandably perceived to be one of the negative aspects of accessing illicit drugs through cryptomarkets:

[A negative aspect of accessing drugs through cryptomarkets would include] the higher value of [criminal] charges, I suppose. - Michael, 36-37

James described the dealing penalties under the Misuse of Drugs Act (1975) as "mental compared to [those for] just personal use," and John decided to stop ordering from international cryptomarket vendors once he learnt about the penalties for importation offences, as he felt that he would be "fully fucked" if caught by the police:

I suddenly caught myself and was like, I didn't realise quite how illegal what I was doing was, and I looked on the New Zealand Police website and saw prison sentences for importing and selling Class A drugs. [...] If it were to go slightly wrong, I'd be fully fucked. - John, 19

Several other participants also chose to purchase only from New Zealand-based cryptomarket vendors instead of international vendors, due to anxieties about the risks associated with drug importation, and there was an overwhelming sense that the Act was not fit to respond to cryptomarket cases. The Misuse of Drugs Act (1975) is now over 40 years old. It was ostensibly intended to reduce the harms associated with drugs by creating "a framework for controlling the use of drugs with a potential to cause dependency and harm" (Law Commission, 2011, p. 87). However, Law Commission (2011) recommendations to make the Act more felicitous, including moving away from a punitive approach to low-level drug offending, and providing a presumption against imprisonment for social dealing, have not been implemented. Other issues with the Act aside, the appropriateness of using Section 6(1) offences and their corresponding penalties to respond to cryptomarket drug orders should be investigated further. Of course, cryptomarkets and the technological developments that accompany them could not have been foreseen at the time that the legislation was passed. Consequently, the type of import and export cases Section 6(1) was intended to respond to at the time that the legislation passed should be explored, as well as whether Section 6(1) is excessively punitive, and if alternative actions would be more suitable for cryptomarket cases. It appears that judges may recognise that Section 6(1) is ill-suited to drug importation resulting from cryptomarket purchases. Lucidity 
had convictions relating to his cryptomarket orders for importation with intent to supply, possession with intent to supply, and cultivation of cannabis. He reported that the judge presiding over his case said that Section 6(1) offences were not intended to respond to cryptomarket activities:

The average person just going on [cryptomarkets] to get a bit of MDMA for them to try with their friends [wouldn't know about Section 6(1)]. Like, I didn't think about importation and things when I first went on [cryptomarkets], I don't think it's a prevalent thing, I just think [about] if it will arrive and if something goes wrong, "Oh no, [it will be a charge of] possession of whatever, "you don't think [about] importation as a separate thing. But, tied into that, judges do realise this. My judge said in the court case, "That law's not really meant for you, it's meant for [other offenders]. " [...] They weren't able to pre-empt anything like [cryptomarkets when the law was passed]. [laughs] [Section 6(1)] is made for your millionaire from South America shipping freighters of cocaine, not for a teenager with some money. - Lucidity, 19

Participants' openly expressed dissatisfaction with the possibility of receiving serious criminal convictions for what they perceived to be low-level drug involvement for personal use and social supply. Lucidity went as far as to say that:

In my opinion, the greatest harm I've experienced is [due to] the law. - Lucidity, 19

The severity of possible criminal charges was a clear negative aspect of cryptomarkets and an emotive issue for participants. Some also expressed concerns about international authorities having access to their information:

If a marketplace does get taken over by the authorities, the people who have access to your details are very powerful people. Here, if you get busted it's going to be by local Wellington police, on the darknet it's going to be, like, the FBI or some shit. You don't want to have to deal with the FBI having your name and address. - John, 19

John distinguished between being apprehended in the domestic conventional market, which would involve being 'busted' by "local Wellington police" and detection resulting from a cryptomarket seizure which could lead to apprehension by “very powerful people." Whether it is conceivable that highly powerful international authorities would have access to, or be interested in, the identities of relatively low-level cryptomarket drug consumers aside, scrutiny from international authorities was a concern that participants revealed, albeit one that was 
peripheral to their fears about domestic authorities. Section 6(1) offences and their penalties were distressing for participants, who felt that they were disproportionate to the actual harm of cryptomarket orders. Considering the severity of importation penalties, several participants selected to only purchase drugs from New Zealand-based cryptomarket vendors.

Diverse perspectives on drug legislation were expressed in interviews. Most participants indicated their support for drug decriminalisation, particularly decriminalisation of cannabis for personal use. Cannabis law reform is currently a highly topical issue in New Zealand, as in 2018, the government announced a 2020 binding referendum on the legalisation of recreational cannabis (Wallis \& Cheng, 2018). Participants showed awareness of arguments in favour of cannabis law reform. Kyle said that he felt that there was "no real need" to criminalise cannabis because "the police don't really enforce it that well," indicating his knowledge of the sharp decline in arrests, prosecutions and convictions related to cannabis use that has occurred in New Zealand since the early 1990s (Wilkins \& Sweetsur, 2012). He went on to advocate for decriminalisation or legalisation of most drugs, stating that government-regulated drug production would "take away a lot of risks."

There was a strong sentiment among participants that laws should be utilised to reduce the harm associated with drugs, not to punish drug users. Support for harm reduction policies was especially evident regarding PDU. Although he acknowledged that drug use in moderation was not a sensible option for him personally, James recognised that punitive criminal justice responses to PDU were unhelpful:

If someone's a smackhead, we shouldn't be smacking them on the head and throwing them in prison. They should go to rehab, you know? - James, 20

Lucidity disclosed that he felt that "the greatest harm [he had] experienced" was due to his convictions, not his drug use or dealing itself, and Adam and Richard both expressed support for decriminalisation of all drugs, citing ideals of freedom and non-interference by the state. Additionally, Richard also drew on the wider issues of the war on drugs "fuel[ling] wars, corruption, racism, and disease."

Numerous participants raised issues with the classification of drugs under the Misuse of Drugs Act (1975). According to Section 3A of the Act, Class A substances ostensibly "pose a very high risk of harm" to individuals and society. Classification of substances under the Act was a source of frustration for some participants, who felt that classifications were often incongruous 
with potential individual and social harm, particularly in the case of LSD, MDMA, and psilocybin. Jackson said:

I think it's outrageous, the fact that magic mushrooms are a Class A substance, like those are supposed to be substances that put your body at serious risk. [...] I think there's a lot of negative impacts being created by the illegal nature of these substances that would otherwise be negated if these were legalised. - Jackson, early twenties

John commented on the classification of LSD as a Class A drug:

While I've used both LSD and MDMA, I would be far more wary about MDMA than I am about LSD. It's possible to overdose on MDMA. If you were to get drunk and be like, "Fuck it, I'm going to rail a whole gram," that could kill you. That's not going to happen with LSD. Why is [MDMA] Class B while [LSD is Class A]? Why do Ifeel more sketchy and more guilty buying and selling MDMA than I do LSD, like in myself? Whereas in the eyes of the police and the government, LSD is far worse. [...] It would probably be far-fetched to say that [I support] the legalisation of LSD and things, but I definitely think it's ridiculous that it's put on the same level as things like meth[amphetamine] and heroin. - John, 19

Participants are not alone in highlighting the inconsistent, and often illogical, nature of drug classification. Nutt, King, Saulsbury and Blakemore (2007) assessed the potential for individual and social harms under the United Kingdom's Misuse of Drugs Act (1971), upon which New Zealand's legislation is based. They found drug classification was highly inconsistent with potential harm. Alcohol, a legal substance, was assessed as one of the most harmful drugs, and Class A drugs ecstasy and LSD were found to have relatively low harm potential, underscoring that drug classifications are not grounded in scientific evidence (Nutt et al., 2007). Additionally, participants viewed the use of Section 6(1) charges to respond to drug importation from cryptomarkets as highly inappropriate. Lucidity felt that Section 6(1) provisions were "fucked":

Supply is the same as importation in terms of sentencing, so if I imported 1.2 [grams] of MDMA to do myself, that's [considered to be] importation which [carries a maximum sentence of] 14 years. - Lucidity, 19

During criminal proceedings, the judge that presided over Lucidity's case recognised that Section 6(1) importation charges were "not really meant for [him]," with Lucidity arguing that 
importation charges are intended for "your millionaire from South America shipping freighters of cocaine." The Misuse of Drugs Act (1975) is now over 40 years old. Cryptomarkets were clearly not features of the drug trading landscape during the 1970s. However, ample suggestions have been made to improve the legislation, with little action (Law Commission, 2011). Andrew described the Act as:

....so old and outdated that the research wasn't done back then, and they're still going with those laws. - Andrew, 23

Participants prioritised education and experimentation. They sought to understand and form their own opinions rather than blindly accept messaging that drug use is unequivocally bad. Richard described drug legislation as "arbitrary," pointing out the double standard between illicit drug use and the use of legal substances such as alcohol, caffeine, and tobacco:

...if anyone believes [that] the things we call drugs today are fairly deemed illegal whilst drinking alcohol, coffee, smoking cigarettes - they should really try [to] compare and determine the differences of why something like marijuana or MDMA is illegal, while alcohol and tobacco are legal, glamourised and encouraged. - Richard, 30

Along those lines, the importance of education and harm reduction was on par with law reform. Participants valued access to non-moralising, non-judgemental, and unbiased drug information, instead of being "fed bullshit from an authority about what [drugs do]," as Adam put it. They felt that it was necessary for harm reduction and drug education information to be widely accessible, instead of being available only to those who actively sought it out. These sentiments provide backing for the extension of cryptomarket-specific harm reduction practices, particularly drug testing. If harm reduction information and practices were more widely available, they could influence cryptomarkets' impact on the transformation of drug-related harms (Martin, 2017a; Mounteney et al., 2017; Sumnall, 2017).

\section{Summary}

Existing cryptomarket research has framed the negative consequences of cryptomarkets in relation to possible harms and harm reduction. Although academic scholarship on the topic of drug cryptomarkets is still in its infancy, little attention has been paid to cryptomarket users' experiences of problems with cryptomarkets. This chapter has started to address this gap in the literature by exploring participants' perceptions of the negative aspects of cryptomarkets. Participants regarded paper trails, time, and criminal charges as notable downsides. 
Discussions of the downsides of cryptomarkets paled in comparison to the benefits that participants discussed in interviews, though they expressed some obvious anxieties. This was particularly evident in relation to Section 6(1) offences under the Misuse of Drugs Act (1975), and the appropriateness of utilising those offences and their penalties to respond to international cryptomarket activity should be considered accordingly. 


\section{Chapter 7: Conclusion}

What I would like your studies to lead towards is some kind of anti-prohibition state in New Zealand. [...] I think we should really take a good hard look at our drugs laws, and invest in really decent in-depth research around these substances and the use of them, and ask ourselves, "Is this much different from alcohol? Is it really worth stopping people from doing this?" and balance it up between the pros and cons, because I think there's an increasing argument for these things building momentum on a global scale. - Jackson, early twenties

This thesis had four primary aims. The first was to gain insight into the experiences of New Zealanders who interacted with drug cryptomarkets. The second was to explore how and why some New Zealanders who use illicit drugs choose to access them through drug cryptomarkets instead of alternatives. The third was to compare illicit drug trading on cryptomarkets with New Zealand's conventional illicit drug market. Lastly, the research sought to contrast the experiences of New Zealanders who accessed cryptomarkets with their overseas counterparts. Academic research into drug cryptomarkets is still developing, and semi-structured, qualitative interviews allowed participants to share their lived experiences of drug cryptomarkets and provide unique insights.

Participants expressed immense frustration with the constraints of the conventional illicit drug market in New Zealand. These constraints acted as push factors, propelling them towards drug cryptomarkets. Push factors in the domestic conventional market centred around stringent border security, poor drug availability and quality, poor drug authenticity and purity, high price, and the perceived risk of violent victimisation. Simultaneously, perceived benefits or 'pulls' of drug cryptomarkets incentivised participants to access them. These included comparatively low price, trustworthy rating and review systems, high quality, and a wide range of products, convenience, and a low perceived risk of violence. Despite the attractions of drug cryptomarkets, participants also discussed their downsides, which included the possibility of leaving paper trails, significant time investment, and the severity of criminal charges that could result from cryptomarket-associated drug importation. Overall, participants revealed the distinct experiences of New Zealand cryptomarket users that resulted from the geographical, social, political, and economic factors that influenced them.

Additionally, Chapter 4 uncovered insights, features, and risks of engagement with drug cryptomarkets, including techniques that participants used to reduce their risk of detection and apprehension by authorities. Two participants, Lucidity and Michael, had acquired criminal 
convictions because of their cryptomarket activities, and their lived experiences were discussed. Lucidity and Michael's narratives of their experiences with the criminal justice process highlighted the difficulties of coping with home detention, as well as the unsuitability of the Misuse of Drugs Act (1975) to respond to their cryptomarket-related activities. Various forms of cryptomarket-facilitated drug trading and sharing were also explored, along with participants' perspectives on New Zealand's drug legislation and law reform.

Important issues that emerged from the analysis centred around notions of individual freedom. Having access to a range of options was important for participants, who considered illicit drug use to be inevitable for many people. In light of the ubiquity of illicit drug consumption, drug cryptomarkets were significant for participants, who perceived that they provided a safer, more ethical means of obtaining drugs, especially given the constraints of New Zealand's conventional illicit drug market. Participants found some aspects of cryptomarkets, such as the time investment required, to be stifling, but negative aspects were mostly related to criminal justice interventions and the enforcement of drug prohibition.

The findings highlighted the need to reconsider legal responses to cryptomarket orders. The logic of drug prohibition notwithstanding, Section 6(1) offences under the Misuse of Drugs Act (1975) are a blunt and outdated tool and their suitability should be reconsidered accordingly, along with whether the Act in its entirety is fit for purpose. Participants' viewpoints indicated the need for pragmatic, compassionate, and harm reduction-based responses to illicit drugs and the use of drug cryptomarkets. Cryptomarkets were revealed to be a logical course of action for those who wish to access illicit drugs in New Zealand, and this should be considered when developing related policy and practice.

There is significant debate around the harm-reducing potential of drug cryptomarkets (Martin, 2017a; Mounteney et al., 2017; Sumnall, 2017). However, participants perceived that using drug cryptomarkets reduced the drug-related harm that they experienced as individuals. Participants' accounts support the idea that cryptomarkets may act as harm reduction tools, and they supported the expansion of cryptomarket-specific information and programmes aimed at reducing drug-related harm, such as drug testing and safe dosage advice. However, as Martin (2017a) asserts, the gentrifying potential of drug cryptomarkets is worrisome. Cryptomarkets may increase drug-related social harms and inequalities between groups of drug users, as there is a clear divide between those who can access cryptomarkets (mostly privileged, young, technically-competent white males who live in developed countries) and those who cannot 
(problematic drug users, and those who experience poverty, social deprivation and unstable housing). The potential for drug cryptomarkets to deepen drug-related inequalities is extremely troubling, and further research on this is urgently needed.

Overall, this thesis has contributed to closing a gap in the literature surrounding engagement with drug cryptomarkets. As they are still in their infancy, the extent of their transformative potential remains to be seen, and it is unclear how current global drug law reform might influence cryptomarkets. It is hoped this thesis will provide a platform for further New Zealandbased research that is sorely needed. 


\section{Appendices}

Appendix A: Recruitment Poster

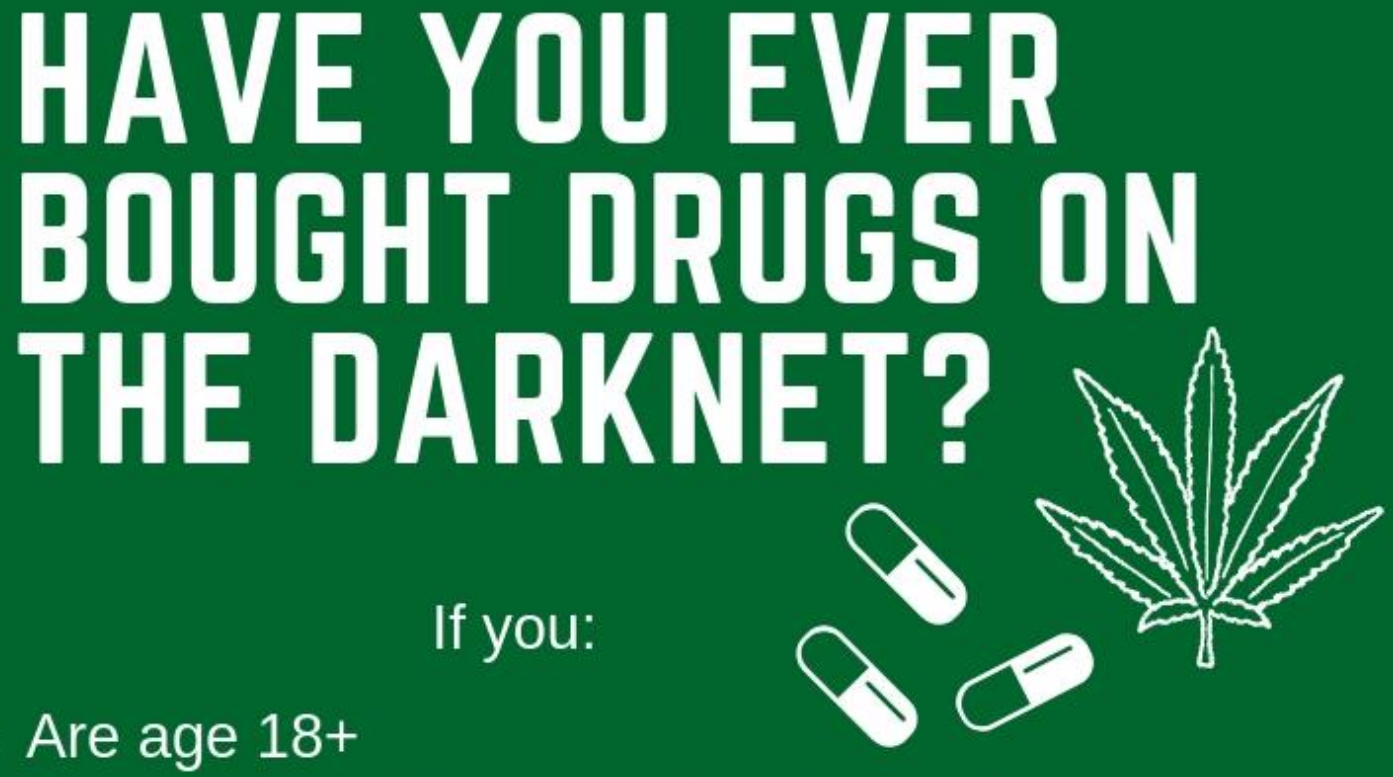

- Have ordered drugs on the darknet for personal use

- Reside in New Zealand, or resided in New Zealand when you were using the darknet

I would love to talk to you. I am a Masters student in Criminology and I am researching the experiences of New Zealanders who have ordered drugs over the darknet.

Participants will be interviewed and receive a $\$ 30$ supermarket voucher for their time. Interviews are confidential. For more information, please contact:

Researcher: Lucy Moss-Mason lucy.moss-mason@vuw.ac.nz
Supervisor: Dr Fiona Hutton fiona.hutton@vuw.ac.nz 044636749

This study has received ethical approval from the VUW Human Ethics

Committee \#25896 


\title{
Appendix B: Information Sheet
}

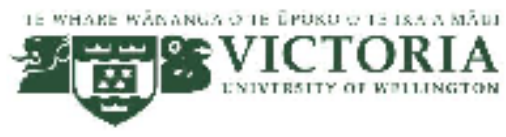

\section{Mapping the terrain of engagement with darknet drug cryptomarkets in New Zealand}

\author{
INFORMATION SHEET FOR PARTICIPANTS - CONSUMERS
}

Thank you for your participation in this research project.

Who am I?

My name is Lucy Moss-Mason and I am a Masters student in Criminology at Victoria University of Wellington. This research project is part of my Masters work for my thesis.

What is the aim of the project?

1. To examine the experiences of New Zealand consumers and dealers of drugs who have used the darknet for buying and/or selling drugs

2. To explore how and why some people choose to buy drugs over the darknet instead of using other sources

3. To compare the accessing drugs through the darknet to accessing drugs through traditional dealing, and to compare the experiences of New Zealanders who access drugs over the darknet to overseas darknet users

How can you help?

If you agree to take part in the research, you can opt participate in a face-to-face interview, or an online interview (either on the normal internet or the darknet). If you choose to meet faceto-face, interviews will take place in an agreed public space (e.g. café, library meeting room), in Wellington. I will ask you questions about your experiences of buying drugs on the darknet. The interviews will be recorded to ensure that no important comments are missed. The interviews will also be transcribed (typed out word for word). It is expected that the interview will take approximately 1 hour. If you choose to meet face-to-face, you will be reimbursed for your time by way of a supermarket voucher valued at $\$ 30$. You may withdraw from the study at any time prior to 1 September 2018. Withdrawing from the study will not have any impact on the supermarket voucher that you received in recognition of your contribution.

What will happen to the information you give?

The information you give is strictly confidential and you will not be named in any write up or report from this interview, but the information that you provide may not remain confidential if the researcher is subpoenaed or otherwise called on by the police. In order to protect yourself, please refrain from providing any specific information about a crime, your identity, or the identity of other individuals.

The information given in the interviews will be used in my Master's thesis, may be published in academic journals, and may also be presented at academic conferences. My supervisor and I are the only people who will read or talk about the interview transcripts and any notes about them. 
All material from the research project will be kept securely (e.g. password protected computer files), and will be destroyed two years after the end of the research period.

This study was approved by the Victoria University Human Ethics Committee, approval number 25896. If you have any questions or concerns about the research, please contact me on lucy.moss-mason@vuw.ac.nz. You can also contact the convenor of the Human Ethics Committee Associate Professor Susan Corbett, susan.corbett@vuw.ac.nz, 04463 5480, or my supervisor Dr Fiona Hutton, fiona.hutton@vuw.ac.nz, 04463 6749, if you have any concerns or queries about the research project or the ethics process.

If you accept this invitation, what are your rights as a research participant?

You do not have to accept this invitation if you don't want to. If you do decide to participate, you have the right to:

- choose not to answer any question;

- $\quad$ ask for the recorder to be turned off at any time during the interview;

- withdraw from the study before 1 September 2018;

- ask any questions about the study at any time;

- receive a copy of your interview recording;

- $\quad$ read over and comment on a written summary of your interview;

- $\quad$ agree on another name for me to use rather than your real name;

- be able to read any reports of this research by emailing the researcher to request a copy. 


\section{Appendix C: Consent Form}

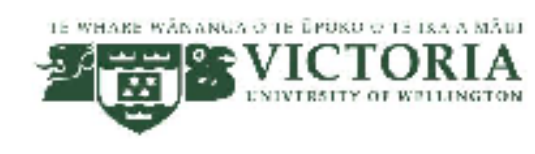

\section{Mapping the terrain of engagement with darknet drug cryptomarkets in New Zealand CONSENT TO INTERVIEW}

This consent form will be held for two years.

Researcher: Lucy Moss-Mason, Institute of Criminology - School of Social and Cultural Studies, Victoria University of Wellington

- I have read the Information Sheet and the project has been explained to me. My questions have been answered to my satisfaction. I understand that I can ask further questions at any time.

- I agree to take part in an audio recorded interview.

I understand that:

- I may withdraw or amend my contribution to this study at any point before 1 September 2018 without giving any reason, and any information that I have provided will be returned to me or destroyed.

- The information I have provided will be destroyed two years after the research is finished.

- Any information I provide will be kept confidential to the researcher and the supervisor. (NB: Please note that the interview is confidential, but if specific information is supplied on activities that are dangerous to the public, the researcher would be obliged to discuss this with a third party and possibly notify the authorities. Please refrain from providing any specific information about a crime or the identity of other individuals.)

- This research may be published in academic journals, through the University library, or may be presented at conferences. My name will not be used in any presentations or publications, nor will any information that would identify me.

- I would like a summary of my interview:

Yes $\square$ No

- I would like to receive a copy of the final report and have added my email Yes $\square$ No address below. 
Signature of participant:

Date:

Contact details: 


\section{Appendix D: Interview Guide}

\section{Draft Interview Schedule/Guide for Consumers}

Please note: The interview is semi-structured, so may deviate from the schedule provided here depending on prompts and the information provided by the participants during the interviews. However, I do not anticipate that any deviations from the below structure will substantially differ from the topic/questions that I have provided below. I have included prompts with the questions to give an indication of the direction that I anticipate that the questions will take.

1. Could we please begin by you telling me a bit about yourself?

Prompts - Age, job, ethnicity

2. Tell me about your experiences with ordering drugs through the darknet? How would you describe your experiences with accessing drugs through the darknet?

Prompts - Tell me about your 'journey' with accessing drugs through the darknet from the start to where you are now. Do you currently access drugs through the darknet or have you stopped? If you have stopped, what are the reasons behind your decision? Can you describe for me the kinds of drugs that you were accessing? How long have you been accessing darknet drugs for/how long did you access them in this way in total?

3. How did you start using drugs? How did you become introduced drugs on the darknet? Prompts - At what point in your 'drug journey' did you access the darknet? In what context did your introduction occur (e.g., through the internet, a friend was doing it)? How has the scene changed over time?

4. Which markets do you access? Which country/countries do you order from?

Prompts - Have you previously accessed markets that are now shut down? How does it affect you when markets are closed?

5. What kind of safety precautions do you take?

Prompts - VPN, Tor, address for delivery

6. Do you engage in the darknet community ways othering than just ordering drugs? (e.g., through forums, purchase of non-drug items)

7. Have you also accessed drugs through other methods (not the darknet)? If yes, what other methods have you used? How do these methods compare to using the darknet? 
1. What are the positives and negatives of ordering through the darknet?

Prompts - Better variety of drugs, better price, better purity and quality, feels safer than buying from a dealer. Negative aspects could include order not being received, drugs not as advertised, order being intercepted by the authorities.

2. Do you think that there are any risks associated with ordering drugs on the darknet? If yes, what are these risks?

Prompts - legal issues, not receiving your order

3. How do you reduce the risks associated with ordering through the darknet/how do you think it could be possible to reduce the risks?

Prompts - online safety precautions, harm reduction information available on forums etc.

4. Do you discuss your darknet purchases with other people? Why/why not?

5. Would you recommend ordering through the darknet? Why/why not?

6. What do you think of media representations of the darknet?

Prompts - Do you feel that the darknet portrayed positively/negatively? What are some of the misconceptions of darknet users that the media has? How have these portrayals affected the community? What would you like to change about media representations of the darknet, if anything?

7. How do you think the experiences of New Zealanders ordering drugs through the darknet might be the same/different to the experiences of people in other countries?

Prompts - tougher border restrictions, fewer domestic vendors

8. Anything else you would like to add/think is important for me to know? 


\section{Draft Interview Schedule/Guide for Dealers}

All of the questions for consumers will also be relevant for dealer participants, but additional questions will also be relevant.

1. Tell me about how you started purchasing drugs through the darknet to deal/started dealing through the darknet as a vendor? (Are you still dealing drugs? If no, what made you stop?)

2. What kind of drugs are you dealing and what is the scale of the operation like? (Without providing specific details - e.g., names and locations involved)

3. Talk me through your online and offline processes involved in dealing (purchasing, delivery drop-offs, packaging, receiving parcels etc.)

4. What have your experiences been like with dealing?

5. What are the positives and negatives of using the darknet to facilitate dealing?

6. Have you ever been involved in other types of drug dealing (not using the darknet)? If yes, how do the different methods that you have used compare?

7. Do you take any specific safety precautions related to dealing and the darknet? If yes, what safety precautions do you take? How do you minimise the risk of being caught?

8. Have you had any negative experiences related to your dealing? (e.g., unsatisfied customers, coming to the attention of the authorities) If yes, how did you manage these issues?

9. How do you think that the experiences of New Zealanders using the darknet to deal drugs might differ from the experiences of dealers overseas? 


\section{Appendix E: Interview Coding Example}

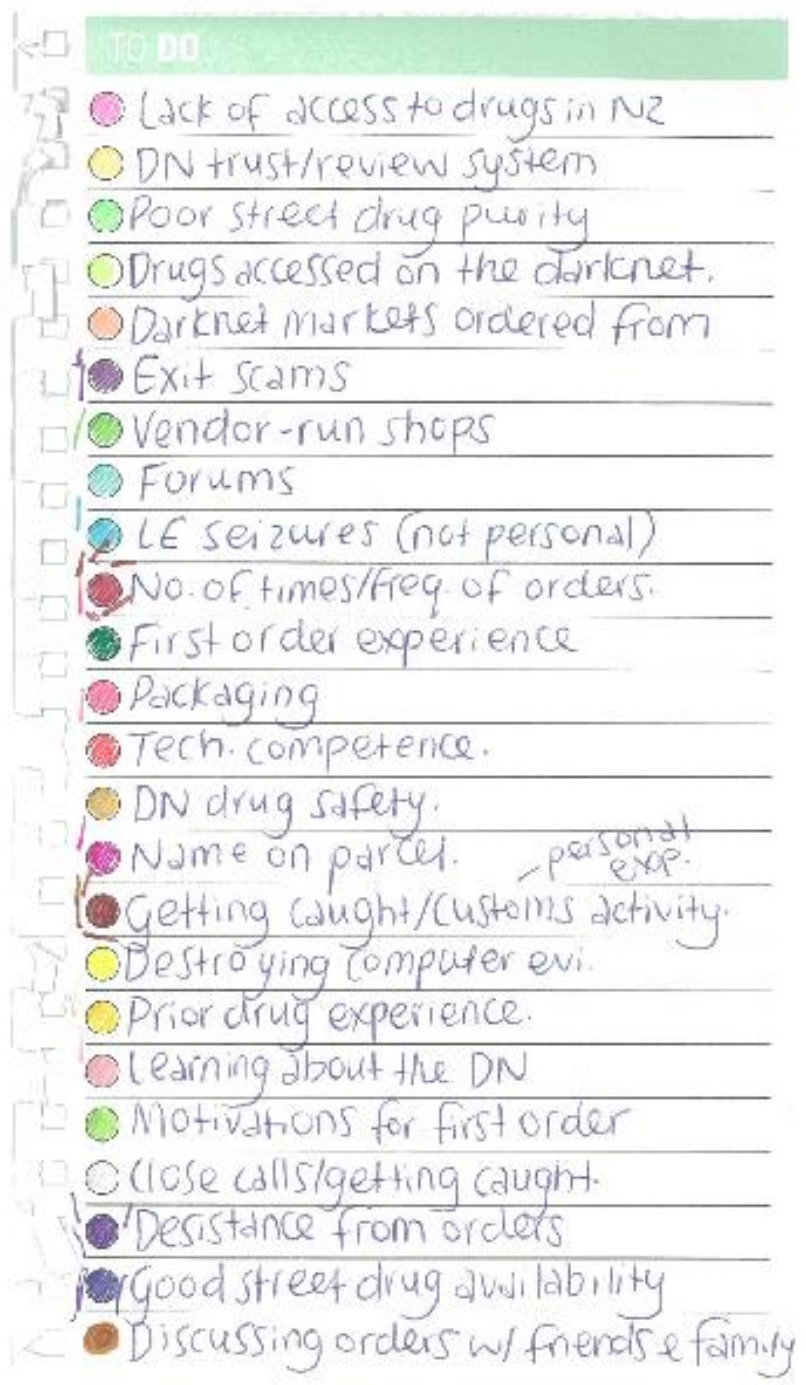




\section{References}

25x-NBOMe. (n.d.). Retrieved from https://psychonautwiki.org/wiki/25x-NBOMe

2C-B. (n.d.). Retrieved from https://psychonautwiki.org/wiki/2C-B

2C-E. (n.d.). Retrieved from https://psychonautwiki.org/wiki/2C-E

4-AcO-DMT. (n.d.). Retrieved from https://psychonautwiki.org/wiki/4-AcO-DMT

4-FA. (n.d.). Retrieved from https://psychonautwiki.org/wiki/4-FA

Abraham, S., Silva, T., Decourcy, R., \& Cardon, J. (2017). Tails \& Tor and other tools for safeguarding online activities. ArXiv. Retrieved from https://arxiv.org/ftp/arxiv/papers/1710/1710.08705.pdf

Aburo, J. M., Beltrán-Sánchez, H., García-Guerrero, V. M., Canudas-Romo, V. (2016). Homicides in Mexico reversed life expectancy gains for men and slowed them for women, 2000-10. Health Affairs, 35(1). 88-95. Doi: 10.1377/hlthaff.2015.0068

Adler, P. A., \& Adler, P. (1983). Shifts and oscillations in deviant careers: The case of upperlevel drug dealers and smugglers. Social Problems, 31(2), 195-207.

Afilipoaie, A., \& Shortis, P. (2015). Operation Onymous: International law enforcement agencies target the dark net in November 2014. GDPO Situation Analysis. Swansea: Global Drug Policy Observatory.

Aguirre, N., Barrionuevo, M., Ramírez, M. J., Río, J. D., \& Lasheras, B. (1999). a-Lipoic acid prevents 3,4-methylenedioxy-methamphetamine (MDMA)-induced neurotoxicity. NeuroReport, 10(17), 3675-3680.

Ahern, J., Stuber, J., \& Galea, S. (2007). Stigma, discrimination and the health of illicit drug users. Alcohol and Drug Dependence, 88(2), 188-196. Doi: 10.1016/j.drugalcdep.2006.10.014

Aldridge, J. (2012, November 7). Dealers in disguise: The virtualisation of retail level drug $\begin{array}{llll}\text { markets } & \text { [Video } & \text { file]. }\end{array}$ https://www.youtube.com/watch? $\mathrm{v}=\mathrm{q} 4 \mathrm{ZsNuC2 \textrm {kqg }}$ 
Aldridge, J., Askew, R. (2017). Delivery dilemmas: How cryptomarket users identify and seek to reduce their risk of detection by law enforcement. International Journal of Drug Policy, 41, 101-109. Doi: 10.1016/j.drugpo.2016.10.010

Aldridge, J., \& Décary-Hétu, D. (2014). Not an 'Ebay for drugs': The cryptomarket 'Silk Road' as a paradigm shifting criminal innovation. SSRN. Doi: 10.2139/ssrn.2436643

Aldridge, J., \& Décary-Hétu, D. (2016a). 'Cryptomarkets and the future of illicit drug markets.' The internet and drug markets (European Monitoring Centre for Drugs and Drug Addiction: Insights 21). Luxembourg: Publications Office of the European Union.

Aldridge, J., \& Décary-Hétu, D. (2016b). Hidden wholesale: The drug diffusing capacity of online drug cryptomarkets. International Journal of Drug Policy, 25, 7-15. Doi: 10.1016/j.drugpo.2016.04.020

Aldridge, J., Stevens, A., \& Barratt, M. J. (2017). Will growth in cryptomarket drug buying increase the harms of illicit drugs? Addiction, 113(5), 789-796. Doi: 10.1111/add.13899

Aldridge, J., Stevens, A., \& Barratt, M. J. (2018). Harms, benefits and the policing of cryptomarkets: A response to commentaries. Addiction, 113(5), 802-804. Doi: 10.1111/add.14169

Alprazolam. (n.d.). Retrieved from https://psychonautwiki.org/wiki/Alprazolam

Andreas, P., \& Wallman, J. (2009). Illicit markets and violence: What is the relationship? Crime, Law and Social Change, 52, 225-229. Doi: 10.1007/s10611-009-9220-6

Andreasen, M. F., Telving, R., Rosendal, I., Eg, M. B., Hasselstrøm, J. B., \& Andersen, L. V. (2015). A fatal poisoning involving 25C-NBOMe. Forensic Science International, 251, e1-e8. Doi: 10.1016/j.forsciint.2015.03.012

Arthur v R [2005] NZCA 51.

Bakken, S. A., Moeller, K., \& Sandberg, S. (2017). Coordination problems in cryptomarkets: Changes in cooperation, competition and valuation. European Journal of Criminology, 15(4), 442-460. Doi: 10.1177/1477370817749177

Bancroft, A. (2017). Responsible use to responsible harm: Illicit drug use and peer harm reduction in a darknet cryptomarket. Health, Risk \& Society, 19(7-8), 336-350. Doi: 10.1080/13698575.1415304 
Bancroft, A., \& Scott Reid, P. (2016). Concepts of illicit drug quality among darknet market users: Purity, embodied experience, craft and chemical knowledge. International Journal of Drug Policy, 25, 42-49. Doi: 10.1016/j.drugpo.2015.11.008

Bancroft, A., \& Scott Reid, P. (2017). Challenging the techno-politics of anonymity: The case of cryptomarket users. Information, Communication and Society, 20(4), 497-512. Doi: 10.1080/1369118X.2016.1187643

Barratt, M. J. (2012a). Silk Road: Ebay for drugs. Addiction, 107(3), 683. Doi: 10.1111/j.13600443.2011.03709.x

Barratt, M. J. (2012b). The efficacy of interviewing young drug users through online chat. Drug and Alcohol Review, 31(4), 566-572. Doi: 10.1111/j.1465-3362.2011.00399.x

Barratt, M. J., \& Aldridge, J. (2016). Everything you always wanted to know about drug cryptomarkets* (*but were afraid to ask). International Journal of Drug Policy, 35, 16. Doi: 10.1016/j.drugpo.2016.07.005

Barratt, M. J., Ferris, J. A., \& Winstock, A. R. (2014). Use of Silk Road, the online drug marketplace, in the United Kingdom, Australia and the United States. Addiction, 109(5), 774-783. Doi: 10.1111/add.12470

Barratt, M. J., Ferris, J. A., \& Winstock, A. R. (2016). Safer scoring? Cryptomarkets, social supply and drug market violence. International Journal of Drug Policy, 35, 24-31. Doi: 10.1016/j.drugpo.2016.04.019

Barratt, M. J., \& Lenton, S. (2010). Beyond recruitment: Participatory online research with people who use drugs. International Journal of Internet Research Ethics, 3, 69-86.

Barratt, M. J., Lenton, S., Maddox, A., \& Allen, M. (2016). 'What if you live on top of a bakery and you like cakes?' - Drug use and harm trajectories before, during and after the emergence of Silk Road. International Journal of Drug Policy, 35, 50-57. Doi: 10.1016/j.drugpo.2016.04.006

Barratt, M. J., \& Maddox, A. (2016). Active engagement with stigmatised communities through digital ethnography. Qualitative Research, 16(6), 701-719. Doi: $10.1177 / 1468794116648766$

Becker, H. S. (1953). Becoming a marihuana user. American Journal of Sociology, 59(3), 235242. Doi: $10.1086 / 221326$ 
Berger, R. (2015). Now I see it, now I don't: Researcher's position and reflexivity in qualitative research. Qualitative Research, 15(2), 219-234. Doi: 10.1177/1468794112468475

Better Practice Advocacy Centre New Zealand. (2018). Prescribing hypnotic medicines: A $\begin{array}{llll}\text { focus on } & \text { zopiclone. } & \text { Retrieved }\end{array}$ https://bpac.org.nz/report/snippet/docs/zopiclone.pdf

Bewley-Taylor, D. R. (2003). Challenging the UN drug control conventions: Problems and possibilities. International Journal of Drug Policy, 14, 171-179. Doi: 10.1016/S09553959(03)00005-7

Bewley-Taylor, D. R. (2005). Emerging policy contradictions between the United Nations drug control system and the core values of the United Nations. International Journal of Drug Policy, 16, 423-431. Doi: 10.1016/j.drugpo.2005.06.007

Biosecurity Act, New Zealand Statutes. (1993).

Black, M. (2014, June 30). Cooks, cops \& crime: Inside the Auckland P scene. Metro. Retrieved from https://www.noted.co.nz/currently/crime/cooks-cops-crime-inside-theauckland-p-scene/

Bowling, B. (1999). The rise and fall of New York murder: Zero tolerance or crack's decline? British Journal of Criminology, 39(4), 531-554. Doi: 10.1093/bjc/39.4.531

Bradley, A. (2018, May 3). New Zealand 'awash' with imported meth. Radio New Zealand. Retrieved from https://www.radionz.co.nz

Braun, V., \& Clarke, V. (2006). Using thematic analysis in psychology. Qualitative Research in Psychology, 3(2), 77-101. Doi: 10.1191/1478088706qp063oa

Broséus, J., Rhumobarbe, D., Mireault, C., Ouellette, V., Crispino, F., \& Décary-Hétu, D. (2016). Studying illicit drug trafficking on darknet markets: Structure and organisation from a Canadian perspective. Forensic Science International, 264, 7-14. Doi: 10.1016/j.forsciint.2016.02.045

Broséus, J., Rhumobarbe, D., Morelato, M., Staehli, L., \& Rossy, Q. (2017). A geographical analysis of trafficking on a popular darknet market. Forensic Science International, 277, 88-102. Doi: 10.1016/j.forsciint.2017.05.021 
Buxton, J., \& Bingham, T. (2015). The rise and challenge of dark net drug markets: Policy Brief 7. Swansea: Global Drug Policy Observatory.

Cant, A., \& Cunliffe, D. (2017). Oral mucosal trauma related to the use of ecstasy $(3,4-$ methylenedioxy-methamphetamine) - A case report. British Journal of Oral and Maxillofacial Surgery, 55(10), e131. Doi: 10.1016/j.bjoms.2017.08.132

Castronova, J. R. (2006). Operation Cyber Chase and other agency efforts to control Internet drug trafficking: The "virtual" enforcement initiative is virtually useless. Journal of Legal Medicine, 27(2), 207-224. Doi: 10.1080/01947640600716440

Caudevilla, F. (2016). 'The emergence of deep web marketplaces: A health perspective.' The internet and drug markets (European Monitoring Centre for Drugs and Drug Addiction: Insights 21). Luxembourg: Publications Office of the European Union.

Caudevilla, F., Ventura, M., Fornís, I., Barratt, M. J., Vidal, C., Iladanosa, C. G., Quintana, P., Muñoz, A., Calzada, N. (2016). Results of an international drug testing service for cryptomarket users. International Journal of Drug Policy, 35, 38-41. Doi: 10.1016/j.drugpo.2016.04.017

Caulkins, J. P., \& Reuter, P. (1998). What price data tells us about drug markets. Journal of Drug Issues, 28(3), 593-612. Doi: 10.1177/00204269802800302

Caulkins, J. P., \& Reuter, P. (2006). Illicit drug markets and economic irregularities. SocioEconomic Planning Sciences, 40, 1-14. Doi: 10.1016/j.seps.2004.08.002

Charmaz, K. (2000). Constructivist and objectivist grounded theory. In N. K. Denzin \& Y. Lincoln (Eds.), Handbook of qualitative research (2nd ed., pp. 509-535). Thousand Oaks, CA: Sage.

Charmaz, K. (2014). Constructing grounded theory (2nd ed.). Thousand Oaks, CA: Sage.

Chen, A. (2011, 1 June). The underground website where you can buy any drug imaginable. Gawker. Retrieved from http://www.gawker.com

Chohan, U. W. (2017a). Cryptocurrencies: A brief thematic review. Discussion Paper Series: Notes on the $21^{\text {st }}$ Century. Canberra: University of New South Wales.

Christin, N. (2013). Traveling the Silk Road: A measurement analysis of a large anonymous online marketplace. Paper presented at the International World Wide Web Conference 
(IW3C2), Rio de Janeiro, Brazil. Retrieved from http://www.andrew.cmu.edu/user/nicolasc/publications/Christin-WWW13.pdf

Ciancaglini, V., Balduzzi, M., McArdle, R., \& Rösler, M. (2015). Below the surface: Exploring the deep web. Retrieved from https://www.trendmicro.de/cloudcontent/us/pdfs/security-intelligence/white-papers/wp_below_the_surface.pdf

Clarke, V., \& Braun, V. (2017). Thematic analysis. The Journal of Positive Psychology, 12(3), 297-298. Doi: 10.1080/17439760.2016.1262613

Cohen, M. M. (2006). Jim Crow's drug war race, Coca Cola, and the southern origins of drug prohibition. Southern Cultures, 12(3), 55-79.

Cohen, S. (1993). Human rights and crimes of the state: The culture of denial. Australia and New Zealand Journal of Criminology, 26(2), 97-115.

Cohen, B. M. Z., \& Allison, W. (2015). Pills, thrills and bellyaches: The effects of criminalising a 'legal high' in Aotearoa New Zealand. New Zealand Sociology, 30(1), 10-29.

Cole, C., Jones, L., McVeigh, J., Kicman, A., Syed, Q., \& Bellis, M. (2011). Adulterants in illicit drugs: A review of empirical evidence. Drug Testing and Analysis, 3(2), 89-96. Doi: $10.1002 /$ dta. 220

Collins, S. (2016, June 4). Agencies struggle to cope with meth's cruel legacy. New Zealand Herald. Retrieved from https://www.nzherald.co.nz

Cooke, H. (2016, June 13). Super-expensive ecstasy is probably not even MDMA in New Zealand. Stuff. Retrieved from https://www.stuff.co.nz

Coomber, R. (1997a). The adulteration of drugs: What dealers do to illicit drugs, and what they think is done to them. Addiction Research, 5(4), 297-306. Doi: $10.3109 / 16066359709004344$

Coomber, R. (1997b). Vim in the veins - Fantasy or fact: The adulteration of illicit drugs. Addiction Research, 5(3), 195-212. Doi: 10.3109/16066359709005261

Coomber, R. (2006). Pusher myths: Re-situating the drug dealer. London: Free Association Books. 
Coomber, R. (2015). A tale of two cities: Understanding differences in levels of heroin/crack market-related violence - A two city comparison. Criminal Justice Review, 40(1), 731. Doi: $10.1177 / 0734016814565817$

Coomber, R., \& Maher, L. (2006). Street-level drug market activity in Sydney's primary heroin markets: Organization, adulteration practices, pricing, marketing and violence. Journal of Drug Issues, 36(3), 719-753. Doi: 10.1177/002204260603600310

Coomber, R., \& Moyle, L. (2014). Beyond drug dealing: Developing and extending the concept of 'social supply' of illicit drugs to 'minimally commercial supply'. Drugs: Education, Prevention and Policy, 21(2), 157-164. Doi: 10.2109/09687637.2013.798265

Coomber, R., Moyle, L., \& South, N. (2016). The normalisation of drug supply: The social supply of drugs as the "other side" of the history of normalisation. Drugs: Education, Prevention and Policy, 23(3), 255-263. Doi: 10.3109/09687637.2015.1110565

Cox, C. (2018). The Canadian Cannabis Act legalizes and regulates recreational cannabis use in 2018. Health Policy, 122(3), 205-209. Doi: 10.1016/j.healthpol.2018.01.009

Cox, J. (2014, January 24). Buying your drugs online is good for you. Vice. Retrieved from https://www.vice.com

Cox, J. (2015, January 12). 'Silk Road Reloaded' just launched a network more powerful than Tor. Motherboard. Retrieved from https://motherboard.vice.com

Cox, J. (2016b). 'Reputation is everything: The role of ratings, feedback and reviews in cryptomarkets.' The internet and drug markets (European Monitoring Centre for Drugs and Drug Addiction: Insights 21). Luxembourg: Publications Office of the European Union.

Cox, J. (2016c). 'Staying in the shadows: The use of Bitcoin and encryption in cryptomarkets.' The internet and drug markets (European Monitoring Centre for Drugs and Drug Addiction: Insights 21). Luxembourg: Publications Office of the European Union.

Creswell, J. W. (2014). Research design: Qualitative, quantitative, and mixed method approaches (4th ed.). Thousand Oaks, CA: Sage.

Crotty, M. (1998). The foundations of social research: Meaning and perspective in the research process. St Leonards, NSW: Allen \& Unwin. 
Csete, J., Kamarulzaman, A., Kazatchkine, M., Altice, F., Balicki, M., Buxton, J., ... Beyrer, C. (2016). Public health and international drug policy. The Lancet, 387(10026), $1427-$ 1480. Doi: 10.1016/S0140-6736(16)00619-X

Cunliffe, J., Martin, J., Décary-Hétu, D., \& Aldridge, J. (2017). An island apart? Risks and prices in the Australian cryptomarket drug trade. International Journal of Drug Policy, 50, 64-73. Doi: 10.1016/j.drugpo.2017.09.005

Davies, N., English, W., \& Grundlingh, J. (2018). MDMA toxicity: Management of acute and life-threatening presentations. British Journal of Nursing, 27(11), 616-622. Doi: 10.12968/bjon.2018.27.11.616

Dawson, M., \& Cárdenas-Haro, J. (2017). Tails Linux operating system: Remaining anonymous with the assistance of an incognito system in times of high surveillance. International Journal of Hyperconnectivity and the Internet of Things, 1(1), 47-55. Doi: 10.4018/IJHIoT.2017010104

Day, M. (2012, August 12). Online drug trade triggers high alert. New Zealand Herald. Retrieved from http://www.nzherald.co.nz

Décary-Hétu, D., \& Giommoni, L. (2016). Do police crackdowns disrupt drug cryptomarkets? A longitudinal analysis of the effects of Operation Onymous. Crime, Law and Social Change, 67, 55-75. Doi: 10.1007/s10611-016-9644-4

Décary-Hétu, D., Paquet-Clouston, M., \& Aldridge, J. (2016). Going international? Risk taking by cryptomarket drug vendors. International Journal of Drug Policy, 35, 69-76. Doi: 10.1016/j.drugpo.2016.06.003

Décary-Hétu, D., \& Quessy-Doré, O. (2017). Are repeat buyers in cryptomarkets loyal customers? Repeat business between dyads of cryptomarket vendors and users. American Behavioral Scientist, 61(11), 1341-1357. Doi: 10.1177/0002764217734265

Degenhardt, L., Bruno, R., \& Topp, L. (2010). Is ecstasy a drug of dependence? Drug and Alcohol Dependence, 107(1), 1-10. Doi: 10.1016/j.drugalcdep.2009.09.009

Degenhardt, L., Chiu, W-T., Sampson, N., Kessler, R. C., Anthony, J. C., Angermeyer, M. ... Wells, J. E. (2008). Towards a global view of alcohol, tobacco, cannabis, and cocaine use: Findings from the WHO World Mental Health Surveys. PLoS Medicine, 5(7), 1053-1067. Doi: 10.1371/journal.pmed.0050141 
Demant, J., Munksgaard, R., \& Houborg, E. (2018). Personal use, social supply or redistribution? Cryptomarket demand on Silk Road 2 and Agora. Trends in Organized Crime, 21, 42-61. Doi: 10.1007/s12117-016-9281-4

Department of the Prime Minister and Cabinet. (2009). Tackling methamphetamine: An action plan. Wellington: Department of the Prime Minister and Cabinet.

Department of the Treasury Financial Crimes Enforcement Network. (2013). Application of FinCEN's regulations to persons administering, exchanging, or using virtual currencies. Retrieved from https://www.fincen.gov/sites/default/files/shared/FIN2013-G001.pdf

Desroches, F. (2007). Research on upper-level drug trafficking: A review. Journal of Drug Issues, 37(4), 827-844. Doi: 10.1177/002204260703700405

Diazepam. (n.d.). Retrieved from https://psychonautwiki.org/wiki/Diazepam

Dickson-Swift, V., James, E. L., Kippen, S., \& Liamputtong, P. (2007). Doing sensitive research: what challenges do qualitative researchers face? Qualitative Research, 7(3), 327-353. Doi: 10.1177/1468794107078515

DMT. (n.d.). Retrieved from https://psychonautwiki.org/wiki/DMT

Dolliver, D. S., Ericson, S. P., \& Love, K. P. (2018). A geographic analysis of drug trafficking patterns on the TOR network. Geographical Review, 108(1), 45-68. Doi: $10.1111 /$ gere. 12241

DOM. (n.d.). Retrieved from https://psychonautwiki.org/wiki/DOM

Drucker, E. (1999). Drug prohibition and public health: 25 years of evidence. Public Health Reports, 114(1), 14-29.

DrugScope. (2014). Business as usual? A status report on new psychoactive substances (NPS) and 'club drugs' in the UK. Retrieved from http://www.re-solv.org/wpcontent/uploads/2015/06/BusinessAsUsual.pdf

Duffy, M., Schaefer, N., Coomber, R., O’Connell, L., \& Turnbull, P. J. (2008). Cannabis and young people: 'It's a social thing'. York: Joseph Rowntree Foundation. 
Dwyer, R., \& Moore, D. (2010). Understanding illicit drug markets in Australia: Notes towards a critical reconceptualization. British Journal of Criminology, 50, 82-101. Doi: 10.1093/bjc/azp065

Ellingham, J. (2013, April 27). Student accused of drug importing freed on bail. Stuff. Retrieved from http://www.stuff.co.nz

Ensor, B. (2016, May 17). Christchurch man nearly died after taking psychedelic drug NBOMe. Stuff. Retrieved from https://www.stuff.co.nz

Epstein, Z. (2014, January 20). How to find the invisible internet. Retrieved from http://bgr.com

Erickson, P. G., Riley, D. M., Cheung, Y-W., O’Hare, P. A. (Eds.). (1997). Harm reduction: A new direction for drug policies and programs. Toronto: University of Toronto Press.

Erowid Experience Vaults. (n.d.). Retrieved from https://erowid.org/experiences/

European Commission. (2012). Europeans and their languages. Retrieved from http://ec.europa.eu/commfrontoffice/publicopinion/archives/ebs/ebs_386_en.pdf

European Monitoring Centre for Drugs and Drug Addiction. (2011). Responding to new psychoactive substances. (Drugs in focus: Briefing of the European Monitoring Centre for Drugs and Drug Addiction.) Retrieved from http://www.emcdda.europa.eu/system/files/publications/645/EMCDDA_DiF22_EN_3 18768.pdf

European Monitoring Centre for Drugs and Drug Addiction. (2017). Drugs and the darknet: Perspectives for enforcement, research and policy. Luxembourg: Publications Office of the European Union.

European Monitoring Centre for Drugs and Drug Addiction. (2018). European Drug Report 2018: Trends and developments. Luxembourg: Publications Office of the European Union.

Ezard, N. (2001). Public health, human rights and the harm reduction paradigm: From risk reduction to vulnerability reduction. International Journal of Drug Policy, 12(3), 207219. Doi: 10.1016/S0955-3959(01)00093-7

Falvey, D. (2018, February 22). Sinister Russian dark web anti-anxiety drug overdose leaves five school children in coma. Express. Retrieved from https://www.express.co.uk 
Felbab-Brown, V. (2005). The coca connection: Conflict and drugs in Colombia and Peru. Journal of Conflict Studies, 25(2), 104-128.

Five people hospitalised after using 'N-Bomb'. (2015, October 9). New Zealand Herald. Retrieved from https://www.nzherald.co.nz

Fox-Brewster, T. (2017, July 20). How the cops took down an alleged \$23 million dark web drug kingpin. Forbes. Retrieved from https://www.forbes.com

Fricker, M. (2016, May 9). Schoolboy died after taking heroin he bought on 'dark web' online black market 'Silk Road'. Mirror. Retrieved from https://www.mirror.co.uk

Friedrichs, D. O. (2009). Critical criminology. In J. M. Miller (Ed.), 21 st century criminology: A reference handbook (pp. 210-218). Thousand Oaks, CA: Sage.

Galuszka, J. (2015, January 27). Accused in Horowhenua drugs case out on bail. Stuff. Retrieved from https://www.stuff.co.nz

Gee, P., Schep, L. J., Jensen, B. P., Moore, G., \& Barrington, S. (2016). Case series: toxicity from 25B-NBOMe - A cluster of N-bomb cases. Clinical Toxicology, 54(2), 141-146. Doi: $10.3109 / 15563650.2015 .1115056$

Gieringer, D. H. (1999). The forgotten origins of cannabis prohibition in California. Contemporary Drug Problems, 26(2), 237-288. Doi: 10.1177/009145099902600204

Gilbert, M., \& Dasgupta, N. (2017). Silicon to syringe: Cryptomarkets and disruptive innovation in opioid supply chains. International Journal of Drug Policy, 46, 160-167. Doi: 10.1016/j.drugpo.2017.05.052

Glaser, B. G., \& Strauss, A. L. (1967). The discovery of grounded theory: Strategies for qualitative research. Chicago, IL: Aldine.

Global Drug Survey. (2017). GDS key findings report 2017. Retrieved from https://www.globaldrugsurvey.com/wpcontent/themes/globaldrugsurvey/results/GDS2017_key-findings-report_final.pdf

Global Drug Survey. (2018). GDS key findings report 2018. Retrieved from https://www.globaldrugsurvey.com/gds-2018/

Goldstein, P. J. (1985). The drugs/violence nexus: A tripartite conceptual framework. Journal of Drug Issues, 15(4), 493-506. Doi: 10.1177/002204268501500406 
Greenberg, A. (2014, 7 November). Global web crackdown arrests 17, seizes hundreds of darknet domains. Wired. Retrieved from https://www.wired.com

Greenwald, G. (2009). Drug decriminalization in Portugal: Lessons for creating fair and successful drug policies. Washington DC: Cato Institute.

Griffiths, P., \& Mounteney, J. (2017). Disruptive potential of the internet to transform illicit drug markets and impact on future drug consumption. Clinical Pharmacology \& Therapeutics, 101(2), 176-178. Doi: 10.1002/cpt.561

Hall, W., \& Kozlowski, L. T. (2018). The diverging trajectories of cannabis and tobacco policies in the United States: Reasons and possible implications. Addiction, 113(4), 595-601. Doi: 10.1111/add.13845

Halliday, J. (2018, March 21). Manchester students jailed for selling £800k of drugs on dark web. Guardian. Retrieved from https://www.theguardian.com

Hesse-Biber, S. N., \& Leavy, P. (2011). The practice of qualitative research. Thousand Oaks, CA: Sage.

Hoffman, A. (2015, January 5). Before darknetmarkets were mainstream. DeepDotWeb. Retrieved from https://www.deepdotweb.com

Home Office. (2015). Tables for drug misuse: Findings from the 2014 to 2015 CSEW. Retrieved from https://www.gov.uk/government/statistics/tables-for-drug-misusefindings-from-the-2014-to-2015-csew

Hough, M., Warburton, H., Few, B., May, T., Man, L-H., Witton, J., \& Turnbull, P. J. (2003). A growing market: The domestic cultivation of cannabis. York: Joseph Rowntree Foundation.

Hunt, T., \& Stewart, M. (2018, February 19). Methamphetamine set to overtake cannabis as biggest drug burden on our court system. Stuff. Retrieved from https://www.stuff.co.nz

Hutton, F. (2005). Risky business: Gender, drug dealing and risk. Addiction Research \& Theory, 13(6), 545-554. Doi: 10.1080/16066350500338237

Hutton, F. (2010). Kiwis, clubs and drugs: Club cultures in Wellington, New Zealand. Australian and New Zealand Journal of Criminology, 43(1), 91-111. Doi: 10.1375/acri.43.1.91 
Hydrocodone. (n.d.). Retrieved from https://psychonautwiki.org/wiki/Hydrocodone

Jacques, S., \& Wright, R. (2015). Code of the suburb: Inside the world of young middle-class drug dealers. Chicago, IL: University of Chicago Press.

Kellehear, A., Rumbold, G. R., \& Hamilton, M. A. (Eds.). (1998). Drug use in Australia: A harm minimisation approach. Melbourne: Oxford University Press.

Kelly, B. C. (2009). Mediating MDMA-related harm: Preloading and Post-loading among ecstasy-using youth. Journal of Psychoactive Drugs, 41(1), 19-26. Doi: $10.1080 / 02791072.2009 .10400671$

Kruithof, K., Aldridge, J. Décary-Hétu, D., Sim, M., Dujso, E., \& Hoorens, S. (2016). Internetfacilitated drugs trade: An analysis of the size, scope and the role of the Netherlands. Cambridge: RAND.

Kueppers, V. B., \& Cooke, C. T. (2015). 25I-NBOMe related death in Australia: A case report. Forensic Science International, 249, e15-e18. Doi: 10.1016/j.forsciint.2015.02.010

Lavorgna, A. (2014). Internet-mediated drug trafficking: Towards a better understanding of new criminal dynamics. Trends in Organized Crime, 17(4), 250-270. Doi: $10.1007 / \mathrm{s} 12117-014-9226-8$

Lavorgna, A. (2016). 'How the use of the internet is affecting drug trafficking practices.' The internet and drug markets (European Monitoring Centre for Drugs and Drug Addiction: Insights 21). Luxembourg: Publications Office of the European Union.

Law Commission. (2011). Controlling and regulating drugs: A review of the Misuse of Drugs Act 1975. Wellington: Law Commission.

Lee, D. (2014, November 10). Dark net raids were 'overblown' by police, says Tor Project. $B B C$. Retrieved from https://www.bbc.com

Lee, E. (1966). A theory of migration. Demography, 3(1), 47-57. Doi: 10.2307/2060063

Lee, R. M., \& Renzetti, C. M. (1990). The problems of researching sensitive topics: An overview and introduction. American Behavioral Scientist, 33(5), 510.528. Doi: $10.1177 / 0002764290033005002$

Lenton, S., \& Single, E. (1998). The definition of harm reduction. Drug and Alcohol Review, 17(2), 213-220. Doi: 10.1080/09595239800187011 
Levine, H. G. (2003). Global drug prohibition: Its uses and crises. International Journal of Drug Policy, 14(2), 145-153. Doi: 10/1016/S0955-3959(03)00003-3

Lewman, A. (2016). 'Tor and links with cryptomarkets.' The internet and drug markets (European Monitoring Centre for Drugs and Drug Addiction: Insights 21). Luxembourg: Publications Office of the European Union.

Liamputtong, P. (2007). Researching the vulnerable: A guide to sensitive research methods. London: Sage.

Maddox, A., Barratt, M. J., Allen, M., \& Lenton, S. (2016). Constructive activism in the dark web: Cryptomarkets and illicit drugs in the digital 'demimonde'. Information, Communication and Society, 19(1), 111-126. Doi: 10.1080/1369118X.2015.1093531

Markoff, J. (2005). What the dormouse said: How the sixties counterculture shaped the personal computer industry. London: Penguin.

Martin, J. (2014). Lost on the Silk Road: Online drug distribution and the 'cryptomarket'. Criminology and Criminal Justice, 14(3), 351-367. Doi: 10.1177/1748895813505234

Martin, J. (2017a). Cryptomarkets, systemic violence and the 'gentrification hypothesis'. Addiction, 113(5), 797-798. Doi: 10.1111/add.14029

Martin, J. (2017b, June 6). Sex, drugs \& rock 'n' roll: Cryptomarkets \& the dark net drug trade - Dr James Martin at RBT \#18 [Video file]. Retrieved from https://www.youtube.com/watch?v=ioEFgglwa_g

Martin, J., \& Christin, N. (2016). Ethics in cryptomarket research. International Journal of Drug Policy, 35, 84-91. Doi: 10.1016/j.drugpo.2016.05.006

May, T., \& Hough, M. (2004). Drug markets and distribution systems. Addiction Research \& Theory, 12(6), 549-563. Doi: 10.1080/16066350412331323119

Maynard, M. (1994). Methods, practice and epistemology: The debate about feminism and research. In M. Maynard \& J. Purvis (Eds.), Researching women's lives from a feminist perspective (pp. 1-26). Abingdon: Routledge.

McCosker, H., Barnard, A., \& Gerber, R. (2001). Undertaking sensitive research: Issues and strategies for meeting the safety needs of all participants. Forum: Qualitative Social Research, 2(1), Art. 22. 
McElrath, K., \& O’Neill, C. (2011). Experiences with mephedrone pre- and post-legislative controls: Perceptions of safety and sources of supply. International Journal of Drug Policy, 22, 120-127. Doi: 10.1016/j.drugpo.2010.11.001

McKeganey, N., \& McGallagly, J. (2013). Nicked: Drug users' views of drug enforcement. Journal of Substance Use, 18(4), 320-334. Doi: 10.3109/14659891.2012.709914

McLaughlin, E. (2010). Critical criminology. In E. McLaughlin \& T. Newburn (Eds.), The SAGE handbook of criminological theory (pp. 153-174). London: Sage.

Measham, F., \& Moore, K. (2009). Repertoires of distinction: Exploring patterns of weekend polydrug use within local leisure scenes across the English night time economy. Criminology \& Criminal Justice, 9(4), 437-464. Doi: 10.1177/1748895809343406

Mephedrone. (n.d.). Retrieved from https://psychonautwiki.org/wiki/Mephedrone

Methylone. (n.d.). Retrieved from https://psychonautwiki.org/wiki/Methylone

Miller, P. G. (2001). A critical review of the harm minimization ideology in Australia. Critical Public Health, 11(2), 167-178. Doi: 10.1080/09581590110039865

Ministry for Primary Industries. (2016). Biosecurity 2025: Direction statement for New Zealand's biosecurity system. Wellington: Ministry for Primary Industries.

Ministry of Business, Innovation and Employment. (2014). The New Zealand sectors report 2014: An analysis of the New Zealand economy by sector. Wellington: Ministry of Business, Innovation and Employment.

Ministry of Health. (2010). Drug use in New Zealand: Key results of the 2007/08 New Zealand Alcohol and Drug Use Survey. Wellington: Ministry of Health.

Ministry of Health. (2015). Cannabis use 2012/13: New Zealand Health Survey. Wellington: Ministry of Health.

Miron, J. A. (2004). Drug war crimes: The consequences of prohibition. Oakland, CA: Independent Institute.

Misuse of Drugs Act, New Zealand Statutes. (1975).

Misuse of Drugs Act, United Kingdom Statutes. (1971). 
Moeller, K., Munksgaard, R., \& Demant, J. (2017). Flow my FE the vendor said: Exploring violent and fraudulent resource exchanges on cryptomarkets for illicit drugs. American Behavioral Scientist, 61(11), 1427-1450. Doi: 10.1177/0002764217734269

Morini, L., Bernini, M., Vezzoli, S., Restori, M., Moretti, M., Crenna, S., Papa, P., Locatelli, C., Osculati, A. M. M., Vignali, C., \& Groppi, A. (2017). Death after 25C-NBOMe and 25H-NBOMe consumption. Forensic Science International, 279, e1-e6. Doi: 10.1016/j.forsciint.2017.08.028

Morselli, C., Décary-Hétu, D., Paquet-Clouston, M., \& Aldridge, J. (2017). Conflict management in illicit drug cryptomarkets. International Criminal Justice Review, 27(4), 237-254. Doi: 10.1177/105767717709498

Mounteney, J., Cunningham, A., Groshkova, T., Sedefov, R., \& Griffiths, P. (2017). Looking forward to the future - More concern than optimism that cryptomarkets will reduce drug-related harms. Addiction, 113(5), 799-800. Doi: 10.1111/add.14056

Mounteney, J., Oteo, A., \& Griffiths, P. (2016). 'The internet and drug markets: Shining a light on these complex and dynamic systems.' The internet and drug markets (European Monitoring Centre for Drugs and Drug Addiction: Insights 21). Luxembourg: Publications Office of the European Union.

Moyle, L., \& Coomber, R. (2015). Earning a score: An exploration of the nature and roles of heroin and crack cocaine 'user-dealers'. British Journal of Criminology, 55(3), 534555. Doi: 10.1093/bjc/azu087

Murphy, S., Waldorf, D., \& Reinarman, C. (1990). Drifting into dealing: Becoming a cocaine seller. Qualitative Sociology, 13(4), 321-343. Doi: 10.1007/BF00989408

Narayanan, A., Bonneau, J., Felten, E., Miller, A., \& Goldfeder, S. (2016). Bitcoin and cryptocurrency technologies: A comprehensive introduction. Princeton, NJ: Princeton University Press.

New Zealand Customs Service. (2017a). Annual report 2017. Wellington: New Zealand Customs Service.

New Zealand Customs Service. (2017b). Customs stops 1.2 tonnes of meth. Retrieved from https://www.customs.govt.nz/about-us/news/media-releases/customs-stops-1.2tonnes-of-meth/ 
New Zealand Customs Service. (2018). Annual report 2018. Wellington: New Zealand Customs Service.

New Zealand Drug Foundation. (n.d.). Drug use and criminal justice. Retrieved from https://www.drugfoundation.org.nz/policy-and-advocacy/drug-use-and-criminaljustice/

New Zealand Government. (2018). Summary of initiatives in Budget 2018. Retrieved from https://treasury.govt.nz/sites/default/files/2018-05/b18-sum-initiatives.pdf

New Zealand Police. (2016). Kiwi darknet illegal drug buyers identified during worldwide operation. Retrieved from http://www.police.govt.nz/news/release/kiwi-darknetillegal-drug-buyers-identified-during-worldwide-operation

New Zealand Police. (2017). Waitemata Police and Customs pleased with success of Operation Tiger. Retrieved from http://www.police.govt.nz/news/release/waitemata-police-andcustoms-pleased-success-operation-tiger-photos

New Zealand Police. (2018). Operation Garden - prevention-focused operation targeting Dark Net drug imports. Retrieved from http://www.police.govt.nz/news/release/operationgarden-\%E2\%80\%93-prevention-focused-operation-targeting-dark-net-drug-imports

Noaks, L., \& Wincup, E. (2004). Criminological research: Understanding qualitative methods. London: Sage.

Nurmi, J., Kaskela, T., Perälä, J., \& Oksanen, A. (2017). Seller's reputation and capacity on the illicit drug markets: 11-month study on the Finnish version of the Silk Road. Drug and Alcohol Dependence, 178, 201-207. Doi: 10.1016/j.drugalcdep.2017.05.018

Nutt, D., King, L. A., Saulsbury, W., \& Blakemore, C. (2007). Development of a rational scale to assess the harm of drugs of potential misuse. The Lancet, 369(9566), 1047-1053. Doi: 10.1016/S0140-6736(07)60464-4.

O’Brien, K., Chatwin, C., Jenkins, C., \& Measham, F. (2015). New psychoactive substances and British drug policy: A view from the cyber-psychonauts. Drugs: Education, Prevention and Policy, 22(3), 217-223. Doi: 10.3109/09687637.2014.989959

O’Neill, M. (2017, August 24). Inside the luxury life of fugitive dark web drug kingpin couple. New Zealand Herald. Retrieved from https://www.nzherald.co.nz 
Ormsby, E. (2016). 'Silk Road: Insights from interviews with users and vendors.' The internet and drug markets (European Monitoring Centre for Drugs and Drug Addiction: Insights 21). Luxembourg: Publications Office of the European Union.

Our results - Overall results for the 2017/18 season. (n.d.). KnowYourStuffNZ. Retrieved from https://knowyourstuff.nz/our-results_2017_18/

Our strategy. (n.d.). Ministry for Primary Industries. Retrieved from https://www.mpi.govt.nz/about-us/our-strategy/

Parker, H., Aldridge, J., \& Measham, F. (1998). Illegal leisure: The normalization of adolescent recreational drug use. London: Routledge.

Paquet-Clouston, M., Décary-Hétu, D., \& Morselli, C. (2018). Assessing market competition and vendors' size and scope on AlphaBay. International Journal of Drug Policy, 54, 87-98. Doi: 10.1016/j.drugpo.2018.01.003

Pates, R., \& Riley, D. (Eds.). (2012). Harm reduction in substance use and high-risk behavior. Chichester: Blackwell.

Peacocke, K. (Producer). (2018). Border patrol [Television series]. New Zealand: Greenstone TV.

Penal Reform International. (2018). Global prison trends 2018. London: Penal Reform International.

Phelps, A., \& Watt, A. (2014). I shop online - recreationally! Internet anonymity and Silk Road enabling drug use in Australia. Digital Investigation, 11(4), 261-272. Doi: 10.1016/j.diin.2014.08.001

Phillips, D. C. (1995). The good, the bad, and the ugly: The many faces of constructivism. Educational Researcher, 24(7), 5-12. Doi: 10.3102/0013189X024007005

Pollack, H. A., \& Reuter, P. (2014). Does tougher enforcement make drugs more expensive? Addiction, 109(12), 1959-1966. Doi: 10.1111/add.12497

Pompidou Group. (2013). Drug related cybercrime and associated use of the Internet: Overview, analysis and possible actions by the Pompidou Group. Strasbourg: Council of Europe.

Postal Services Act, New Zealand Statutes. (1998). 
Power, M. (2015, February 12). Why are pills so strong at the moment? Mixmag. Retrieved from https://mixmag.net

Preble, E., \& Casey, J. J. (1969). Taking care of business - The heroin user's life on the street. International Journal of the Addictions, 4(1), 1-24. Doi: 10.3109/10826086909061998

Psychonautics. (n.d.). Retrieved from https://psychonautwiki.org/wiki/Psychonautics

Quodling, A. (2015, April 22). Doxxing, swatting and the new trends in online harassment. The Conversation. Retrieved from http://theconversation.com

Race, K. (2008). The use of pleasure in harm reduction: Perspectives from the history of sexuality. International Journal of Drug Policy, 19(5), 417-423. Doi: 10.1016/j.drugpo.2007.08.008

Reith, G. (2004). Consumption and its discontents: Addiction, identity and the problems of freedom. British Journal of Sociology, 55(2), 283-300. Doi: 10.1111/j.14684446.2004.00019.x

Reuter, P. (1983). Disorganized crime: The economics of the visible hand. Cambridge, MA: MIT Press.

Reuter, P. H. (2001). The limits of supply-side drug control. Santa Monica, CA: RAND.

Reuter, P. (2009). Systemic violence in drug markets. Crime, Law and Social Change, 52(3), 275-284. Doi: 10.1007/s10611-009-9197-x

Reuter, P., \& Greenfield, V. (2001). Measuring global drug markets: How good are the numbers and why should we care about them? World Economics, 2(4), 159-173.

Rhumobarbe, D., Staehli, L., Broséus, J., Rossy, Q., \& Esseiva, P. (2016). Buying drugs on a darknet market: A better deal? Studying the online illicit drug market through the analysis of digital, physical and chemical data. Forensic Science International (Online), 267, 173-182. Doi: 10.1016/j.forsciint.2016.08.032

Rincón-Ruiz, A., \& Kallis, G. (2013). Caught in the middle, Colombia's war on drugs and its effects on forest and people. Geoforum, 46, 60-78. Doi: 10.1016/j.geoforum.2012.12.009

Ritter, A. (2006). Studying illicit drug markets: Disciplinary contributions. International Journal of Drug Policy, 17, 453-463. Doi: 10.1016/j.drugpo.2006.09.004 
RollSafe. (n.d.). Retrieved from https://rollsafe.org/

Room, R. (2005). Stigma, social inequality and alcohol and drug use. Drug and Alcohol Review, 24(2), 143-155. Doi: 10.1080/09595230500102434

Sameeh, T. (2017a, July 31). Geographical analysis of drug trafficking on a popular darknet marketplace. DeepDotWeb. Retrieved from https://www.deepdotweb.com

Sameeh, T. (2017b, July 31). The deep web, novel psychoactive substances (NPS) and psychonauts. DeepDotWeb. Retrieved from https://www.deepdotweb.com

Schwandt, T. A. (1998). Constructivist, interpretivist approaches to human inquiry. In N. K. Denzin \& Y. S. Lincoln (Eds.), The landscape of qualitative research: Theories and issues (pp. 221-259). Thousand Oaks, CA: Sage.

Schwendinger, H., \& Schwendinger, J. (1970). Defenders of order or guardians of human rights? Issues in Criminology, 5(2), 123-157.

Seidman, I. (2006). Interviewing as qualitative research: A guide for researchers in education and the social sciences (3rd ed.). New York, NY: Teachers College Press.

Sest, N., \& March, E. (2017). Constructing the cyber-troll: Psychopathy, sadism, and empathy. Personality and Individual Differences, 119, 69-72. Doi: 10.1016/j.paid.2017.06.038

Sheridan, J. L., \& Butler, R. A. (2007). Highs and lows: Patterns of use, positive and negative effects of benzylpiperazine-containing party pills (BZP-party pills) amongst young people in New Zealand. Harm Reduction Journal, 4(18). Doi: 10.1186/1477-7517-418

Sheridan, J., \& Butler, R. (2010). "They're legal so they're safe, right?" What did the legal status of BZP-party pills mean to young people in New Zealand? International Journal of Drug Policy, 21, 77-81. Doi: 10.1016/j.drugpo.2009.02.002

Sheridan, J., Butler, R., \& Wheeler, A. (2009). Initiation into methamphetamine use: Qualitative findings from an exploration of first time use among a group of New Zealand users. Journal of Psychoactive Drugs, 41(1), 11-17. Doi: $10.1080 / 02791072.2009 .10400670$

Spotz, K. (2014, July 17). What I've learned as an internet drug dealer. Vice. Retrieved from https://motherboard.vice.com 
Sprague, J. E., Huang, X., Kanthasamy, A., \& Nichols, D. E. (1994). Attenuation of 3,4methylenedioxymethamphetamine (MDMA) induced neurotoxicity with the serotonin precursors tryptophan and 5-hydroxytryptophan. Life Sciences, 55(15), 1193-1198.

Stanley, E. (2012). Interviewing victims of state crime. In D. Gadd, S. Karstedt \& S. F. Messner (Eds.), The SAGE handbook of criminological research methods (pp. 231-243). London: Sage.

State Services Commission. (2018, December 11). New chief executive, New Zealand Customs Service appointed. Scoop. Retrieved from http://www.scoop.co.nz/stories/BU1812/S00274/new-chief-executive-new-zealandcustoms-service-appointed.htm

Statistics New Zealand. (2013). Census QuickStats about national highlights. Wellington: Statistics New Zealand.

Stebbins, R. A. (2001). Exploratory research in the social sciences. Thousand Oaks, CA: Sage.

Stewart, M., \& Hunt, T. (2018, January 4). Summer of love tinged with danger as MDMA reaches new peaks at NZ festivals. Stuff. Retrieved from https://www.stuff.co.nz

Sumnall, H. R. (2017). The harm reduction impact of cryptomarkets: Inequality and opportunity. Addiction, 113(5), 801-802. Doi: 10.1111/add.14065

Taylor, A. L. (2007). Addressing the global tragedy of needless pain: Rethinking the United Nations Single Convention on Narcotic Drugs. The Journal of Law, Medicine \& Ethics, 35(4), 556-570. Doi: 10.1111/j.1748-720X.2007.00180.x

Taylor, M., \& Potter, G. R. (2013). From “social supply" to "real dealing”: Drift, friendship, and trust in drug-dealing careers. Journal of Drug Issues, 43(4), 392-406. Doi: $10.1177 / 0022042612474974$

Te Aka Online Māori Dictionary. (n.d.-a). Koha. Retrieved from http://maoridictionary.co.nz/search?\&keywords=koha

Te Aka Online Māori Dictionary. (n.d.-b). Pākehā. Retrieved from http://maoridictionary.co.nz/search?idiom $=\&$ phrase $=\&$ proverb $=\&$ loan $=\&$ keywords $=\mathrm{p}$ akeha 
Thielman, S. (2015, May 29). Silk Road operator Ross Ulbricht sentenced to life in prison. Guardian. Retrieved from https://www.theguardian.com

Top Markets! (n.d.). Retrieved from https://www.deepdotweb.com/marketplacedirectory/categories/top-markets/

Trip Reports. (n.d.). Retrieved from http://bluelight.org/vb/forums/40-Trip-Reports

Tzanetakis, M. (2018). Comparing cryptomarkets for drugs: A characterisation of sellers and buyers over time. International Journal of Drug Policy, 56, 176-186. Doi: 10.1016/j.drugpo.2018.01.022.

Tzanetakis, M., Kamphausen, G., Werse, B., \& von Laufenberg, R. (2016). The transparency paradox. Building trust, resolving disputes and optimising logistics on conventional and online drugs markets. International Journal of Drug Policy, 35, 58-68. Doi: 10.1016/j.drugpo.2015.12.010

Ugwudike, P. (2015). An introduction to critical criminology. Bristol: Policy Press.

United Nations Office on Drugs and Crime. (2013). The international drug control conventions. Vienna: United Nations.

United Nations Office on Drugs and Crime. (2018a). Annual prevalence of drug use. Retrieved from https://dataunodc.un.org/drugs/prevalence table

United Nations Office on Drugs and Crime. (2018b). Retail and wholesale purity levels. Retrieved from https://dataunodc.un.org/drugs/purity

United Nations Office on Drugs and Crime. (2018c). World drug report 2018. Retrieved from https://www.unodc.org/wdr2018/

Usher, T. (2017, July 14). What super strength ecstasy actually does to you. Vice. Retrieved from https://www.vice.com

van Boekel, L. C., Brouwers, E. P. M., van Weeghel, J., \& Garretsen, H. F. L. (2013). Stigma among health professionals towards patients with substance use disorders and its consequences for healthcare delivery: Systematic review. Drug and Alcohol Dependence, 131(1-2), 23-35. Doi: 10.1016/j.drugalcdep.2013.02.018

van Buskirk, J., Bruno, R., Dobbins, T., Breen, C., Burns, L., Naicker, S., \& Roxburgh, A. (2017). The recovery of online drug markets following law enforcement and other 
disruptions. Drug and Alcohol Dependence, 173, 159-162. Doi: 10.1016/j.drugalcdep.2017.01.004

van Buskirk, J., Naicker, S., Roxburgh, A., Bruno, R., \& Burns, L. (2016). Who sells what? Country-specific substance availability on the Agora cryptomarket. International Journal of Drug Policy, 25, 16-23. Doi: 10.1016/j.drugpo.2016.07.004

van Buskirk, J., Roxburgh, A., Bruno, R., Naicker, S., Lenton, S., Sutherland, R., Whittaker, E., Sindicich, N., Matthews, A., Butler, K., \& Burns, L. (2016). Characterising dark net marketplace purchasers in a sample of regular psychostimulant users. International Journal of Drug Policy, 35, 32/37. Doi: 10.1016/j.drugpo.2016.01.010

van Buskirk, J., Roxburgh, A., Farrell, M., \& Burns, L. (2014). The closure of Silk Road: What has this meant for online drug trading? Addiction, 109(4), 517-518. Doi: $10.1111 / \mathrm{add} / 12422$

van der Gouwe, D., Brunt, T. M., Laar, M., \& Pol, P. (2017), Purity, adulteration and price of drugs bought on-line versus off-line in the Netherlands. Addiction, 112(4), 640-648. Doi: $10.1111 /$ add. 13720

van Duyne, P. C., \& Levi, M. (2005). Drugs and money: Managing the drug trade and crime money in Europe. London: Routledge.

van Hout., M. C., \& Bingham, T. (2013a). 'Silk Road', the virtual drug marketplace: A single case study of user experiences. International Journal of Drug Policy, 24(5), 385-391. Doi: 10.1016/j.drugpo.2013.01.005

van Hout, M. C., \& Bingham, T. (2013b). 'Surfing the Silk Road': A study of users' experiences. International Journal of Drug Policy, 24(6), 524-529. Doi: 10.1016/j.drugpo.2013.08.011

van Hout, M. C., \& Bingham, T. (2014). Responsible vendors, intelligent consumers: Silk Road, the online revolution in drug trading. International Journal of Drug Policy, 25(2), 183-189. Doi: 10.1016/j.drugpo.2013.10.009

van Slobbe, J. (2016). 'The drug trade on the deep web: A law enforcement perspective.' The internet and drug markets (European Monitoring Centre for Drugs and Drug Addiction: Insights 21). Luxembourg: Publications Office of the European Union. 
Vanwesenbeeck, I. (2013). Prostitution push and pull: Male and female perspectives. Journal of Sex Research, 50(1), 11-16. Doi: 10.1080/00224499.696285

Wallis, J., \& Cheng, D. (2018, December 18). Justice Minister confirms recreational cannabis referendum at 2020 election. New Zealand Herald. Retrieved from https://www.nzherald.co.nz/

Walsh, C. (2011). Drugs, the internet and change. Journal of Psychoactive Drugs, 43(1), 5563. Doi: 10.1080/02791072.2011.566501

Warren, C. A. B. (2011). Qualitative interviewing. In J. F. Gubrium \& J. A. Holstein (Eds.), Handbook of interview research (pp. 83-102). Thousand Oaks, CA: Sage.

Weiss, R. S. (1995). Learning from strangers: The art and method of qualitative interview studies. New York, NY: Free Press.

Wellings, K., Branigan, P., \& Mitchell, K. (2000). Discomfort, discord and discontinuity as data: Using focus groups to research sensitive topics. Culture, Health \& Sexuality, 2(3), 255-267. Doi: 10.1080/136910500422241

Werb, D., Rowell, G., Guyatt, G., Kerr, T., Montaner, J., \& Wood, E. (2011). Effect of drug law enforcement on drug market violence: A systematic review. International Journal of Drug Policy, 22(2), 87-94. Doi: 10.1016/j.drugpo.2011.02.002

What is a DDoS Attack? (n.d.). Retrieved from https://www.deepdotweb.com/marketplacedirectory/categories/top-markets/

While markets get seized: Pedophiles launch a crowdfunding site. (2014, November 9). DeepDotWeb. Retrieved from https://www.deepdotweb.com

Wilkins, C., Bhatta, K., \& Casswell, S. (2002). A 'demand side' estimate of the dollar value of the cannabis black market in New Zealand. Drug and Alcohol Review, 21(2), 145-151. Doi: $10.1080 / 09595230220139046$

Wilkins, C., \& Casswell, S. (2003). Organized crime in cannabis cultivation in New Zealand: An economic analysis. Contemporary Drug Problems, 30(4), 757-777. Doi: $10.1177 / 009145090303000403$ 
Wilkins, C., Reilly, J. L., Pledger, M., \& Casswell, S. (2005). Estimating the dollar value of the illicit market for cannabis in New Zealand. Drug and Alcohol Review, 24(3), 227234. Doi: $10.1080 / 09595230500170290$

Wilkins, C., Sweetsur, P. (2012). Criminal justice outcomes for cannabis use offences in New Zealand, 1991-2008. International Journal of Drug Policy, 23(6), 505-511. Doi: 10.1016/j.drugpo.2012.03.002

Wilkins, C., Sweetsur, P., \& Parker, K. (2014). The impact of the prohibition of benzylpiperazine (BZP) "legal highs" on the availability, price and strength of BZP in New Zealand. Drug and Alcohol Dependence, 144, 47-52. Doi: 10.1016/j.drugalcdep.2014.07.011

Williams, E. H. (1914, February 8). Negro cocaine "fiends" are a new Southern menace: Murder and insanity increasing among lower class blacks because they have taken to "sniffing" since deprived of whisky by prohibition. New York Times. Retrieved from https://www.nytimes.com

Workman, M. (2018, January 4). More high-potency ecstasy in New Zealand than ever, says drug-testing group. New Zealand Herald. Retrieved from https://www.nzherald.co.nz

Zetter, K. (2012, April 16). 8 suspects arrested in online drug market sting. Wired. Retrieved from https://www.wired.com

Zimmerman, P. R. (1995). The official PGP user's guide. Cambridge, MA: MIT Press.

Zopiclone. (n.d.). Retrieved from https://psychonautwiki.org/wiki/Zopiclone 